\title{
Corrosion Protection of SiC-Based Ceramics with CVD Mullite Coatings
}

\author{
RECEVIVD \\ JUL 059996 \\ OSTI
}

April 20, 1996

Report Prepared by

Vinod Sarin, Rao Mulpuri, Michael Auger

Boston University

Manufacturing Engineering

44 Cummington Street

Boston, MA 02215

under

ORNL/Sub/94-SS110/01

for

OAK RIDGE NATIONAL LABORATORY

Oak Ridge, Tennessee 37831

Managed by

LOCKHEED MARTIN ENERGY RESEARCH CORP.

for the

U.S.DEPARTMENT OF ENERGY

under contract DE-AC05-960R22464

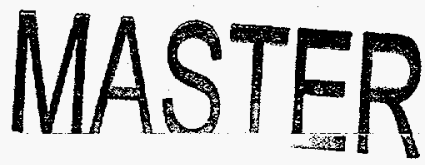




\section{Corrosion Protection of SiC-Based Ceramics with CVD Mullite Coatings}

Research sponsored by the U.S. Department of Energy, Office of Fossil Energy Advanced Research and Technology Development Material Program

Report Prepared by

Vinod Sarin, Rao Mulpuri, Michael Auger

Boston University

Manufacturing Engineering

44 Cummington Street

Boston, MA 02215

under

ORNL/Sub/94-SS110/01

for

OAK RIDGE NATIONAL LABORATORY

Oak Ridge, Tennessee 37831

Managed by

LOCKHEED MARTIN ENERGY RESEARCH CORP.

for the

U.S.DEPARTMENT OF ENERGY

under contract DE-AC05-960R22464 


\section{DISCLAIMER}

Portions of this document may be illegible in electronic image products. Images are produced from the best available original document. 
Abstract

Introduction

Research Approach

Multi-Layered System

Direct Deposition

Experimental Methods

The CVD System

Materials

X-Ray Diffractometry

Scanning Electron Microscopy

Transmission Electron Microscopy

Metallography

Oxidation and Corrosion Analysis

Micro and Macro Scratch Test

Results and Discussion

Multi-Layered Coating System

Performance

$\mathrm{TEOS}+\mathrm{AlCl}_{3}+\mathrm{H}_{2}+\mathrm{CO}_{2}$ System

Coating Morphology

$\mathrm{SiCl}_{4}+\mathrm{AlCl}_{3}+\mathrm{H}_{2}+\mathrm{CO}_{2}$ System

Thermodynamic Analysis

Effect of Temperature

Effect of Pressure

Effect of Stoichiometry

Effect of Hydrogen Gas Concentration 
Effect of Using Alternative Halides

Mullite Deposition

Coating Morphology, Crystal Structure, Composition

Effect of Temperature

Effect of Pressure

Effect of Stoichiometry

Coating Evolution

Solubility Range of Mullite

Powder Synthesis

Adhesion Testing

Macro-Scratch Testing

Micro Scratch Testing

Corrosion Testing

Summary and Conclusions 
Research sponsored by the U.S. Department of Energy, Fossile Energy Advanced Research and Technology Development Materials Program, DOE/FE AA 1510100 , Work Breakdown Structure Element BU-2

\section{Abstract}

$\mathrm{SiC}$ based ceramics have been identified as the leading candidate materials for elevated temperature applications in harsh oxidation/corrosion environments. It has been established that a protective coating can be effectively used to avoid problems with excessive oxidation and hot corrosion. However, to date, no coating configuration has been developed that can withstand the rigorous requirements imposed by such applications. Chemical vapor deposited (CVD) mullite coatings due to their desirable properties of toughness, corrosion resistance, and good coefficient of thermal expansion match with $\mathrm{SiC}$ are being developed as a potential solution.

Formation of mullite on ceramic substrates via chemical vapor deposition was investigated. Thermodynamic calculations performed on the $\mathrm{AlCl}_{3}-\mathrm{SiCl}_{4}-\mathrm{CO}_{2}-\mathrm{H}_{2}$ system were used to construct equilibrium CVD phase diagrams. Through process optimization, crystalline CVD mullite coatings have been successfully grown on SiC and $\mathrm{Si}_{3} \mathrm{~N}_{4}$ substrates. Results from the thermodynamic analysis, process optimization, and effect of various process parameters on deposition rate and coating morphology are discussed. 


\section{INTRODUCTION}

In the recent years, interest has grown in the potential use of ceramics in high temperature engineering applications as a means of increasing operating temperatures and improving efficiencies. For example, the operating efficiencies of heat engines have been improved significantly by using uncooled ceramic components at higher temperatures than those attainable with super alloys. [1] Silicon-based ceramics such as $\mathrm{Si}_{3} \mathrm{~N}_{4}$ and $\mathrm{SiC}$ currently appear to be the leading candidate materials due to their unique combination of high strength and thermal conductivity, low thermal expansion, and good high temperature stability. [2] Ceramics possess excellent room and elevated temperature strength as well as thermal stability. However, the brittleness of these materials has limited their usefulness in high contact and structural applications. Some of the potential applications range from structural components in gas turbine and heat engines to hot gas filters. Gas turbines are used in aircraft and in power generation and have been tested for use in automobiles. [3] Potential ceramic components include combustor liners, even turbine blades. Attempts to manufacture valves and piston heads have already been made in internal combustion engines. [4] Ceramics could also be used in heat exchanger tubes in industrial furnaces for glass remelting, steel soaking, and aluminum reclamation. [5] 


\section{Need for Coatings}

Many engineering operations are conducted at high temperatures in an air or oxygen environment. Oxides unlike most of the carbides and nitrides are typically stable at high temperature in an oxygen and oxygen-nitrogen atmosphere. In case of $\mathrm{Si}_{3} \mathrm{~N}_{4}$ and $\mathrm{SiC}$ oxidation does not appear to be a problem due to the formation of a passive $\mathrm{SiO}_{2}$ surface layer at moderate oxygen pressures. This thin, self-healing layer protects the $\mathrm{Si}$ based substrates from catastrophic oxidation by effectively minimizing diffusion of $\mathrm{O}_{2}$ to the substrate. However, corrosion can occur as a result of the combined effect of the oxygen plus gaseous, condensed, or particulate impurities induced via the gas stream. These impurities can either increase the rate of passive oxidation by modifying the transport rate of oxygen through the protective scale, cause active oxidation via formation of $\mathrm{SiO}$ which accelerates the degradation process, or produce compositions such as $\mathrm{Na}_{2} \mathrm{SiO}_{3}$ which chemically attack the ceramic via rapid corrosion. [6,7] Small quantities of impurities can have a pronounced effect on the corrosion behavior of $\mathrm{Si}_{3} \mathrm{~N}_{4}$ and $\mathrm{SiC}$. This is especially important in applications where heavy residual fuels are being considered. In some cases, strength degradation by as much as $30-45 \%$ was observed.

In addition, in gas turbine engine testing, contact stresses were identified as the major cause of damage to structural components made of ceramics such as $\mathrm{Si}_{3} \mathrm{~N}_{4}$ and SiC. The surface damage is attributed to high localized tensile stresses due to bi-axial loading at interfaces resulting from aerodynamic forces and relative motion due to thermal expansion. [8] Tensile stresses are localized at the surface and decrease rapidly inward. These localized stresses may exceed the baseline strength of the ceramic, thus damaging the surface of the component and reducing its strength. This susceptibility to 
stress damage could lead to projections that ceramic components, especially under sliding contact may fail unpredictably and prematurely.

Since the eventual failure of these ceramics is mainly due to surface damage, it is proposed that this damage can be reduced via the application of a thin coating that can withstand higher amounts of stresses and is more resistant to corrosion. $[9,10]$ Since the ceramic components are used in high temperature engineering applications, the coating should also posses good adherence, and thermal shock properties.

\section{Coatings to Date}

High temperature protective coatings have shown some promise but failed to meet all the requirements of the applications. The coating properties required for a specific application were generally achieved through the selection of material properties and coating process parameters. In general, the desired ceramic properties include low thermal conductivity, a relatively high coefficient of thermal expansion, and most importantly, chemical and mechanical stability in the application environment. Plasma sprayed oxide coatings demonstrated improvements in thermal stress resistance, quite interestingly due to the coating porosity that is characteristically produced by this process. [11] However, the adhesion of these coatings was found to be inadequate. In addition, gas permeability and condensed salt penetration into the porous coating structure may induce coating degradation. Moreover, most state-of-the-art ceramic coating materials, mainly the stabilized zirconias, may also exhibit inherent thermodynamic instability problems when subjected to combustion environments that contain impurities such as sodium, potassium, vanadium, phosphorous and sulfur. Multi- 
layered CVD coatings of aluminum nitride and zirconia-toughened alumina $\left(\mathrm{AlN} / \mathrm{Al}_{2} \mathrm{O}_{3}+\mathrm{ZrO}_{2}\right)$ although extremely adherent, failed at temperatures above $1100^{\circ} \mathrm{C}$ due to compositional deterioration resulting in coating blistering. [12] Reactions between the ceramic coatings and the corrosive combustion gases or condensates may also cause failure of some coatings. Thus the utilization of ceramic components under stringent conditions mandates not only that coatings be adherent and oxidation resistant, but also that they be chemically stable for extended periods at extremely high temperatures. Recent review papers suggest that further improvements of thermal barrier coatings are still required with respect to corrosion and thermal shock resistance. [10] Diffusion coatings containing mullite as a major phase have shown some promise in thermal cycle tests. Duplex coatings with a mullite inter-layer, and a high alumina content coating on

the surface protected $\mathrm{SiC}$ from corrosion. [13] High temperature atmospheric plasma sprayed mullite coatings have also shown some promise as corrosion resistant coatings. [14] Although the coatings were unable to completely protect the ceramic under severe corrosion environments, it was evident that the problems were primarily due to the inability of the plasma spray process to produce dense, completely crystalline coatings. Consequently, mullite is identified as an excellent candidate coating material, provided dense crystalline coatings could be produced. Chemical vapor deposition is chosen as a processing technique because of the several underlying benefits associated with the technique.

\section{Chemical Vapor Deposition}

The CVD technique is currently used to synthesize a wide range of materials for various applications including solid state devices, wear resistant coatings for cutting tool 
applications, oxidation/corrosion resistance applications, thermal shock resistance, monolithic free-standing CVD structures, and for processing microstructurally graded powders. CVD is chosen as the processing technique for many applications primarily because of the superior adherence characteristics of the coatings grown by this process. This is due to the chemical nature of the bonding at the coating/substrate interface as opposed to a mechanical bonding in case of a physical vapor deposition (PVD) process. Additionally CVD also provides the ease and convenience in tailoring the required properties via the control of the microstructure and morphology of the deposit by the control of process parameters and deposition conditions. It also allows for uniform deposition on materials with complicated shapes, cavities, and porosity. [18] Neartheoretical densities are usually achieved due to the atom-by-atom deposition process. It is possible to vary the composition and/or structure of the coating material during deposition, allowing for graded coatings. High temperature materials can be deposited via CVD at temperatures far below their melting points or sintering temperatures. In addition, commercialization of the CVD process is relatively easy as demonstrated by the wide usage in the ceramic cutting tool and wear parts production. However, the CVD process is inherently very complicated and needs to be thoroughly understood in order to synthesize new coatings. The science base available to accurately predict the process attributes for a new CVD process is very limited. Recently there have been attempts to formulate concepts to reduce the ambiguity involved with empirical ways of developing new coatings. [19-21] In addition, since the process requires operation at elevated temperatures, the effects of the high deposition temperatures on the phase stability of the substrate also needs to be well understood. Most importantly, extreme care needs to be taken in handling the toxic and corrosive reactants and byproducts. 


\section{RESEARCH APPROACH}

Two different approaches were taken in order to obtain the final mullite composition in the coating. A multi-layered system consisting of alternating layers of $\mathrm{Al}_{2} \mathrm{O}_{3}$ and $\mathrm{SiO}_{2}$ was investigated since the deposition of $\mathrm{Al}_{2} \mathrm{O}_{3}$ and $\mathrm{SiO}_{2}$ is well studied. The second approach was to directly deposit mullite from vapor phase reagents consisting of both $\mathrm{Al}$ and $\mathrm{Si}$ species. Figure 1 summarizes the various process routes that could lead to the ultimate formation of mullite coating.

\section{Multi-Layered System}

$\mathrm{Al}_{2} \mathrm{O}_{3}$ and $\mathrm{SiO}_{2}$ coatings were grown using already known precursors used for their deposition commercially on a day-to-day basis. This was done in order to facilitate easy deposition of the coatings, followed by a post deposition treatment via annealing in order to form mullite. Mullite was formed by deKaiser in his diffusion couple experiment of $\mathrm{Al}_{2} \mathrm{O}_{3}$ and $\mathrm{SiO}_{2}$ pellets at high temperatures in the range of $1500^{\circ} \mathrm{C}$. [22] The reaction between pressed alumina and silica pellets at $1600{ }^{\circ} \mathrm{C}$ has shown the formation of mullite crystals with their c-axis parallel to the direction of diffusion of silica into alumina. This led to crystallites of mullite being oriented perpendicular to the interface. 
It was projected that similar results could be obtained by depositing thin alternating layers of $\mathrm{Al}_{2} \mathrm{O}_{3}$ and $\mathrm{SiO}_{2}$, and annealing the coatings to cause diffusion. The overall composition of the coating could be controlled accurately by appropriate selection of the relative coating thicknesses. Initially the multi-layers would have a definite interface with abrupt changes in composition, which can result in great amounts of residual stresses in the multi-layered coating. As the heat treatment step progresses, and the two materials start to participate in the inter-diffusion process, this interface becomes very gradual. The goal was to make sure there are no sharp interfaces, and ultimately to ensure there is complete diffusion across the layers to produce mullite.

The multi-layers were designed to facilitate easy diffusion across the layers. This can be accomplished by growing alumina and silica layers as thin as possible so the diffusion depths that need to be overcome are smaller facilitating complete diffusion across the layers. The thinner layers may result in higher residual stresses in the layers due to the thermal mismatch. There may be an optimum thickness for these layers. Additionally the microstructure of the coating within each individual layer needs to be adjusted so small grain sizes are possible, making grain boundary diffusion more pronounced. The multi-layers will consist of diffusion couples of $\alpha$ - or $\gamma-\mathrm{Al}_{2} \mathrm{O}_{3}$ and amorphous $\mathrm{SiO}_{2}$. Rate equations will be used in identifying reasonable diffusion times and temperatures to make complete diffusion possible. Care needs to be taken when selecting the diffusion temperature, since it may have a detrimental effect on the substrate. When a mullite layer was formed on a polycrystalline $\mathrm{Al}_{2} \mathrm{O}_{3}$ via reaction with $\mathrm{SiC}$ through formation of $\mathrm{SiO}$, a volumetric increase of $9.7 \%$ resulted thus applying compressive stresses on the mullite coating. This information would be very useful in designing the multi-layers. For example, the multi-layers can be designed to achieve functional grading to have compatibility with the substrate on the lower end and 
compatibility with the application environment on the upper end. This can simply be done by changing the relative thicknesses of the $\mathrm{Al}_{2} \mathrm{O}_{3}$ and $\mathrm{SiO}_{2}$ layers. The final resultant coating would have a pure mullite phase starting from the substrate to a composite of mullite and corundum on the outermost layer.

\section{Direct Deposition}

Since there were many difficulties encountered in the multi-layered approach, direct deposition of mullite was attempted. Two different Si donors (TEOS and $\mathrm{SiCl}_{4}$ ) were considered along with $\mathrm{AlCl}_{3}, \mathrm{CO}_{2}$, and $\mathrm{H}_{2}$. This would be an industrially preferred method for various reasons: i) it would be no longer necessary to monitor the thickness of the individual $\mathrm{Al}_{2} \mathrm{O}_{3}$ and $\mathrm{SiO}_{2}$ layers, ii) there would no sharp interfaces after deposition, and iii) the post-deposition anneal step would be totally eliminated. Essentially mullite can be grown in one deposition step.

There are two ways of obtaining the final mullite coating through this route. Deposit mullite directly, or codeposit $\mathrm{Al}_{2} \mathrm{O}_{3}$ and $\mathrm{SiO}_{2}$ and anneal the coating to obtain mullite. Control of the composition and the phase of the deposit is important since these factors can have a significant effect on product properties. In the case when mullite is not deposited directly, the diffusion depths will be considerably lower compared to the multilayered system, and consequently the diffusion times and temperatures necessary will not be as high. The temperature required for complete transformation was expected to be in the range of $1100^{\circ} \mathrm{C}$, based on information from bulk processing. 
In the case of direct deposition, it needs to be determined whether the final product is achieved by a direct deposition of mullite from the reactants, or if $\mathrm{Al}_{2} \mathrm{O}_{3}$ and $\mathrm{SiO}_{2}$ or an intermediate compound is formed first and then a solid state reaction makes the deposition of mullite possible. Boundary layer effects can influence the way the reactants are transported to the surface based on their density, viscosity, and wetting parameters. Many studies [23] showed that the viscosities of mixed oxides could be several orders of magnitude smaller than that of their individual components.

A true co-precipitation process would involve continued condensation and growth of species with -Al-O-Si- bonds. It is clear however, that reactions leading to -Si-O-Siand -Al-O-Al- bonds can also occur. In case of hydrolysis reactions, it has been shown that $\mathrm{Al}$ tends to hydrolyze faster than $\mathrm{Si}$. It has also been shown that the formation of these species can be controlled by avoiding large excess of water, and also by the addition of a catalyst . [24]

Two different systems were investigated in order to deposit mullite directly in one step. $\mathrm{AlCl}_{3}, \mathrm{CO}_{2}, \mathrm{H}_{2}$ and tetraethoxysilane - TEOS $\left(\mathrm{Si}\left[\mathrm{OC}_{2} \mathrm{H}_{5}\right]_{4}\right)$ mixture and $\mathrm{AlCl}_{3}$, $\mathrm{SiCl}_{4}, \mathrm{CO}_{2}, \mathrm{H}_{2}$ mixture. The second mixture turned out to be the viable solution for the direct deposition of crystalline mullite. 


\title{
EXPERIMENTAL METHODS
}

\author{
The CVD System
}

A schematic of the CVD system is shown in Figure 2. The reaction chamber is a 5.5 inch diameter vertical reactor made of Inconel 600 alloy, thus providing resistance to thermal shock, yet exhibit a reasonable amount of chemical inertness, which is important in a CVD process. The temperature was maintained by resistive heating coils with a three-zone furnace capable of temperatures up to $1200^{\circ} \mathrm{C}$. A pneumatic system provided the convenience of easy switch-over between the furnace and the cooling hood on the reactor. A concentric base-plate allowed the inlet gases and exhaust gases to flow through the bottom of the reactor. The temperature of the base was controlled by water flow. Gases and vapor sources were placed remotely, and were carried into the chamber by stainless steel or inconel tubes depending on the severity of the requirement. The lines were heated when necessary. The flow rates of the gases were precisely controlled with mass flow controllers (1259C, 1461C, MKS Instruments, Andover, MA). Vapor sources were maintained at constant temperatures, and an inert bubbling gas was often used to accelerate the evaporation process. A carrier gas was introduced down stream to quickly carry the vapor to the reactor chamber. Mass flow controllers were often used to control the flow rate of vapors. Chamber pressure was maintained at the desired level by a closeloop controlled pressure controller incorporating a gas ballast in conjunction with a throttling valve before the dry pump. A process controller was also incorporated into the 
system. This controller would enable accurate control of the reaction temperature, the source temperatures, gas flow rates, and the chamber pressure.

\section{Materials}

The substrates used for deposition were mainly Hexaloy SiC (Carborundum Company, Niagara Falls, NY) and slip cast $\mathrm{Si}_{3} \mathrm{~N}_{4}$ (GN-10, Allied Signal, Torrance, CA). All the substrates were polished bars of $3 \times 4 \times 20 \mathrm{~mm}$ size. The substrates were placed "standing-up" at various levels in the reactor in order to study the deposition characteristics at different distances from gas entry. The different gases and chemicals used in the experiments were:

\begin{tabular}{|l|l|l|l|}
\hline Chemical & Form & Supplier & Purity \\
\hline Hydrogen & Gas & Matheson & 99.997 \\
\hline Argon & Gas & Wesco & 99.999 \\
\hline Chlorine & Gas & Matheson & 99.96 \\
\hline HCl & Gas & Matheson & 99.99 \\
\hline Carbon Dioxide & Gas & Airco & 99.999 \\
\hline Silicon Chloride & Liquid & Strem & 99.995 \\
\hline TEOS & Liquid & Strem & 99.99 \\
\hline Aluminum & Solid & ALCOA & 99.9 \\
\hline
\end{tabular}




\section{X-Ray Diffractometry}

$\mathrm{X}$-Ray diffractometry was performed on a Nicolet $\mathrm{I} 2$ diffractometer with a $\mathrm{Cu} \mathrm{X}$ ray tube and a $\mathrm{Ni}$ filter resulting in a $\mathrm{Cu} \mathrm{Ka}$ radiation. The $\mathrm{X}$-ray beam width was maintained at $2.5 \mathrm{~mm}$. The unit was run at a standard voltage of $40 \mathrm{KV}$ and a standard current of $20 \mathrm{~mA}$. At this voltage and current level, the $\mathrm{X}$-rays were estimated to penetrate an average depth of $50 \mu \mathrm{m}$, thus covering not only the depth of the coating, but also part of the substrate. Thus, all the diffraction data also contained substrate information. Typically angles of $2 \theta$ from 90 to 10 degrees were scanned at the rate of .04 degrees every 2 seconds. The $2 \theta$ and $\omega$ angles were driven by stepper motors controlled by Falcon microprocessor. Smaller steps and longer times were used when slower scans were necessary in order to obtain a higher resolution. The specimens were mounted on polymer disks, and a sample spinner was used to rotate the samples while scanning in order to average out any orientation effects in the coating/substrate combination. A high purity silicon standard was used as a reference for calibration throughout the work. The diffraction data was collected in a MicroVax II computer with graphic attachment and printed in the form of $2 \theta$ angles vs. X-ray intensity. Specific peaks were marked for dspacings and relative intensity. The X-ray diffraction patterns were compared to the values listed in the JCPDS diffraction file.

\section{Scanning Electron Microscopy}

The coatings were examined in a JEOL JSM6100 scanning electron microscope (SEM). The samples were mounted on aluminum or copper stubs and usually sputtered 
with gold to obtain conductivity on the surface. A Hummer VI-A sputter coater was used. They were also often coated with carbon with a Cressington 108 Carbon/A evaporator. While taking cross section micrographs samples were usually viewed at 90 degrees, or tilted to a 15 degree angle. Micrographs were usually either digitized and printed on thermal paper, or instant photographs were taken using a Polaroid attachment. The microscope was also equipped with a Kevex X-ray energy dispersive spectroscope (EDS) and a detector attachment. The output was processed, normalized for background, and printed as spectra corresponding to the elements. Penetration depth in the silicon based ceramics was estimated at approximately $1 \mu \mathrm{m}$ for a voltage of 5 to $10 \mathrm{kV}$. Quantitative analysis for elemental composition was performed on a computer attachment.

\section{Transmission Electron Microscopy}

To better understand the structure, defects, the inter-diffusion between the layers, as well as the coating/substrate interface, transmission electron microscopy (TEM) was necessary. In order to produce electron transparent cross-sections, coated samples were cut on a Buehler ${ }^{\circledR}$ Isomet low speed diamond saw. The cross-sectional samples were produced by gluing two films face-to-face, resulting in a "sandwich". The samples were glued to a $3 \mathrm{~mm}$ copper grid with epoxy, followed by grinding, polishing, and dimpling in the usual fashion. The dimpled samples were ion-milled in a Gatan Duomill, using a 5 $\mathrm{kV}$ source at $8-10^{\circ}$ incidence angles. Special care was taken to avoid irradiation damage during ion milling by milling at low angles and by cooling the sample using liquid nitrogen. The samples were studied in a JEOL $200 \mathrm{CX}$ TEM operated at $200 \mathrm{kV}$. 
Chemical analysis of the films was carried out in a VG HB603 scanning transmission electron microscope (STEM).

\section{Metallography}

Samples were mounted in bakelite phenolic. In case of cross-section mounting, diallyl pthalate was used for edge retention. The samples were also often nickel plated to avoid edge-rounding. The mounted specimens were ground and polished with diamond impregnated wheels and diamond slurry. A Struers automatic polisher was used. The mounts were loaded on the sample fixture and first ground with 40 and $20 \mu \mathrm{m}$ diamond wheels. $300 \mathrm{rpm}$ wheel speed with wheel and sample spindle spinning in opposite direction was used for this step. $200 \mathrm{~N}$ load was used during grinding. Samples were then polished with $15,6,3$, and $1 \mu \mathrm{m}$ diamond suspension on Petrodisks at $150 \mathrm{rpm}$ and $100 \mathrm{~N}$ load. The samples were also etched with $10 \% \mathrm{HF}$ solution in order to evaluate the crystalline nature of the mullite coating.

\section{Oxidation and Corrosion Analysis}

Preliminary high temperature testing of the layered samples has been performed at 1200,1400 and $1600{ }^{\circ} \mathrm{C}$. A 4 inch diameter $\mathrm{Al}_{2} \mathrm{O}_{3}$ tube furnace was used. The samples were placed in $\mathrm{Al}_{2} \mathrm{O}_{3}$ boats and were heated to the temperature and cooled at reasonably fast rates (Up to $1000{ }^{\circ} \mathrm{C}$ a minute). So, the samples also have a reasonable amount of thermal shock inherently put in them. The annealing tests were performed in a positive argon atmosphere, and the oxidation tests were done in static air. 
All oxidation experiments were performed in a Lindberg horizontal tube furnace with $\mathrm{MoSi}_{2}$ elements capable of temperatures up to $1700^{\circ} \mathrm{C}$. There was approximate hot zone of 12 inches. A 4 inch mullite tube was used to house the samples. The ends were capped with refractory flanges. Samples were usually mounted in an alumina boat and moved to the middle of the hot zone.

Corrosion resistance evaluation was performed at Oak Ridge National Laboratory. Mullite coated $\mathrm{Si}_{3} \mathrm{~N}_{4}$ samples were typically loaded with $\mathrm{Na}_{2} \mathrm{SO}_{4}$ in the liquid form while being heated to approximately $200^{\circ} \mathrm{C}$. The specimens were typically loaded with about $5 \mathrm{mg} / \mathrm{cm}^{2}$ of $\mathrm{Na}_{2} \mathrm{SO}_{4}$. Corrosion experiments were conducted for up to 100 hours at $1000{ }^{\circ} \mathrm{C}$ and $101 \mathrm{kPa}$. The $\mathrm{Na}_{2} \mathrm{SO}_{4}$ loaded specimens were placed on an $\mathrm{Al}_{2} \mathrm{O}_{3}$ holder and exposed to a flowing oxygen environment $\left(200 \mathrm{~cm}^{3} / \mathrm{min}\right)$ in a quartz tube heated by an electric resistance furnace. The resulting specimens were mounted in epoxy and polished to examine corrosion products and resulting surface microstructures. A JEOL Superprobe 733 electron microprobe analyzer (EMPA) equipped with wavelength dispersive spectrometer and an energy dispersive spectrometer (EDS) were used for morphology characterization and phase identification. Further details of the corrosion testing procedure are described elsewhere. [25]

\section{Micro and Macro Scratch Test}

Two types of scratch tests were used to characterize the adhesion of the coatings. While the Macro scratch test gives a quick value of the adherence without much preparation of the sample involved, it was shown that it is not a true measure of coating 
adhesion, since it takes into account such factors as surface friction. [26] However, the test was believed to be useful for quality control purposes through an indication of the coating durability. The micro scratch test eliminates some of the problems associated with macro scratch test and gives a better indication of interfacial adhesion, but requires that the sample be metallographically polished in cross section. One frequently observed problem in this process is the edge-rounding of the coating during polishing, causing errors in adhesion measurement. Both the tests yield a critical load $\mathrm{L}_{\mathrm{C}}$, which is used as a measure of adhesion.

In Macroscratch test, scratch testing with a Rockwell ${ }^{\circledR} \mathrm{C}$ diamond indenter was used. The test was performed with continuously increasing normal load (typically in the order of several Newtons) until the onset of coating removal from the substrate. This is detected with an acoustic emission detector mounted on top of the indenter. A load cell measures the load as the indenter traverses. The load at which the coating debonds from the substrate is called the critical load. This value is used as a measure of the work energy or shear stress required to debond the coating, and therefore used as an indication of its adherence.

The Microscratch test $[26,27]$ encompasses scratching a metallographically polished surface of the sample normal to the coating/substrate interface, exposing a portion of the interface-substrate-coating. A modified microhardness tester (Tukon Wilson Instruments) equipped with an Oriel motorized micrometer was used for testing. The indenter was fixed, while the sample stage was driven with the micrometer. A scratch is generated generally perpendicular to the interface via a diamond indenter. A Knoop indenter was used with its long axis aligned parallel to the direction of scratching. The scratch was applied starting from the substrate towards the coating. Variations 
include scratching at an angle to the interface, and scratching from the coating towards the substrate. The scratching steps were repeated with increasing normal loads until the onset of crack formation at the coating/substrate interface. Several scratches were made at various loads, and the samples were examined in the SEM. The load at which the coating debonds from the substrate is termed as the critical load. This value is used as a measure of the work energy or shear stress required to debond the coating, and therefore an indication of its adherence. 


\section{RESULTS AND DISCUSSION}

This section is divided into seven parts. Results from the multi-layered approach are discussed in the first part. Direct deposited system with TEOS precursor is discussed in the second part. Results of the extensive thermodynamic equilibrium calculations for the $\mathrm{AlCl}_{3}-\mathrm{SiCl}_{4}-\mathrm{CO}_{2}-\mathrm{H}_{2}$ direct deposition system for mullite are discussed in the third part. In the fourth part, results from the thermodynamic analysis are correlated with the deposition variables to evaluate the possible rate-limiting mechanisms. In addition, composition, morphology, and crystallographic orientation of the mullite coatings are also discussed in this section. In the fifth section, the solid solubility range of mullite when produced by CVD is discussed. In the sixth and seventh sections, results from adhesion and corrosion resistance evaluation of mullite are discussed.

\section{Multi-Layered Coating System}

Multilayers of $\alpha-\mathrm{Al}_{2} \mathrm{O}_{3}$ and vitreous $\mathrm{SiO}_{2}$ were grown on $\mathrm{SiC}$ and $\mathrm{Si}_{3} \mathrm{~N}_{4}$ substrates by CVD. The CVD reactor was modified so that the alternating layers could be deposited using the same fixturing without having to take the sample out of the reactor. The thickness of the layers was adjusted such that the overall composition of the coating was that of stoichiometric mullite. The reactant gas concentration and time 
between changeovers was used to obtain the desired composition of the overall coating. The one problem that was anticipated with this approach is that the interfaces between layers were of abrupt changes in composition and could lead to mismatch problems.

$\mathrm{SiO}_{2}$ was deposited by the pyrolysis of Tetraethoxysilane $\left(\mathrm{Si}\left[\mathrm{OC}_{2} \mathrm{H}_{5}\right]_{4}\right)$ resulting in amorphous coatings. The deposition reaction was carried out at $800^{\circ} \mathrm{C}$ at 50 torr pressure. The chemical reaction is as follows : [28]

$\left(\mathrm{Si}\left[\mathrm{OC}_{2} \mathrm{H}_{5}\right]_{4}\right)$

$$
\longrightarrow \quad \mathrm{SiO}_{2}+2 \mathrm{CO}+2 \mathrm{CH}_{4}+2 \mathrm{C}_{2} \mathrm{H}_{4}+2 \mathrm{H}_{2}
$$

Tetraethoxysilane (TEOS) was bubbled from a constant temperature Inconel container kept at $100^{\circ} \mathrm{C}$. Typically $25 \mathrm{cc}$ of Ar was used as the bubbling gas, and the vapor was carried to the chamber with approximately 2 liters of Ar through heated 316 stainless steel tubes. Vapor pressure curves of TEOS in conjunction with the bubbler temperature and bubbling and carrier Ar flow rates were used in order to estimate the amount TEOS being introduced into the chamber. Growth rates were typically in the order of $1 \mu \mathrm{m}$ per hour. The $\mathrm{SiO}_{2}$ layer was amorphous and had a globular morphology. The coating was also dense and uniform in thickness.

$\mathrm{Al}_{2} \mathrm{O}_{3}$ coatings were grown on $\mathrm{Si}_{3} \mathrm{~N}_{4}$ and $\mathrm{SiC}$ substrates in a reactor geometry that was also suitable for depositing $\mathrm{SiO}_{2}$. Process parameters used for depositing $\mathrm{Al}_{2} \mathrm{O}_{3}$ were varied within the range established for $\mathrm{SiO}_{2}$. The reactor geometry and process parameters had to be adjusted so as to accommodate both $\mathrm{SiO}_{2}$ and $\mathrm{Al}_{2} \mathrm{O}_{3}$ coatings. Insitu formed $\mathrm{AlCl}_{3}$, and $\mathrm{H}_{2} \mathrm{O}$ formed by the water-gas-shift reaction of $\mathrm{H}_{2}$ and $\mathrm{CO}_{2}$ were used as the reactants in formation of $\mathrm{Al}_{2} \mathrm{O}_{3}$. An external generator was used to produce 
$\mathrm{AlCl}_{3}$ vapor by placing aluminum chips in an inconel tube in a tube furnace and flowing $\mathrm{H}_{2}$ and $\mathrm{Cl}_{2}$ gases over them. Several condensation problems were encountered in transporting the vapor from the source to the chamber because the vapor had to pass through the cold reactor base. These problems were overcome with better handling of the vapor, changes in base fixturing, and efficient control of the base temperature. An internal generator housed at the lower end of the vertical reactor eliminated the condensation problems, but did not provide the independent control of the temperature of the $\mathrm{Al}$ chips, since the temperature of the Al chips was defined by the hot wall reactor temperature in the lower region. The external $\mathrm{AlCl}_{3}$ generator was maintained at $325^{\circ} \mathrm{C}$. $\mathrm{Cl}_{2}$ is usually carried through the generator with a low flow rate Ar carrier. The generator was very effective and resulted in $100 \%$ conversion efficiency. This was confirmed by weighing the $\mathrm{Al}$ chips at the beginning and end of every experiment. For example, for a $\mathrm{Cl}_{2}$ flow rate of $15 \mathrm{sccm}$, a weight loss in the $\mathrm{Al}$ chips of $1.35 \mathrm{~g}$ was observed, which is close to the theoretical value of $1.3692 \mathrm{~g}$.

The underlying chemical reactions for the formation of $\mathrm{Al}_{2} \mathrm{O}_{3}$ by the hydrolysis method are as follows:

Source:

$2 \mathrm{Al}+3 \mathrm{Cl}_{2}$

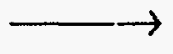

$2 \mathrm{AlCl}_{3}$

Water-gas-shift:

$\mathrm{CO}_{2}+\mathrm{H}_{2}$

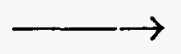

$\mathrm{H}_{2} \mathrm{O}+\mathrm{CO}$

Deposition:

$2 \mathrm{AlCl}_{3}+3 \mathrm{H}_{2} \mathrm{O}$

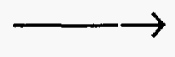

$\mathrm{Al}_{2} \mathrm{O}_{3}+6 \mathrm{HCl}$

The water-gas-shift reaction is the most important and potentially rate-limiting reaction in the formation of $\mathrm{Al}_{2} \mathrm{O}_{3}$ and has been shown to be important in controlling the 
thickness and structure of the deposit accurately. Growth rates were in the order of 0.5 $\mu \mathrm{m}$ per hour. The resulting alumina coatings had a corundum( $\alpha$ ) structure. This agrees generally with the known phase transformation characteristics of amorphous $\mathrm{Al}_{2} \mathrm{O}_{3}$ as a function of temperature, [29] although formation of phases by CVD need not necessarily be in agreement with trends in the conventional processes.

Layered coatings with overall thicknesses of 1 to $1.5 \mu \mathrm{m}$ were grown on $\mathrm{SiC}$ and $\mathrm{Si}_{3} \mathrm{~N}_{4}$ substrates. Since the mismatch in thermal expansion coefficient between $\mathrm{Si}_{3} \mathrm{~N}_{4}$ and $\mathrm{SiO}_{2}$, and $\mathrm{Si}_{3} \mathrm{~N}_{4}$ and $\mathrm{Al}_{2} \mathrm{O}_{3}$ is of the same magnitude, both the configurations of $\mathrm{SiO}_{2}$ being the inter layer with $\mathrm{Al}_{2} \mathrm{O}_{3}$ being the outer layer and vice-versa have been tried. Since a layer of $\mathrm{SiO}_{2}$ is always expected to be naturally present on the $\mathrm{Si}$ based substrates, it was believed that there may be an advantage with using $\mathrm{SiO}_{2}$ as the interlayer. Figure 3 shows $\mathrm{SiO}_{2} / \mathrm{Al}_{2} \mathrm{O}_{3}$ layered coating on a $\mathrm{Si}_{3} \mathrm{~N}_{4}$ substrate with the line scan images showing the amount of $\mathrm{Si}$ and $\mathrm{Al}$ present across the coating/substrate interface.

The multilayered coatings were annealed at different temperatures in order to facilitate the formation of mullite via interfacial reactions. The annealing was performed in a positive $\mathrm{Ar}$ atmosphere in order to prevent oxidation from the environment. Initially an annealing temperature of $1200^{\circ} \mathrm{C}$ was chosen. No significant change was observed in the coating morphology or the interfacial characteristics of the coatings on both $\mathrm{Si}_{3} \mathrm{~N}_{4}$ and $\mathrm{SiC}$ substrates. X-ray analysis performed on these coatings before and after annealing showed no detectable phase changes in the coating. Figure 4 shows the X-ray diffraction pattern of the multi-layered coating after heat treatment showing pure $\alpha$ $\mathrm{Al}_{2} \mathrm{O}_{3}$ peaks in the coating and no transformation. A small diffusion zone was observed between the $\mathrm{Al}_{2} \mathrm{O}_{3}$ and $\mathrm{SiO}_{2}$ layers. Figure 5 is a TEM micrograph of an $\mathrm{Al}_{2} \mathrm{O}_{3}-\mathrm{SiO}_{2}$ interface after a 2 hour anneal at $1200^{\circ} \mathrm{C}$, showing the presence of a $50 \mathrm{~nm}$ reaction zone 
between the pure $\mathrm{SiO}_{2}$ and pure $\mathrm{Al}_{2} \mathrm{O}_{3}$ regions. Chemical analysis of this reaction layer in the STEM using a $1 \mathrm{~nm}$ electron probe showed the formation of a compound in which the $\mathrm{Al}: \mathrm{Si}$ atomic ratio was measured to be $65: 35$ (see EDS spectra in Figure 5) which is close to the theoretical ratio in stoichiometric mullite. This coating exhibited no visible signs of cracking upon cooling. The diffusion zone, however was not large enough to cover the entire coating cross-section. In other words, there were large portions of pure $\mathrm{Al}_{2} \mathrm{O}_{3}$ and pure $\mathrm{SiO}_{2}$ layers that did not exhibit any inter-diffusion.

In order to widen the diffusion zone, the temperature of the post deposition anneal was increased to $1350^{\circ} \mathrm{C}$. This treatment resulted in the delamination of the $\mathrm{Al}_{2} \mathrm{O}_{3}$ layer. TEM micrograph (Figure 6) of this sample shows partial transformation of the amorphous $\mathrm{SiO}_{2}$ layer immediately next to the $\mathrm{Al}_{2} \mathrm{O}_{3}$ coating into crystalline silica. Cracks were observed at the crystalline $\mathrm{SiO}_{2}$ layer and $\mathrm{Al}_{2} \mathrm{O}_{3}$ interface indicating that phase transformation may be responsible for coating delamination. These results have led to projections that transformation of amorphous $\mathrm{SiO}_{2}$ is the reason that most of the coatings developed on $\mathrm{Si}$ based substrates exhibit poor adhesion. It is therefore felt that for any coating configuration to maintain adherence at elevated temperatures on Si based substrates, it is essential that this problem be addressed. It was necessary to understand the amorphous to crystalline transformations in coatings under CTE mismatch and growth stresses.

To quantify the dependence of devitrification on pressure and temperature, experiments were conducted on bulk silica powders. The degree of transformation was found to be dependent on the pressure, and further to increase with an increase in pressure. Figure 7 shows the $\{101\}$ peak of $\alpha$-cristobalite for various pressures at 1270 ${ }^{\circ} \mathrm{C}$. Similar trend was observed at other temperatures. Almost $100 \%$ transformation was 
observed at $1360{ }^{\circ} \mathrm{C}$ even without any pressure. Monolithic $\mathrm{SiO}_{2}$ coatings were grown on $\mathrm{SiC}$ in order to perform comparative studies. The samples were hot pressed in a similar fashion in order to identify the extent and location of devitrification, and the extent of cracking both in the coating and at the interface. As for the dependence of transformation on pressure, the opposite trend compared to the bulk powders was observed. The formation of cristobalite was inhibited by the application of external pressure in coatings. Crack formation was observed at the very point of crystallization of the coating. In all observations, transformation occurred at the point of higher tensile stress within the coating. Details of this work were presented elsewhere. [30]

Vitreous to crystalline transformation in silica led to coating spallation due to cracking caused by volume changes. The transformation was affected by stresses within the coating. Stresses that aid volume contraction in silica enhanced transformation, while those that aid volume expansion inhibited transformation. It was concluded that the multi-layered approach to form mullite coatings was not viable since very high temperatures were needed in order to facilitate reasonable diffusion between $\mathrm{Al}_{2} \mathrm{O}_{3}$ and $\mathrm{SiO}_{2}$ layers. Furthermore, the high temperature treatment causes transformations within the coating leading to failure before any considerable diffusion can take place.

\section{Performance}

Although the multi-layered coatings did not facilitate formation of mullite, they performed better than uncoated ceramic substrates to certain temperatures. Preliminary high temperature testing of these samples was performed at 1200,1400 and $1600^{\circ} \mathrm{C}$ in static air. The samples were placed in $\mathrm{Al}_{2} \mathrm{O}_{3}$ boats and were heated to the set 
temperature and cooled at relatively fast rates (approximately $1000{ }^{\circ} \mathrm{C}$ a minute), inherently inducing a reasonable amount of thermal shock. In all the coating configurations tested, no major damage to the coatings was observed up to $1200^{\circ} \mathrm{C}$ on $\mathrm{Si}_{3} \mathrm{~N}_{4}$ substrates, and up to $1400{ }^{\circ} \mathrm{C}$ on $\mathrm{SiC}$ substrates for short times. $\mathrm{X}$-ray analysis performed on these coatings before and after the testing showed no phase change in the coating.

\section{$\mathrm{TEOS}+\mathrm{AlCl}_{3}+\mathrm{H}_{2}+\mathrm{CO}_{2}$ System}

Thermodynamic calculations were used to determine limiting criteria for the codeposition of $\mathrm{SiO}_{2}$ and $\mathrm{Al}_{2} \mathrm{O}_{3}$ from TEOS- $\mathrm{AlCl}_{3}-\mathrm{CO}_{2}-\mathrm{H}_{2}$ mixtures and aid in establishing rate-limiting gaseous species. Additionally, this information was used to help determine the range of input conditions which would produce $\mathrm{SiO}_{2}$ and $\mathrm{Al}_{2} \mathrm{O}_{3}$ at equilibrium. Relative proportions in concentrations of the reactants necessary ( $\mathrm{Si}\left[\mathrm{OC}_{2} \mathrm{H}_{5}\right]_{4}$, and $\mathrm{AlCl}_{3}$ ) to deposit $\mathrm{SiO}_{2}$ and $\mathrm{Al}_{2} \mathrm{O}_{3}$ were varied over a set of

temperatures $\left(800^{\circ}, 900\right.$ and $\left.1000^{\circ} \mathrm{C}\right)$ and pressures (50 and 100 torr). CVD phase diagrams were constructed by varying the concentration of $\mathrm{AlCl}_{3}$ over a range of 0.1 to 1.5 moles and that of $\left.\mathrm{Si}_{[} \mathrm{OC}_{2} \mathrm{H}_{5}\right]_{4}$ over a range of 0.1 to 0.4 moles. Figure 8 shows the CVD phase diagrams generated using these set of conditions.

The phase diagrams indicate that $\mathrm{SiO}_{2}$ and $\mathrm{Al}_{2} \mathrm{O}_{3}$ can never form simultaneously for any of the input conditions. However, compounds such as $\mathrm{Al}_{2} \mathrm{SiO}_{5}$ are formed along with $\mathrm{Al}_{2} \mathrm{O}_{3}$ and $\mathrm{SiO}_{2}$ at different conditions. It was also found that $\mathrm{Al}_{2} \mathrm{O}_{3}$ and $\mathrm{SiC}$ may be formed simultaneously over a range of input conditions and reactant concentrations. These phases may be used as an intermediate layer in the cases when $\mathrm{SiC}$ is used as a 
substrate. The calculations also suggest that multi-layers of aluminosilicate compound $\left(\mathrm{Al}_{2} \mathrm{SiO}_{5}\right)$ with either $\mathrm{Al}_{2} \mathrm{O}_{3}$ or $\mathrm{SiO}_{2}$ can be deposited with the same input conditions by varying the concentration of the reactant species. Thickness of these layers can be adjusted to obtain the overall relative proportions of $\mathrm{Al}_{2} \mathrm{O}_{3}$ and $\mathrm{SiO}_{2}$ necessary to form mullite.

\section{Coating Morphology and Al/Si Ratios}

It was projected that the absence of a sharp interface and the gradual change in the thermal expansion coefficient would decrease the residual stresses and improve adherence by avoiding interfacial cracking. The composition of the codeposited coating was successfully varied by varying the proportions of the individual reactants necessary to grow monolithic $\mathrm{Al}_{2} \mathrm{O}_{3}$ and $\mathrm{SiO}_{2}$ coatings. For example this was achieved by varying the temperature of the TEOS bubbler, in effect varying the amount of TEOS entering the chamber.

Successful deposition of $\mathrm{Al}_{2} \mathrm{O}_{3}$ in the same reactor geometry used for $\mathrm{SiO}_{2}$ deposition enabled the codeposition of $\mathrm{SiO}_{2}$ and $\mathrm{Al}_{2} \mathrm{O}_{3}$. Reactant concentrations and process parameters were adjusted to control composition, specifically the $\mathrm{Al}_{2} \mathrm{O}_{3} / \mathrm{SiO}_{2}$ ratio. Energy Dispersion Spectra and Quantitative Analysis were performed to determine these ratios. The acceleration voltage of the filament in the scanning microscope was selected so as to reduce the influence of substrate material. A variety of process conditions were investigated to find their influence on the $\mathrm{Al}_{2} \mathrm{O}_{3} / \mathrm{SiO}_{2}$ ratio in these coatings. 
Figures 9 shows the energy dispersion spectra and quantitative analysis performed on three samples that were grown with increasing amounts of TEOS. Peaks corresponding to $\mathrm{Al}$ and $\mathrm{Si}$ were observed throughout the coating. The relative proportions of the constituent materials were calculated by normalizing the atomic percent to 100 . The gold present in the spectra is the conductive coating on the samples. The increase in Si content in the coatings is very evident from the spectra. The Al:Si ratio is approximately $5: 1$ in one case, versus $3: 2$ in the other. The acceleration voltage of the filament in the scanning microscope was selected so as to reduce the influence of substrate material. To verify this effect $\mathrm{Al}_{2} \mathrm{O}_{3}$ coatings were grown on WC-Co substrates. Only $\mathrm{Al}$ in the coating and $\mathrm{Au}$ in the conductive coating were detected. This confirmed the fact that the substrate material had no effect on the energy dispersion spectra at the chosen filament voltage. It was also observed that $\mathrm{SiO}_{2}$ is the dominant growth species in the codeposited system. Thermodynamic analyses also indicate this trend. It was also known that growth rate of $\mathrm{SiO}_{2}$ as a single phase coating is in the order of $1 \mu \mathrm{m}$ an hour as opposed to $0.5 \mu \mathrm{m}$ for monolithic $\mathrm{Al}_{2} \mathrm{O}_{3}$. X-ray diffraction analysis of the substrate/coating system showed no peaks related to the coating, indicating that the coatings were amorphous. It is believed that $\mathrm{SiO}_{2}$ is formed via the pyrolysis of tetraethoxysilane, and $\mathrm{AlCl}_{3}$ takes the available oxygen from the TEOS byproducts and readily forms the oxide thus not taking oxygen from water-gas-shift reaction to form a crystalline deposit. Other variations to this coating configuration such as constant $\mathrm{Al}_{2} \mathrm{O}_{3}$ deposition with intermittent introduction of TEOS were attempted but essentially resulted in amorphous deposits. 


\section{$\mathrm{SiCl}_{4}+\mathrm{AlCl}_{3}+\mathrm{H}_{2}+\mathrm{CO}_{2}$ System}

\section{Equilibrium Thermodynamic Analysis}

Several calculations were performed on the $\mathrm{AlCl}_{3}-\mathrm{SiCl}_{4}-\mathrm{CO}_{2}-\mathrm{H}_{2}$ system at different process parameters at each set of deposition conditions. Some additional calculations were also performed by substituting $\mathrm{AlCl}_{3}$ and $\mathrm{SiCl}_{4}$ with $\mathrm{AlBr}_{3}$ and $\mathrm{SiBr}_{4}$, and $\mathrm{AlF}_{3}$ and $\mathrm{SiF}_{4}$. Table 1 summarizes the different process conditions that were chosen for calculations. The amount of individual species (both gaseous and condensed) from the computer output is used to generate the CVD phase diagrams. These diagrams represent, for a set of reaction conditions, and input reactant concentrations, all the possible phases that would be present at equilibrium. The reaction that yields mullite from $\mathrm{AlCl}_{3}$ and $\mathrm{SiCl}_{4}$ is assumed to be as follows:

$$
6 \mathrm{AlCl}_{3}+2 \mathrm{SiCl}_{4}+13 \mathrm{CO}_{2}+13 \mathrm{H}_{2} \longrightarrow 3 \mathrm{Al}_{2} \mathrm{O}_{3} \cdot 2 \mathrm{SiO}_{2}+13 \mathrm{CO}+26 \mathrm{HCl}
$$

Figure 10 shows a ternary CVD phase diagram of $\mathrm{AlCl}_{3}-\mathrm{SiCl}_{4}-\mathrm{CO}_{2}-\mathrm{H}_{2}$ system at $1000^{\circ} \mathrm{C}$ and 75 torr. The ratio of $\mathrm{H}_{2}:\left(\mathrm{AlCl}_{3}+\mathrm{SiCl}_{4}+\mathrm{CO}_{2}\right)$ was maintained at 5:1. Since the concentration of $\mathrm{H}_{2}$ was fixed at 500 moles, the total moles of $\mathrm{AlCl}_{3}+\mathrm{SiCl}_{4}+\mathrm{CO}_{2}$ was 100. As one would expect, $\mathrm{Al}_{2} \mathrm{O}_{3}$-based products form along the $\mathrm{AlCl}_{3}-\mathrm{CO}_{2}$ line, and $\mathrm{SiO}_{2}$-based products form along the $\mathrm{SiCl}_{4}-\mathrm{CO}_{2}$ line. Pure oxides form at high $\mathrm{CO}_{2}$ concentrations, oxides+carbon in the medium $\mathrm{CO}_{2}$ concentration, and oxides+carbides in the low $\mathrm{CO}_{2}$ concentration. To avoid carbon in the deposit, operating in the regime where there is excess $\mathrm{CO}_{2}$ available for the reaction is necessary. Excess carbon towards the left portion of the diagram is a result of the lack of availability of $\mathrm{O}_{2}$ in the reaction to 
form the gaseous byproduct, $\mathrm{CO}$. According to the phase diagram, pure mullite can only be obtained as a line compound, between the mullite $+\mathrm{Al}_{2} \mathrm{O}_{3}$ and mullite $+\mathrm{SiO}_{2}$ regions. Since Gibbs free energy of formation of $\mathrm{SiO}_{2}$ is lower than that of mullite, which is lower than that of $\mathrm{Al}_{2} \mathrm{O}_{3}$, all the oxygen available is first used to form $\mathrm{SiO}_{2}$, then mullite, and then $\mathrm{Al}_{2} \mathrm{O}_{3}$.

Based on the CVD phase diagram (Figure 11), reactant gas composition of $\mathrm{AlCl}_{3}$ and $\mathrm{SiCl}_{4}$ were varied (mole fractions from $10^{-5}$ to 1 ) keeping the $\mathrm{CO}_{2}: \mathrm{H}_{2}$ ratio at $1: 2$ to narrow the composition range. The resulting phase diagram (Figure 11) shows that mullite can be obtained with these starting reactants if the stoichiometry of $\mathrm{AlCl}_{3}: \mathrm{SiCl}_{4}$ is maintained at the same level as that of mullite $(\mathrm{Al}: \mathrm{Si}=3: 1)$. It should be noted that theoretically, any deviation from this input stoichiometry results in excess $\mathrm{Al}_{2} \mathrm{O}_{3}$ or $\mathrm{SiO}_{2}$. However, it is projected that mullite will have a range of solid solubility when produced via $\mathrm{CVD}$, as shown with the shaded region in Figure 11. Since excess $\mathrm{SiO}_{2}$ in mullite is detrimental to elevated temperature properties of these coatings, it is critical to ensure that no residual $\mathrm{SiO}_{2}$ is obtained. This can be easily achieved, as indicated by the CVD phase diagram by shifting the input reactant stoichiometry slightly to the $\mathrm{Al}$ rich side.

\section{Effect of Temperature}

Temperature was varied from $800^{\circ} \mathrm{C}$ to $1200^{\circ} \mathrm{C}$ in steps of $200^{\circ} \mathrm{C}$. The results are shown in the CVD phase diagrams in Figures 12. When the temperature was reduced to $800^{\circ} \mathrm{C}$, the formation of mullite was not predicted. Instead, sillimanite $\left(\mathrm{Al}_{2} \mathrm{O}_{3} \cdot \mathrm{SiO}_{2}\right)$

is formed in the high $\mathrm{CO}_{2}$ concentration range. At $1200{ }^{\circ} \mathrm{C}$, many phases that were present at $1000^{\circ} \mathrm{C}$ (Figure 13), including carbon were absent throughout the phase 
diagram. Based on the analysis of output gas stoichiometry at $1200^{\circ} \mathrm{C}$, gaseous products such as $\mathrm{CH}_{4}$ were formed, rather than formation of carbon as a solid deposit. At this temperature, carbon free deposits of mullite can be obtained over a much broader range of input parameters compared to $1000^{\circ} \mathrm{C}$.

\section{Effect of Pressure}

Pressure was varied from 2 torr to 150 torr. The results are shown in the CVD phase diagrams in Figures 14. As the pressure is increased from 2 to 150 torr, the region over which mullite can be formed widens, and a fewer number of phases are present. Additionally, as the pressure is decreased from 150 to 2 torr, the level of free carbon is reduced (also compare these figures with Figure 10). Lower pressures are preferred for obtaining carbon-free deposits, since at lower pressures, carbon has a higher affinity to form gaseous products such as $\mathrm{CH}_{4}$ than forming a solid deposit. Thus there is a trade-off between the extent of formation of mullite and obtaining carbon-free deposits.

\section{Effect of Stoichiometry}

To determine the appropriate ratios of the $\mathrm{Al}$ and $\mathrm{Si}$ species in the reactant mix, $\mathrm{AlCl}_{3}$ and $\mathrm{SiCl}_{4}$ concentrations were varied at the $1000^{\circ} \mathrm{C}$ and 75 torr condition. The region over which the compositions were varied is shown on the ternary diagram with the lines $\mathrm{AA}, \mathrm{BB}$ and $\mathrm{CC}$ in Figure 15. $\mathrm{CO}_{2}$ concentration throughout the line $\mathrm{AA}$ was maintained at 90 moles. Thus, the total $\left(\mathrm{AlCl}_{3}+\mathrm{SiCl}_{4}\right)$ concentration was 10 moles. $\mathrm{AlCl}_{3}$ composition was varied from 0 to 10 moles, and the results were plotted in terms 
of composition of the reaction products and the $\mathrm{AlCl}_{3}$ deposition efficiency. The deposition efficiency is calculated by dividing the number of moles of the product by the number of moles of $\mathrm{AlCl}_{3}$ that contributes to that product. Figure 16 shows the concentration and efficiency curves. Mullite concentration was found to increase gradually with increasing $\mathrm{AlCl}_{3}$ concentration with the highest at 7.5 moles of $\mathrm{AlCl}_{3}$, which also matches with the stoichiometry of mullite. The $\mathrm{SiO}_{2}$ concentration in the deposit is the highest at 0 moles of $\mathrm{AlCl}_{3}$ and reduces to zero at 7.5 moles $\mathrm{AlCl}_{3} \cdot \mathrm{Al}_{2} \mathrm{O}_{3}$ concentration increases from zero at 7.5 moles $\mathrm{AlCl}_{3}$ to its highest at 10 moles of $\mathrm{AlCl}_{3}$. The efficiency of mullite formation is $100 \%$ from 0 to 7.5 moles of $\mathrm{AlCl}_{3}$, at which point $\mathrm{Al}_{2} \mathrm{O}_{3}$ starts to form.

Section $\mathrm{BB}$ was taken at the constant $\mathrm{CO}_{2}$ concentration line of 50 moles as shown in Figure 15, thus the total $\mathrm{AlCl}_{3}+\mathrm{SiCl}_{4}$ concentration is 50 moles. $\mathrm{AlCl}_{3}$ concentration was varied from 0 to 50 moles $\left(\mathrm{SiCl}_{4}\right.$ from 50 to 0 moles). The results of the calculations were plotted in terms of $\mathrm{AlCl}_{3}$ concentration. Figure 17 shows the concentration and efficiency profiles. The trends observed in this case were very similar to the ones in the previous case, except that the efficiency of mullite formation is the highest when the Al:Si ratio is that of stoichiometric mullite. In addition, carbon was observed as a product throughout the analysis.

Section $\mathrm{CC}$ was taken at a constant $\mathrm{SiCl}_{4}$ concentration of 3 moles. Thus, the total $\left(\mathrm{AlCl}_{3}+\mathrm{CO}_{2}\right)$ concentration was 97 moles. $\mathrm{AlCl}_{3}$ concentration was varied from 10 to 80 moles ( 87 to 17 moles of $\mathrm{CO}_{2}$ ). Figure 18 shows the concentration and efficiency diagrams. The concentration of the resulting mullite remains fairly constant throughout the diagram. However, the efficiency of mullite formation is the highest at the low $\mathrm{AlCl}_{3}$ concentration. It is evident from the phase diagram that it is important to operate in the 
mullite $+\mathrm{Al}_{2} \mathrm{O}_{3}$ region is now smaller than before. The $\mathrm{SiC}+\mathrm{SiO}_{2}+\mathrm{C}$ region is approximately the same size as when $\mathrm{AlCl}_{3}$ and $\mathrm{SiCl}_{4}$ were used. $\mathrm{SiC}+\mathrm{SiO}_{2}$ region is now much larger, and $\mathrm{SiO}_{2}+\mathrm{C}$ region starts to appear at lower $\mathrm{CO}_{2}$ concentrations than before; however, the overall region is smaller than before.

When $\mathrm{AlCl}_{3}$ and $\mathrm{SiCl}_{4}$ were replaced with $\mathrm{AlF}_{3}$ and $\mathrm{SiF}_{4}$, a completely different phase diagram emerges. A halide phase $\mathrm{AlF}_{3}$ is observed at low $\mathrm{CO}_{2}$ concentrations and high $\mathrm{AlF}_{3}$ concentrations. This indicates that at low oxygen concentrations, $\mathrm{AlF}_{3}$ does not react with the available hydrogen in order to form $\mathrm{HF}$ and $\mathrm{Al}$ as a deposit. A large region of pure $\mathrm{Al}_{2} \mathrm{O}_{3}$ is also observed in the diagram. Mullite is mostly observed along the $\mathrm{SiF}_{4}-\mathrm{CO}_{2}$ line, and is again seen as a line compound, but formed over a much narrower range of reactant concentrations. In addition, there was a region near the high $\mathrm{CO}_{2}$ concentration where no solid phases were formed.

This confirms that using the $\mathrm{AlBr}_{3}$ and $\mathrm{SiBr}_{4}$ and $\mathrm{AlF}_{3}$ and $\mathrm{SiF}_{3}$ systems does not provide any added benefit, and that in fact they are not favorable for producing mullite through this method. Thus only the $\mathrm{SiCl}_{4}$ and $\mathrm{AlCl}_{3}$ combination was used for experimentation.

\section{Mullite Deposition}

Reactant concentrations in the deposition experiments were varied within the general ranges investigated in the thermodynamic analysis. Deposition of $\alpha-\mathrm{Al}_{2} \mathrm{O}_{3}$ via hydrolysis of $\mathrm{AlCl}_{3}$ was used as a guideline in establishing the initial process characteristics such as the reactor geometry (fixturing, sample holders). However, it was 
later found that the optimum reactor geometry necessary for mullite deposition was entirely different from that for alumina. Reactants were introduced from the bottom of the chamber and exhausted from the top. $\mathrm{Si}_{3} \mathrm{~N}_{4}$ and $\mathrm{SiC}$ substrates were placed at three different levels within the constant temperature hot-zone. A block diagram representing the process is as shown in Figure 21. $\mathrm{AlCl}_{3}$ was formed by chlorinating the $\mathrm{Al}$ chips like in the case of $\mathrm{Al}_{2} \mathrm{O}_{3}$ deposition. $\mathrm{SiCl}_{4}$ was evaporated from liquid stage at room temperature.

Deposition was generally non-uniform along the length of the reactor. This is due to the fact that the system consisted of a hot wall reactor, and the reactants are depleted as they pass through the reactor via deposition on the fixtures and the reactor walls. However, the deposition was uniform in the radial direction, and the coatings were fairly uniform within the length of the $20 \mathrm{~mm}$ long samples, except for the approximately $1-2$ $\mathrm{mm}$ portion of the substrate that was held in the fixture. Growth rates were calculated by dividing the total weight gain in a sample by the total surface area, thus making it convenient for comparison. For a typical experiment at $950^{\circ} \mathrm{C}$ and 75 torr condition for 120 minutes, the samples gained an average weight of $5 \mathrm{mg}$, thus making the growth rate approximately $0.0138 \mathrm{mg} / \mathrm{cm}^{2}$-min. The $\mathrm{AlCl}_{3}: \mathrm{SiCl}_{4}$ ratio in the input reactant mixture was 2:1. A comparison of the experimental and calculated equilibrium rates and efficiencies indicates that for each specific set of conditions, the experimental deposition rates and efficiencies were less than the theoretical rates and efficiencies. This means that generally, thermodynamic equilibrium conditions were not attained in the conditions studied in this reactor geometry. 
The coating starts with very fine grains and grows into larger grains as the growth process continues. It can also be seen that the grains grow in a columnar fashion thus supporting the fact that there is an orientation effect within the coating.

Although all the electron diffraction patterns in the TEM taken at various points within the coating confirmed that the coating was mullite, several variations in grain structure were observed. Figure 26 shows a cross-section TEM micrograph of a typical mullite coating on $\mathrm{SiC}$. An initial nano-crystalline layer was observed (as confirmed by fringes in electron diffraction), and then large crystals of columnar mullite, often starting with small equiaxed crystals. A detailed TEM and STEM analysis was presented elsewhere. [31] Chemical analysis on the STEM indicated that in addition to the microstructural variations, there is also a pronounced compositional variation through the thickness of the coating. Al/Si ratio varied from as low as 1.5 at the substrate/coating interface to as high as 8 near the surface. Al/Si composition increased gradually through the nanocrystalline region, and then at the interface with the crystalline region, a sharp jump in $\mathrm{Al} / \mathrm{Si}$ ratio was observed. The composition of the coating was found to be uniform parallel to the coating/substrate interface throughout the coating. Thus, the compositional variation is not random, and is only in the growth direction. This effect was investigated through variations in temperature, pressure, reactant gas stoichiometry, and the coating evolution with time.

\section{Effect of Temperature}

Temperature was varied between $800^{\circ} \mathrm{C}$ and $1050^{\circ} \mathrm{C}$ at $50^{\circ} \mathrm{C}$ increments. All the experiments were carried out at a constant pressure of 75 torr, keeping all the reactant 
stoichiometries constant. The corresponding SEM coating surface micrographs, EDS spectra, and X-ray diffraction patterns are shown in Figures 27 to 29 . The coating deposited at $800^{\circ} \mathrm{C}$ has a very globular morphology as opposed to a faceted morphology at $950^{\circ} \mathrm{C}$. X-ray diffraction indicates that there is no detectable crystalline phase present in the coating. Nevertheless, $\mathrm{Al}$ and $\mathrm{Si}$ were both present in the coating as shown by the EDS spectrum. The $\mathrm{Al} / \mathrm{Si}$ ratio was approximately $2: 1$. At $850^{\circ} \mathrm{C}$ the coating has a predominantly globular structure with small faceted crystals growing from the large grains. X-ray diffraction indicates a small detectable amount of mullite in the coating. To my knowledge this is the lowest temperature ever at which crystalline mullite was reported synthesized by any process. Although it is hard to estimate, it would be safe to say that the coating has no specific orientation at this stage. The Al/Si ratio in the EDS analysis was 2.65 . At $900^{\circ} \mathrm{C}$, the globular grains are smaller, and the crystallites start to grow. In addition, a network of cracks was observed, indicating that there may be stresses between the amorphous and the crystalline "layers" of the coating possibly due to thermal mismatch upon cooling, or during growth. X-ray diffraction analysis shows mullite as the only crystalline phase present in the coating. The diffaction pattern indicates that there is no specific orientation in the deposit. EDS analysis indicates the $\mathrm{Al} / \mathrm{Si}$ ratio near the surface as 3.77 . At $1000^{\circ} \mathrm{C}$, much larger grains compared to the 950 ${ }^{\circ} \mathrm{C}$ case were observed. In addition, large clusters of crystals were also observed, usually accompanied by a network of microcracks around them. These cracks could be due to the growth stresses resulting from growth mismatch between the coating and the large clusters. Thus, higher temperatures promote deposition and hence grain growth. X-ray diffraction analysis indicates that the coating was oriented just the same way as the coating at $950^{\circ} \mathrm{C}$. The $\mathrm{Al} / \mathrm{Si}$ ratio near the surface was calculated to be 4.56 . At 1050 ${ }^{\circ} \mathrm{C}$, very large crystals were observed. These crystals appear to grow by "dominating" the small crystals underneath. Again, X-ray diffraction indicates that the coatings were 
highly oriented. Temperatures above $1050{ }^{\circ} \mathrm{C}$ could not be attained with the current system, although the furnace was capable of temperatures up to $1200^{\circ} \mathrm{C}$, due to problems with efficiently maintaining the reactor base temperature below the allowable operating temperature of the Viton ${ }^{\circledR}$ o-ring.

The effect of temperature on the deposition rate is shown in Figure 30. The mullite deposition rate decreased from $800^{\circ} \mathrm{C}$ to $850^{\circ} \mathrm{C}$ and then increased. Figure 31 shows the Arrhenius plot corresponding to an activation energy $7.4 \mathrm{kcal} / \mathrm{mol}$. Although this activation energy is characteristic of a mass-transport limited process, the result should be interpreted with caution since a variation in $\mathrm{Al} / \mathrm{Si}$ ratio was observed in the coating. In addition, the extent of crystallinity was also a variable.

\section{Effect of Pressure}

Pressure was varied between 50 and 200 torr, keeping the temperature constant at $950^{\circ} \mathrm{C}$. The corresponding SEM micrographs, EDS spectra, and X-ray diffraction analyses are presented in Figures 32 - 34. At 50 torr, relatively small crystallites were formed compared to the 75 torr condition. The growth rates were also lower. At the 100 torr condition, grains with varying sizes were observed on the surface. At the 150 torr condition, a much larger grain size was observed, again with a range of grain sizes within the coating. X-ray diffraction analysis indicates that the grains are not as oriented as in the 75 torr condition. Also the $\mathrm{Al} / \mathrm{Si}$ ratio as observed by the EDS analysis is lower than that at the 75 torr case. At 200 torr, the coating is not very dense, and exhibits major porosity through large spaces left between crystals. The crystals appear to be growing independent of the surface beneath them, unlike in the previous cases, where the crystals were growing at the expense of other grains. It is as if these crystals were nucleating 
irrespective of the chemistry of the surface beneath them. The Al/Si ratio was high at 5.75. The growth rate, and thus the grain size, however, were lower than in the 150 torr condition, a reversal in the trend with pressure observed so far. This is possibly because the reaction starts to slow down as the total pressure is increased beyond a certain level, although further experimentation is required to fully understand this reaction. Pressures in the order of 300 torr and above could not be attained because of limitations such as condensation of the $\mathrm{AlCl}_{3}$ vapor in the feed-through at the base of the reactor due to the increased residence time. A simple calculation shows that the residence time at 300 torr would be 1 second in the hot zone, four times the amount observed at 75 torr.

The effect of total system pressure on deposition rate is shown in Figure 35. The deposition rate increased almost linearly at low system pressures; however, with a further increase in system pressure, the rate of increase was reduced, with a subsequent reduction in the deposition rate. This effect can be attributed to the depletion of reactants with increase in pressure due to the hot wall deposition system.

\section{Effect of Stoichiometry}

The $\mathrm{AlCl}_{3}$ and $\mathrm{SiCl}_{4}$ concentrations were varied keeping the rest of the reactants and the deposition conditions constant. This set of experiments were carried out at the $950^{\circ} \mathrm{C}$ and 75 torr condition. The corresponding SEM micrographs, X-ray diffraction patterns, and the EDS analyses are presented in Figures 36 - 38. When only $\mathrm{SiCl}_{4}$ was introduced, globular grains of approximately $5 \mu \mathrm{m}$ size were observed. X-ray diffraction analyses indicate no detectable crystalline phase in the coating. When the $\mathrm{AlCl}_{3}: \mathrm{SiCl}_{4}$ ratio was maintained at $1: 2$, a large difference in grain size was observed. The grains were much smaller, in the order of $1 \mu \mathrm{m}$, with an occasional crystallite within the coating. When the $\mathrm{AlCl}_{3}: \mathrm{SiCl}_{4}$ ratio was increased to $2: 3$, a very interesting morphology was 
Comparison of the growth rates at various levels in the reactor and the reactant depletion effects suggest that the formation of mullite does not require the formation of $\mathrm{H}_{2} \mathrm{O}$ through the water-gas-shift reaction. Further experimentation is necessary in order to understand the exact mechanism involved.

\section{Coating Evolution}

To understand the nucleation and growth characteristics of mullite on $\mathrm{Si}_{3} \mathrm{~N}_{4}$ and $\mathrm{SiC}$, a number of experiments were carried out at the $950^{\circ} \mathrm{C}$ and 75 torr condition. Coatings were grown for varied amounts of time in order to estimate the growth rates and morphologies with respect to time. Because in-situ observations cannot be made in this hot wall reactor, separate experiments had to be carried out for $30,60,90,120$, and 150 minutes. The corresponding SEM micrographs, EDS spectra, and X-ray diffraction analyses of the samples processed for different times are presented in Figures $40-42$. After 30 minutes of deposition, the coating appears to have a globular morphology with some large grains dominating the growth process. The EDS spectra show that the Al:Si atomic ratio in the coating was 1.12 . The coating is very uniform and is approximately 1 $\mu \mathrm{m}$ thick. After 60 minutes, fine crystals start to form on top of the globular grains. The Al: Si ratio as seen from the EDS analysis is 2.91 . At this stage, the coating is approximately $2.5 \mu \mathrm{m}$ thick. After 90 minutes, the coating appears to be completely crystalline with the grains growing much larger. The Al: Si ratio in the coating is 4.54. The coating is now approximately $5 \mu \mathrm{m}$ thick. The 120 minute condition was discussed earlier. After 150 minutes, the grains continue to grow to approximately $10 \mu \mathrm{m}$ size. The Al: Si ratio is now at a high 7.35. The coating is now approximately $15 \mu \mathrm{m}$ thick. There seems to be a rapid increase in coating growth rate as time progresses. This also further confirms that the $\mathrm{Al}$ content in the mullite coating is proportional to the growth rate. 
Based on the observations, it can be inferred that the mullite coating in general starts being low in Al content, irrespective of the inlet gas composition. The coating grows at a relatively slow pace with a gradual increase in Al content. At a certain stage when a critical Al concentration is reached in the deposit, crystallites start to nucleate and then grow into large crystals in a columnar fashion. The growth rate and the $\mathrm{Al}$ content increase with time. One possible explanation for this is that since the coatings are grown on $\mathrm{SiC}$ and $\mathrm{Si}_{3} \mathrm{~N}_{4}, \mathrm{Si}$ may have a natural tendency to nucleate faster than $\mathrm{Al}$. Pure $\mathrm{SiO}_{2}$ produced by the hydrolysis of $\mathrm{SiCl}_{4}$ is amorphous. This is possibly the reason why the coatings start off being "amorphous". The slow nucleation of $\mathrm{Al}$ in turn could cause a build-up of $\mathrm{Al}$ species at the reacting surface. Since the difference between the bulk gas concentration of $\mathrm{Al}$ and surface concentration of $\mathrm{Al}$ is now lower. This is not completely understood and further experimentation is required. Thus, the $\mathrm{Al}$ species in the bulk gas stream will end up reacting with the $\mathrm{H}_{2} \mathrm{O}$ in the "gas phase", resulting in powder formation. This is supported by the fact that initially (lower deposition times) the Al content in the powders collected was high. However, experiments with long times (120 minutes) yielded powders with low $\mathrm{Al}$ content. Thus, once $\mathrm{Al}$ starts to nucleate on the surface at a faster rate, the concentration gradient across the boundary layer is steep, causing the $\mathrm{Al}$ flux to increase. In addition, the orientation of mullite crystals in the caxis direction and the increase in $\mathrm{Al}$ content points out to the fact that there is preferential nucleation and growth of $\mathrm{Al}$, once the crystallite is formed. In essence, from a CVD process perspective, for $\mathrm{Al}$ nucleation, initially the rate-limiting step appears to be nucleation, and then possibly diffusion through the boundary layer. 


\section{Solid Solubility Range of Mullite}

Crystalline mullite was detected by X-ray diffraction when the Al:Si atomic ratio in the coating estimated by EDS spectra was as low as 1:1. This result could be misleading since EDS analysis gives an overall composition of the coating, whereas Xray diffraction analysis reveals only the crystalline phases present in the coating. Thus, it is difficult to estimate the lower limit for the composition of mullite through this method, especially since any excess $\mathrm{SiO}_{2}$ present in the coating is most likely in an amorphous form, and would not be detected by X-ray analysis. On the other hand, at the upper limit, the $\mathrm{Al}: \mathrm{Si}$ atomic ratios calculated from the EDS spectra can be used as an exact indication of the composition of mullite, since the coating is in crystalline form, at least to appearance, and also since no $\mathrm{Al}_{2} \mathrm{O}_{3}$ peaks were detected by $\mathrm{X}$-ray diffraction. With this assumption, the highest $\mathrm{Al}: \mathrm{Si}$ atomic ratio observed in the coatings was at the condition when the experiment was run for 150 minutes, and is 7.35 . This translates to an $\mathrm{Al}_{2} \mathrm{O}_{3}: \mathrm{SiO}_{2}$ ratio of 3.685 . This was the highest observed at this set of process conditions. This does not mean that this is the highest attainable Al stoichiometry in mullite via CVD or by any other method for that matter. Based on the trends in the experiments at this stage, longer times would probably yield mullite coatings with higher Al content.

\section{Powder Synthesis}

At high concentrations of the chlorides, $\left(\mathrm{AlCl}_{3}\right.$ and $\left.\mathrm{SiCl}_{4}\right)$, considerable amount of powder was formed in the chamber. Very low concentration of chlorides resulted in 
runs with little powder in the chamber, but also with low growth rates. In general at higher pressures more powder was observed. The powders made appeared to be crystalline in nature as confirmed by X-ray diffraction. Figure 43 shows the X-ray diffraction pattern of a typical mullite powder. The "hump" at the lower $2 \Theta$ angles indicates that there may be a certain amount of amorphous phase present in the powder. The powders, however had varying compositions all the way from very $\mathrm{Al}$ rich to very $\mathrm{Si}$ rich based on the process conditions. Figure 44 shows the SEM and TEM micrographs of the powders. The TEM micrograph of a single grain shows that there is an orientation effect even in powders. In addition, they are probably oriented along the c-axis growth direction.

\section{Adhesion Testing}

Adhesion is possibly the most important characteristic of a coating to be considered irrespective of the environment in which it will be used. Coating/substrate adhesion is mainly dependent on the atomic interactions between the coating and the substrate material. Extent of diffusion between the substrate and the coating to a large extent defines the adhesion strength of the coating/substrate combination. CVD being a thermal process aides the necessary solid-state diffusion to enable sharing of atoms/ molecules between the coating and the substrate. In addition, there are often chemical interactions between the substrate material and the reacting gases resulting in intermediate compounds, further enhancing the adhesion. Factors such as a mismatch in thermal expansion coefficient, coating porosity, and substrate preparation may also affect adhesion to a great extent. In case of mullite on $\mathrm{SiC}$ and $\mathrm{Si}_{3} \mathrm{~N}_{4}$, as discussed earlier, CTE mismatch does not appear to be a major factor. In addition, the coatings were, in general, 
of $9 \mu \mathrm{m} / \mathrm{sec}$. All scratches were made from the substrate into the coating. Figures 46 and 47 show the scratch tracks on $\mathrm{SiC}$ and $\mathrm{Si}_{3} \mathrm{~N}_{4}$ samples mounted in cross-section. No failure in the form of delamination of the coating was observed in mullite coatings on $\mathrm{SiC}$. This is attributed to the match in thermal coefficient of expansion between mullite and $\mathrm{SiC}$, thus minimizing the stresses upon cooling. Unlike the case of the macro-scratch test, the substrate material does not really have an impact on the critical load via the failure of the substrate underneath the coating. Thus, the critical load for mullite on SiC is estimated to be higher than $100 \mathrm{~g}$. Loads in excess of $100 \mathrm{~g}$ were not possible due to limitations with the diamond indenter. In case of $\mathrm{Si}_{3} \mathrm{~N}_{4}$, cracks were observed right at the coating/substrate interface, indicating delamination at a critical load of $100 \mathrm{~g}$.

\section{Corrosion Testing}

Corrosion resistance evaluation was performed at Oak Ridge National Laboratory. Mullite coated $\mathrm{Si}_{3} \mathrm{~N}_{4}$ samples were exposed to $\mathrm{Na}_{2} \mathrm{SO}_{4}+\mathrm{O}_{2}$ atmosphere for 100 hours at $1000^{\circ} \mathrm{C}$. Initial results from the analysis look very promising. [32] Figure 48 shows a back-scattered electron image along with X-ray elemental maps of the mullite coating in cross section after hot corrosion. The dot maps show that the coating is intact at both the $\mathrm{Na}_{2} \mathrm{SO}_{4} /$ mullite and mullite/ $\mathrm{Si}_{3} \mathrm{~N}_{4}$ interfaces, and that no diffusion of $\mathrm{Na}_{2} \mathrm{SO}_{4}$ through the coating was observed. A small amount of $\mathrm{Na}$ was present at the $\mathrm{Na}_{2} \mathrm{SO}_{4}$ interface. In comparison, a $\mathrm{Si}_{3} \mathrm{~N}_{4}$ sample tested at identical conditions reacted significantly with $\mathrm{Na}$ present to depths in the order of $20 \mathrm{~mm}$. In addition, X-ray diffraction analyses performed before and after hot corrosion show that no additional phases were formed, and that the coating was stable, and retained its crystalline structure as shown in Figure 49. The natural tendency of the mullite coatings to increase in Al content as the 
deposition progresses may have helped in the superior corrosion resistance of these coatings, since it was believed that a high $\mathrm{Al}$ mullite, or an $\mathrm{Al}_{2} \mathrm{O}_{3}+$ mullite composite would perform better than stoichiometric mullite under hot corrosion environments. 


\section{SUMMARY AND CONCLUSIONS}

Three different routes to grow CVD mullite coatings have been investigated. Multi-layers of $\mathrm{CVD} \mathrm{SiO}_{2}$ and $\alpha-\mathrm{Al}_{2} \mathrm{O}_{3}$ coatings were grown on $\mathrm{Si}_{3} \mathrm{~N}_{4}$ and $\mathrm{SiC}$ substrates. Heat treatment of these coatings resulted in cracking and delamination at the $\mathrm{SiO}_{2} / \mathrm{Al}_{2} \mathrm{O}_{3}$ interface prior to the diffusion formation of mullite. It was determined that this failure was due to transformations within the TEOS grown vitreous $\mathrm{SiO}_{2}$ layer, and that the phase transformations were primarily due to stresses created at the $\mathrm{SiO}_{2} / \mathrm{Al}_{2} \mathrm{O}_{3}$ interface due to thermal expansion mismatch.

Thermodynamic analysis of the TEOS- $\mathrm{AlCl}_{3}-\mathrm{CO}_{2}-\mathrm{H}_{2}$ mixtures showed that under equilibrium conditions, mullite can be formed for certain process parameters. Although the coatings had Al:Si ratios at the stoichiometric level, and the process could be altered to grow coatings with varying $\mathrm{Al} / \mathrm{Si}$ ratios, the process essentially resulted in amorphous coatings. This was not pursued further since amorphous coatings are not suitable for high temperature applications with operating temperatures in the order of the transformation temperature of the coating due to difficulties similar to the ones encountered in the multilayered route.

Equilibrium thermodynamic analysis was performed on the $\mathrm{AlCl}_{3}-\mathrm{SiCl}_{4}-\mathrm{CO}_{2}-\mathrm{H}_{2}$ system in order to evaluate the formation of mullite. CVD ternary phase diagrams were constructed for process variations between $\mathrm{AlCl}_{3}, \mathrm{SiCl}_{4}$ and $\mathrm{CO}_{2}$. Concentration and deposition efficiency plots were also calculated for certain conditions. It was found that 
pure mullite can be obtained at high $\mathrm{CO}_{2}$ concentrations. In addition, the CVD phase plots show that low concentrations of the chlorides need to be used in order to obtain high deposition efficiency, and carbon-free deposits. It was also found that there was no underlying benefit to using bromides and fluorides as alternative halide sources. The information from the phase diagrams was effectively used as a guideline in identifying the initial process conditions for experimentation.

A CVD reactor was constructed for the direct deposition of mullite. Mullite coatings were grown for the first time via CVD. Certain process conditions also yielded crystalline mullite powders. Adherent and dense mullite coatings were grown on $\mathrm{Si}_{3} \mathrm{~N}_{4}$ and $\mathrm{SiC}$ substrates. The only crystalline phase found by X-ray diffraction analysis was mullite. It was found that mullite coatings can only be grown within a fairly narrow window of experimental conditions. The coating evolution with time was investigated. The coating in general started off with a high Si amorphous phase, and increased in $\mathrm{Al}$ concentration. At a certain critical Al concentration, crystallites started to form and with time grew into large crystals. The crystals grew in the c-axis direction and oriented themselves in the [001] direction. The size of the crystals increased with time to a certain point and then reduced due to the rapid growth rate. Totally amorphous, partly crystalline, and completely crystalline surfaces were obtained based on the process parameters. Increasing temperature in general yielded larger crystals and thicker coatings. Higher pressures resulted in larger crystallites, but resulted in porous coatings due to the high growth rates and low area coverage. Increase in $\mathrm{Al}$ content in the inlet gas mixture resulted in larger crystal size and higher $\mathrm{Al}$ content on the surface.

The coatings in general exhibited superior adhesion characteristics. Adherence of mullite coatings on $\mathrm{SiC}$ substrates was better than that on $\mathrm{Si}_{3} \mathrm{~N}_{4}$ substrates. A typical 
critical load in macro-scratch test was above $100 \mathrm{~N}$, and in micro-scratch test was $100 \mathrm{~g}$ on $\mathrm{Si}_{3} \mathrm{~N}_{4}$ and exceeded that on $\mathrm{SiC}$. The coatings performed very well under $\mathrm{Na}_{2} \mathrm{SO}_{4}$ salt and $\mathrm{O}_{2}$ atmospheres at $1000^{\circ} \mathrm{C}$ for 100 hours. The superior corrosion characteristics of these coatings could be attributed to the natural tendency of the coatings to increase in $\mathrm{Al}$ content, resulting in graded coatings.

Further studies are required in order to optimize these coatings. There currently exists inadequate information concerning the kinetics, nucleation, and growth of mullite on Si-based substrates. This information is necessary to develop a useful corrosion resistant coating for high temperature applications. 


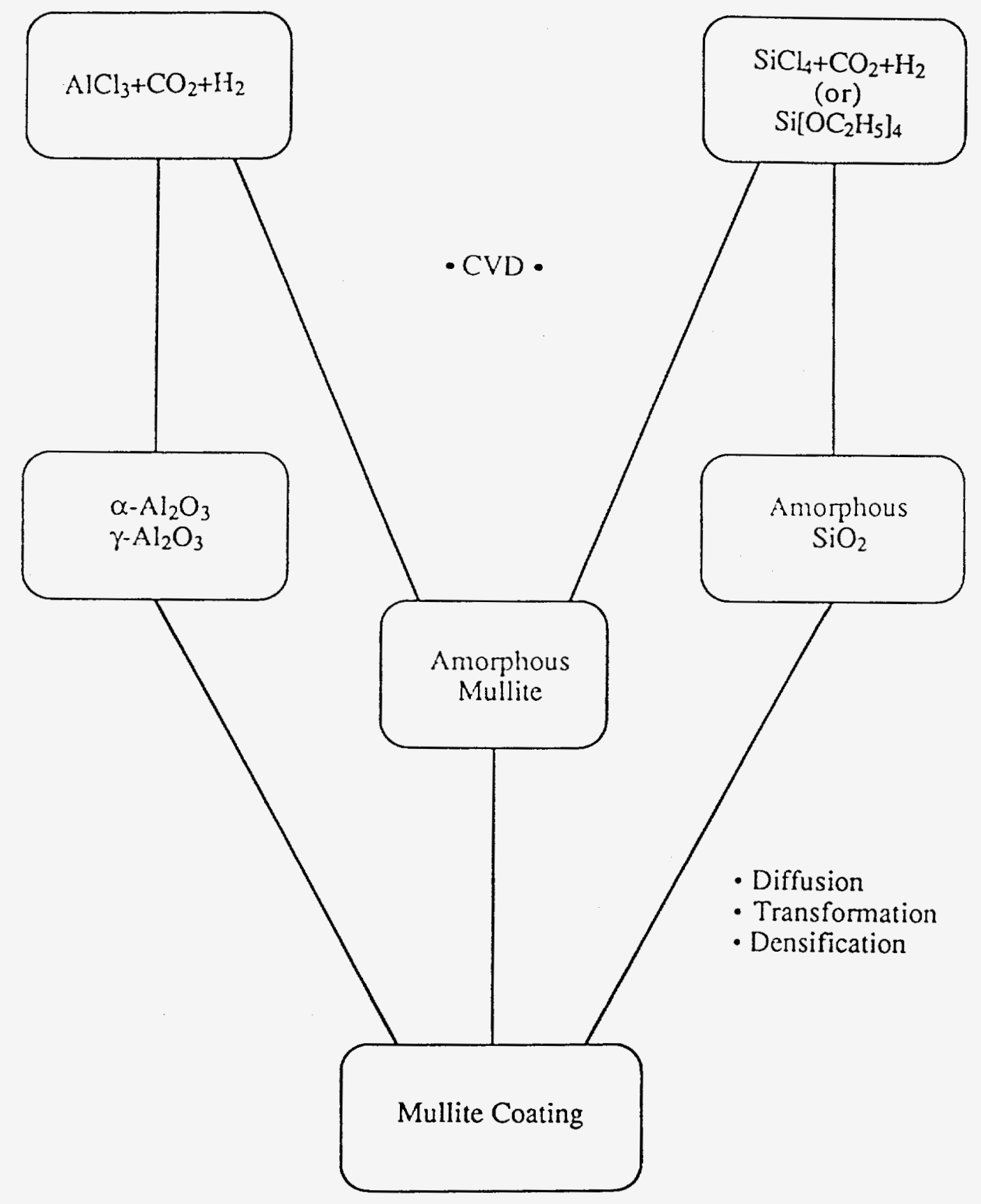

Figure 1 Various Reaction Paths to Obtain Mullite Coatings 


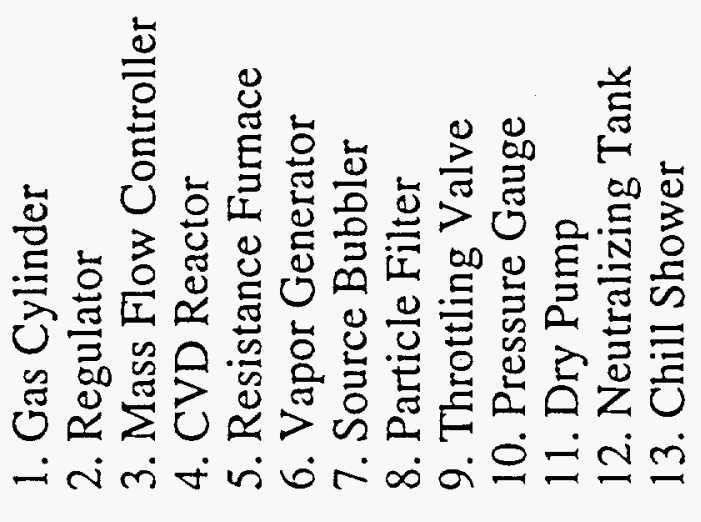
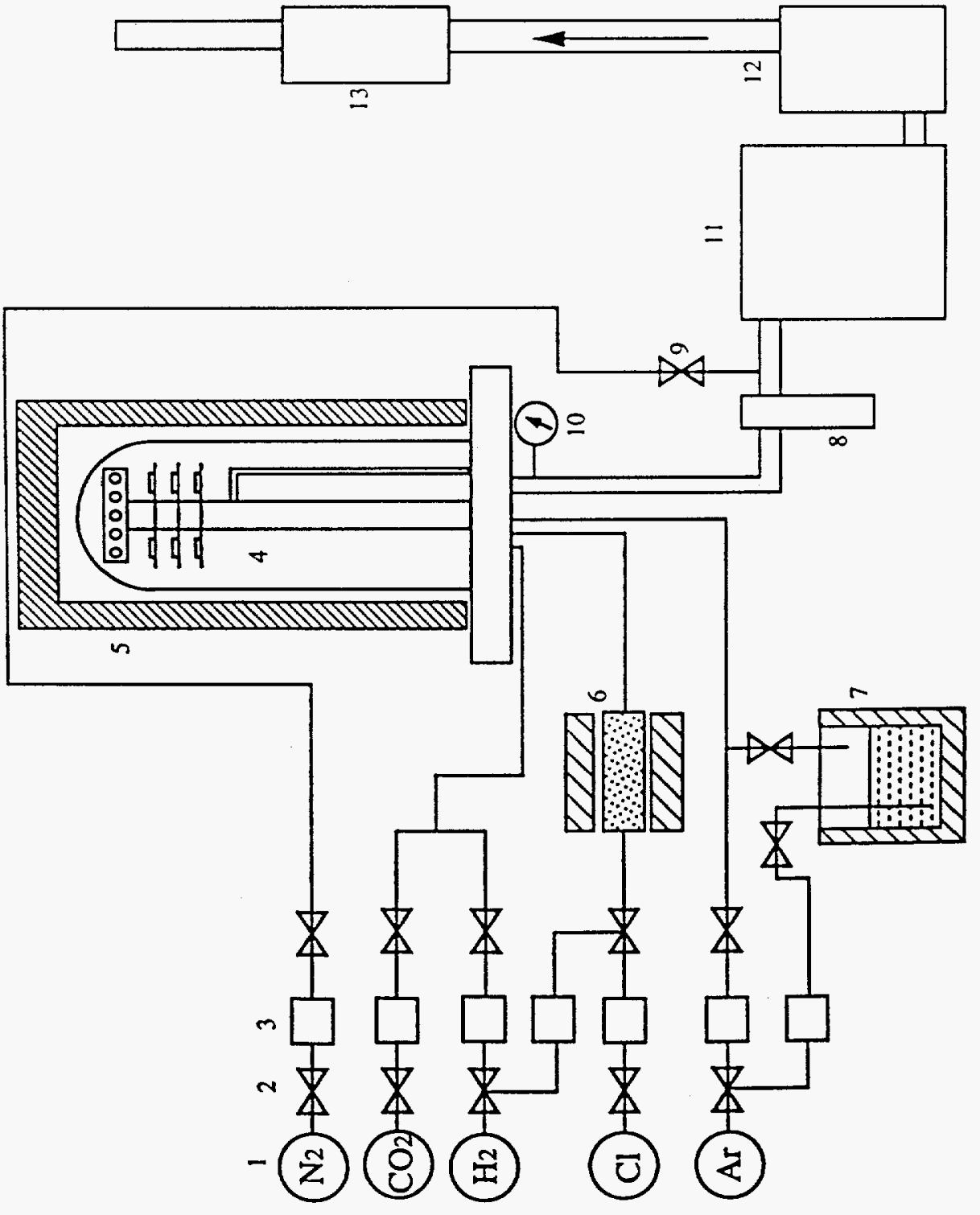

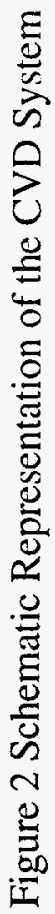



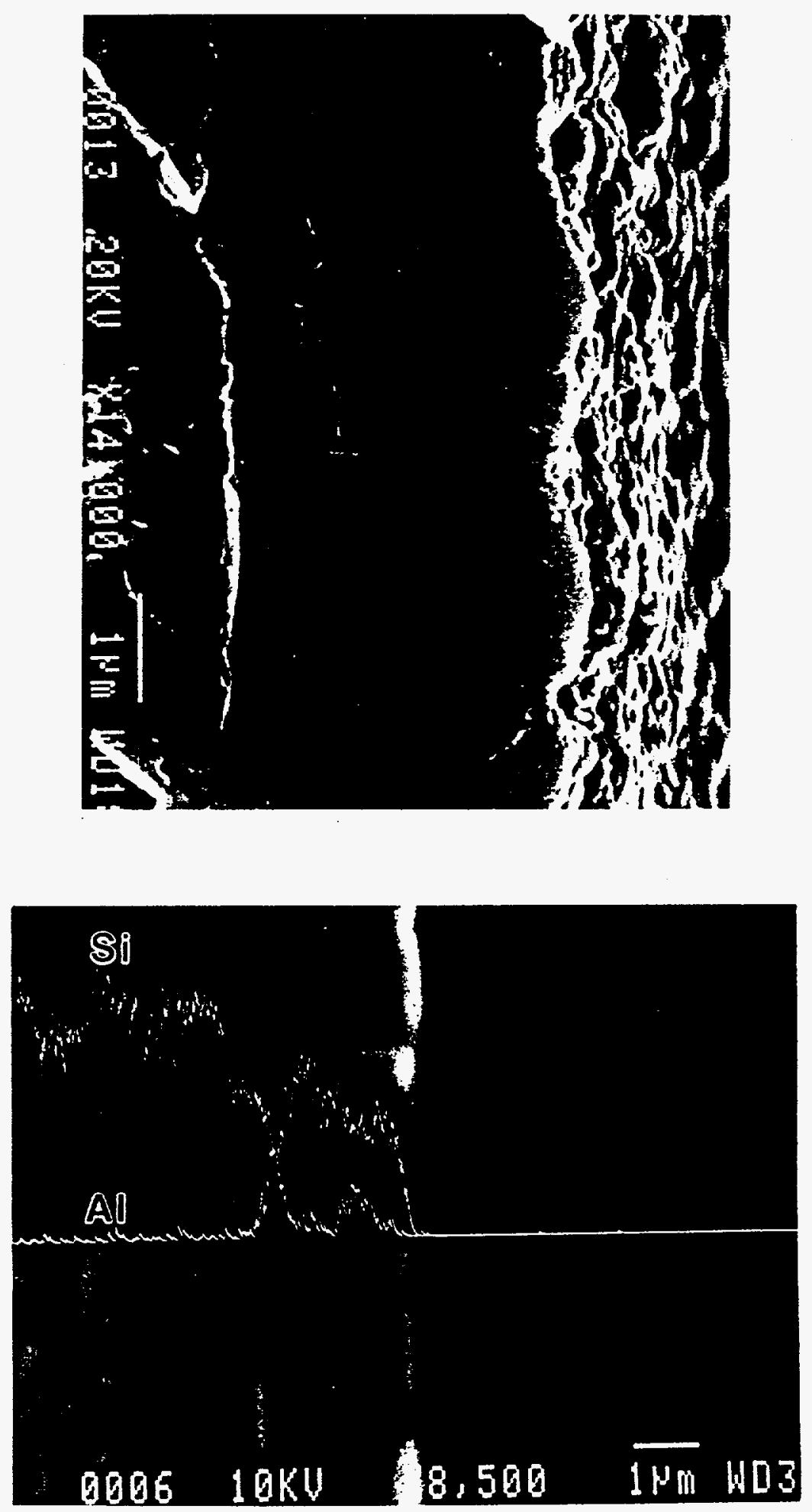

Figure $3 \mathrm{SEM}$ Micrograph of the $\mathrm{SiO}_{2} / \mathrm{Al}_{2} \mathrm{O}_{3}$ Multi-layered coating with $\mathrm{Al}$ and $\mathrm{Si}$ Line Scans 


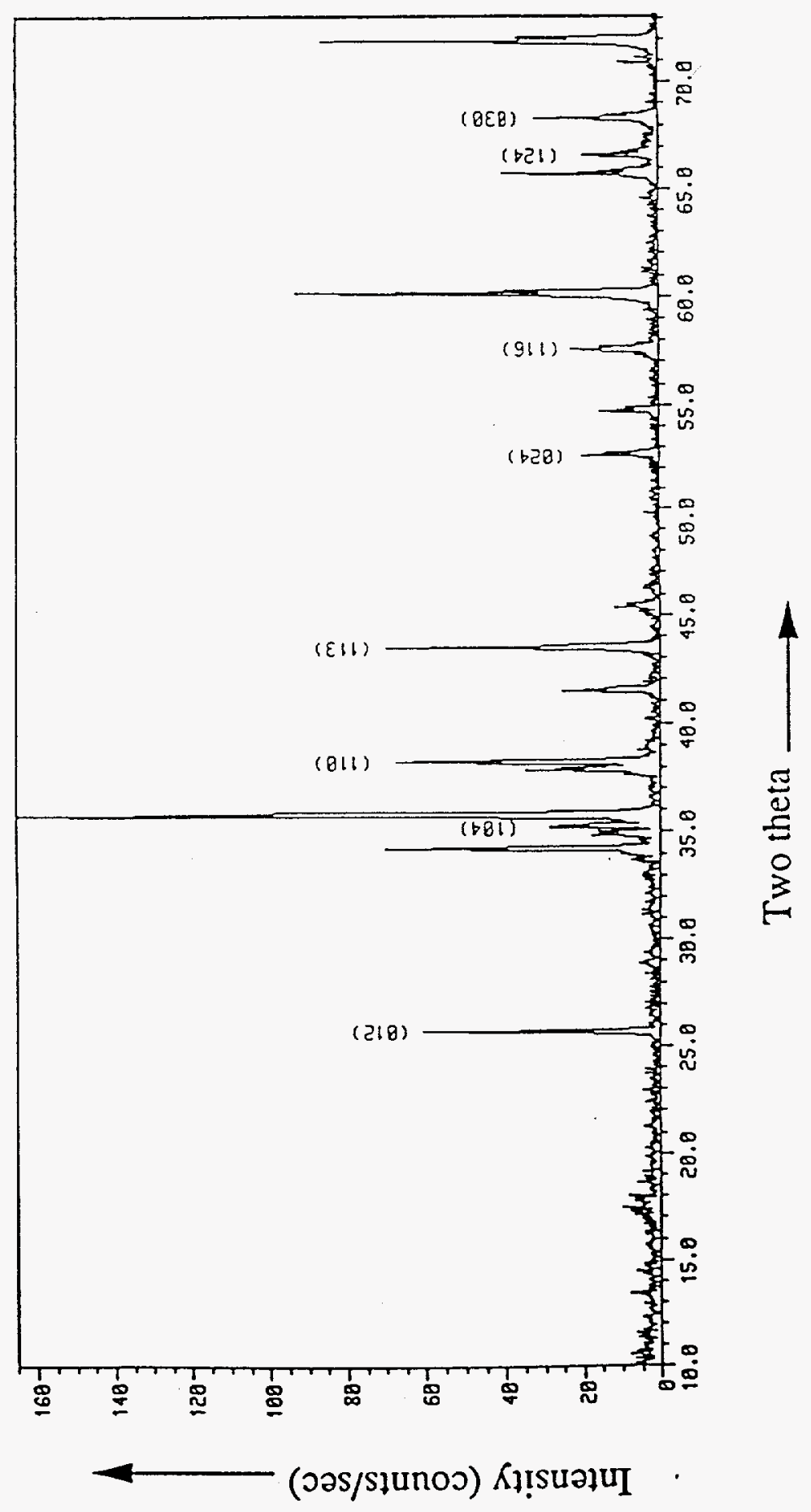

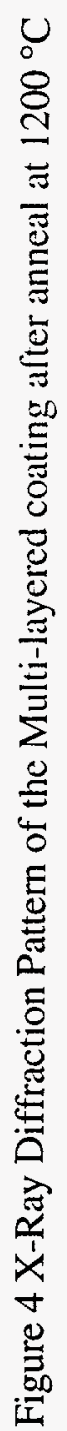




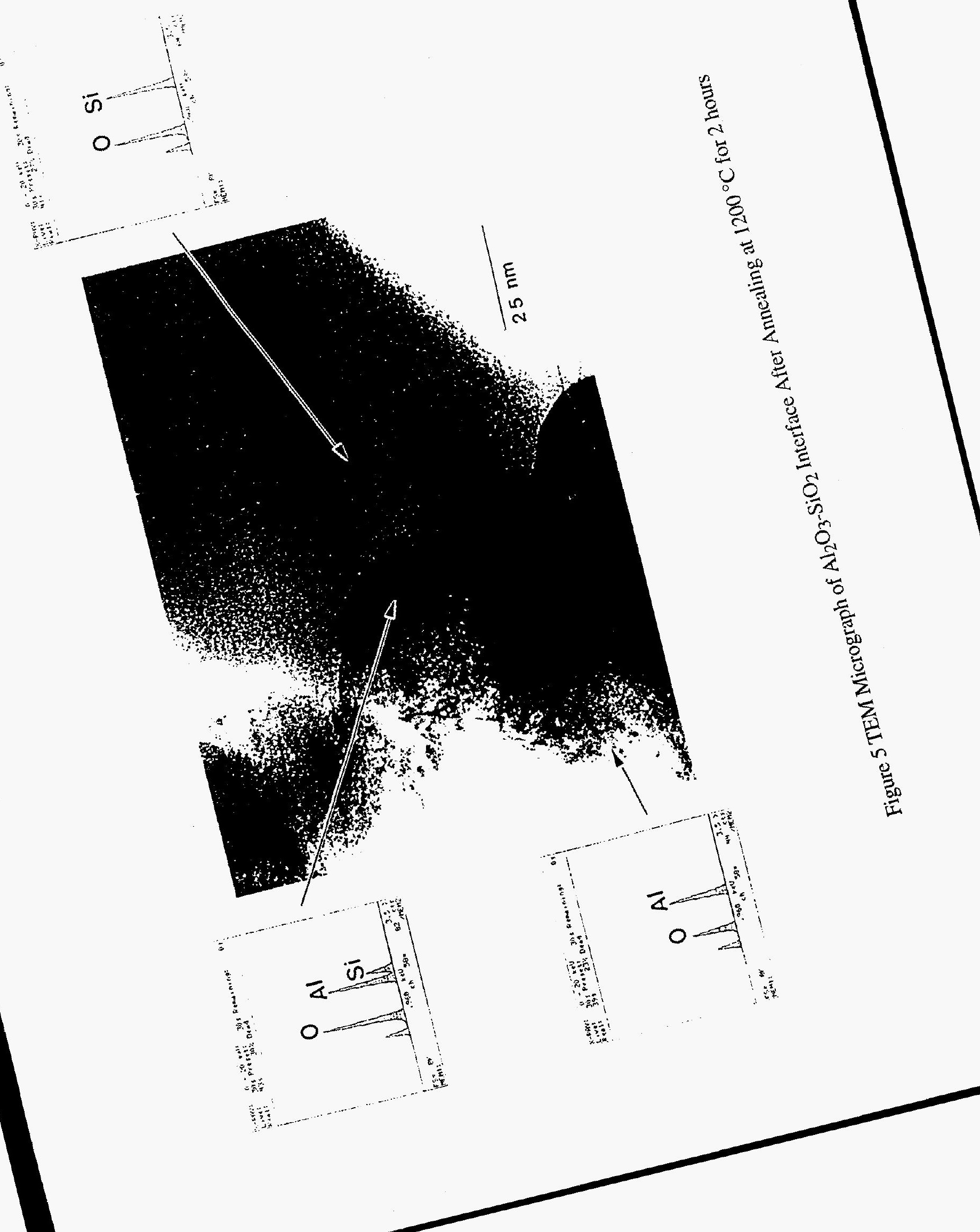



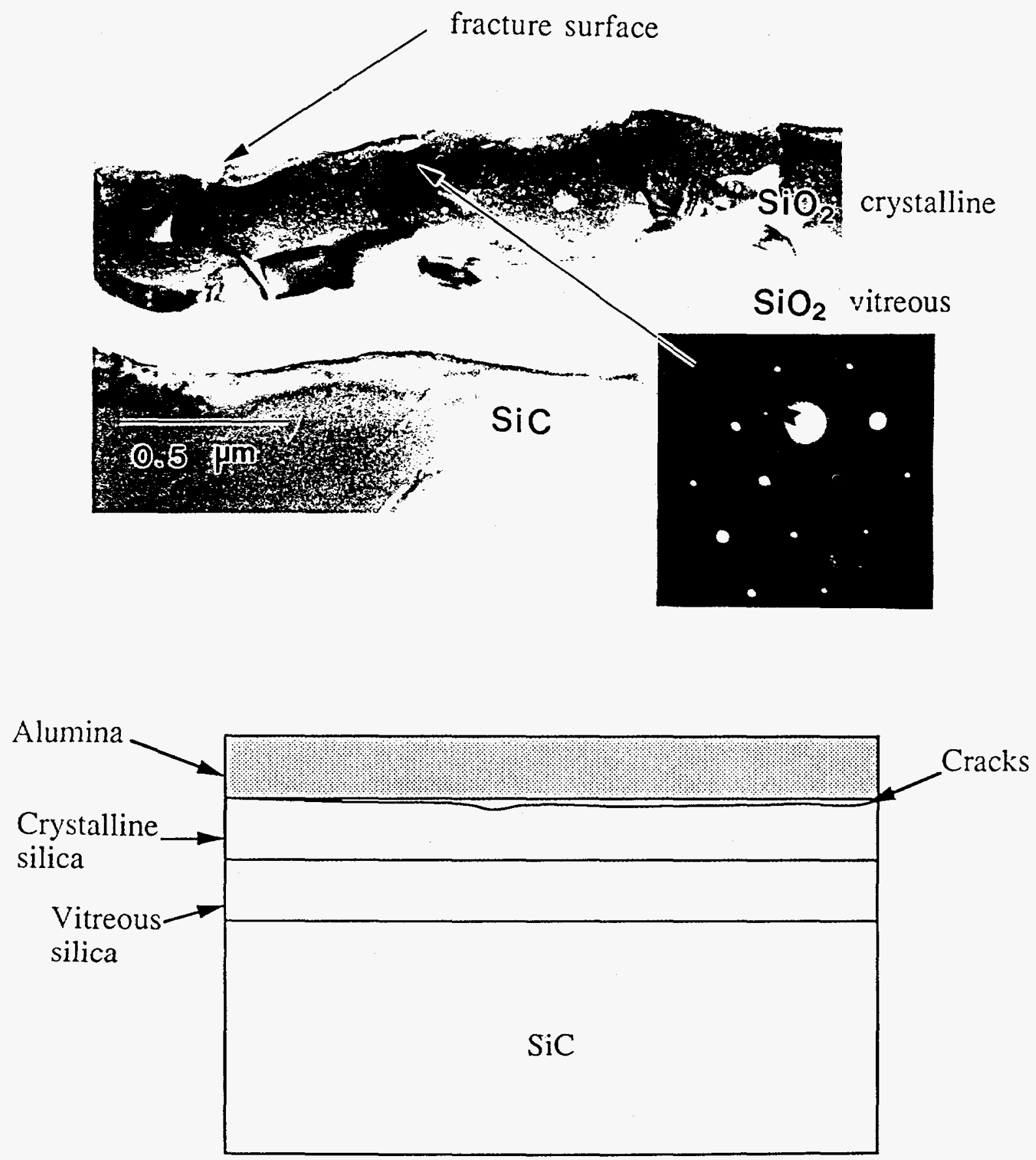

Figure 6 a) TEM Micrograph of $\mathrm{Al}_{2} \mathrm{O}_{3}-\mathrm{SiO}_{2}$ Interface showing delamination of the Multilayered coating annealed at $1350^{\circ} \mathrm{C}$ for 2 hours showing (inset) the diffraction pattern of the crystalline $\mathrm{SiO}_{2}$ layer, b) Schematic of the Coating Configuration 


$$
\mathrm{T}=1270^{\circ} \mathrm{C} ; \text { Time }=2 \mathrm{hr}
$$

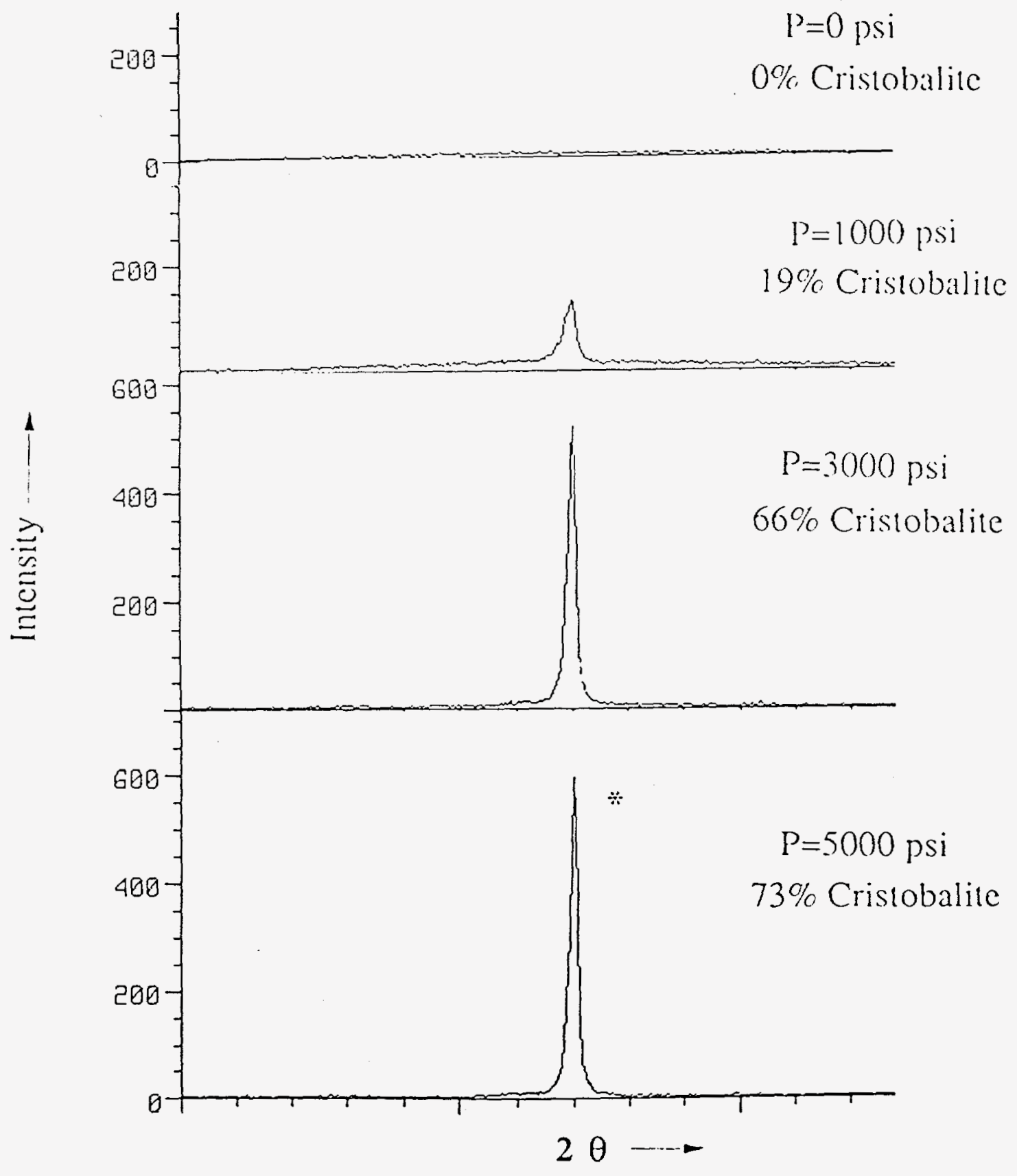

* $\{101\}$ Peak of $\alpha$-Cristobalite

Figure 7 Effect of Pressure on Devitrification of $\mathrm{SiO}_{2}$ Powders 
a)

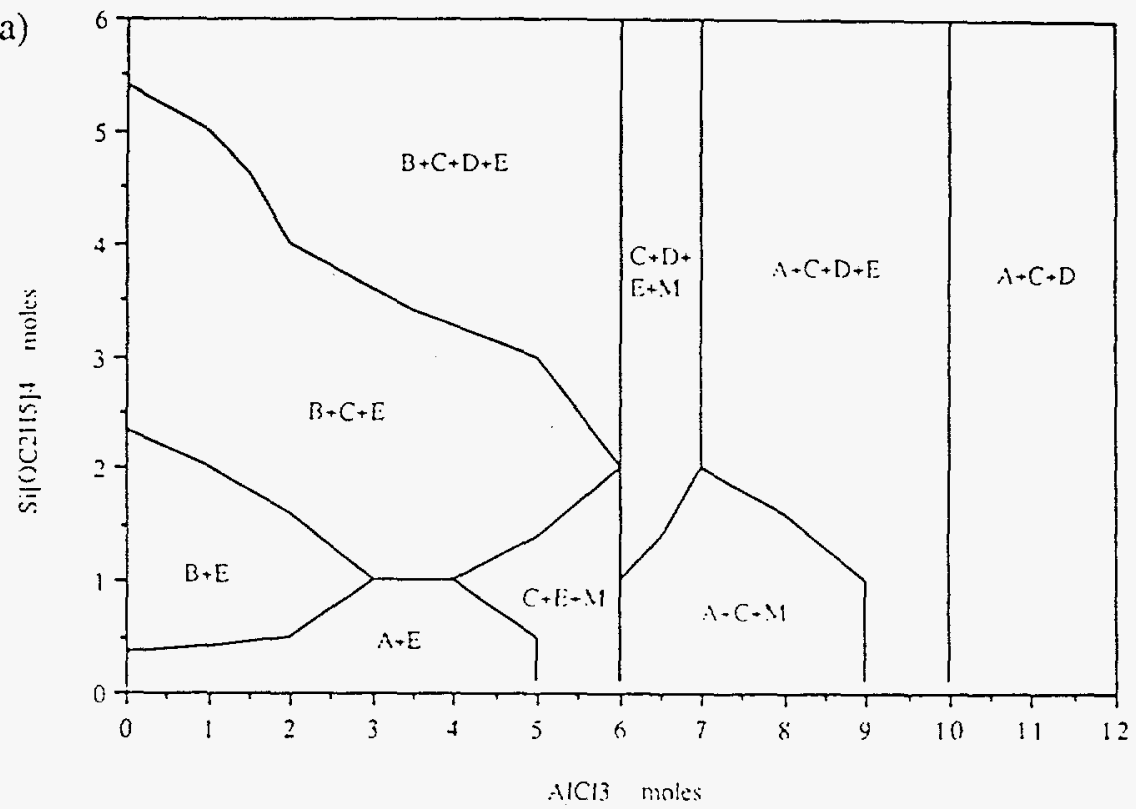

b)

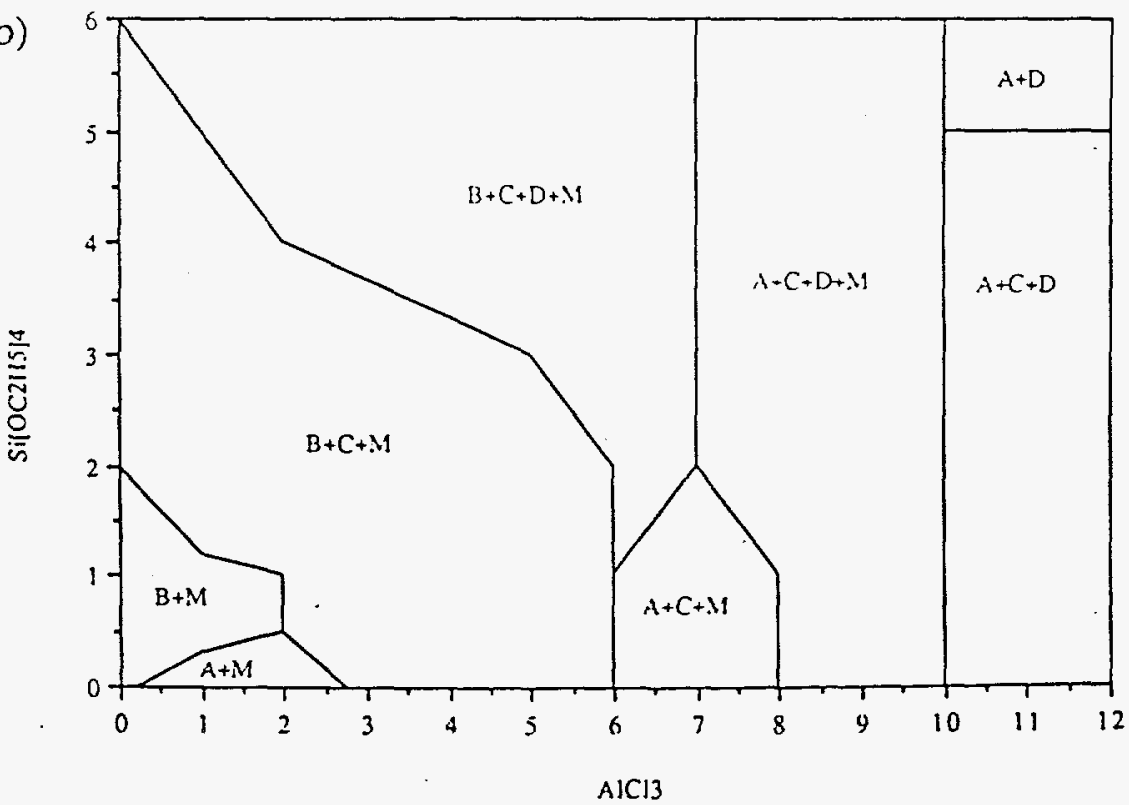

A. $\mathrm{Al}_{2} \mathrm{O}_{3}$

B. $\mathrm{SiO}_{2}$

C. $\mathrm{C}$

D. $\mathrm{SiC}$

E. $\mathrm{Al}_{2} \mathrm{SiO}_{5}$

M. Mullite
A. $\mathrm{Al}_{2} \mathrm{O}_{3}$

B. $\mathrm{SiO}_{2}$

C. $\mathrm{C}$

D. $\mathrm{SiC}$

E. $\mathrm{Al}_{2} \mathrm{SiO}_{5}$

M. Mullite

Figure $8 \mathrm{CVD}$ Phase Plots of the TEOS-AlCl $3-\mathrm{CO}_{2}-\mathrm{H}_{2}$ System at a) $800^{\circ} \mathrm{C}$ and 50 Torr, b) $800{ }^{\circ} \mathrm{C}$ and 100 Torr, c) $900^{\circ} \mathrm{C}$ and 50 Torr, d) $1000^{\circ} \mathrm{C}$ and 50 Torr (Contd.....) 
a)

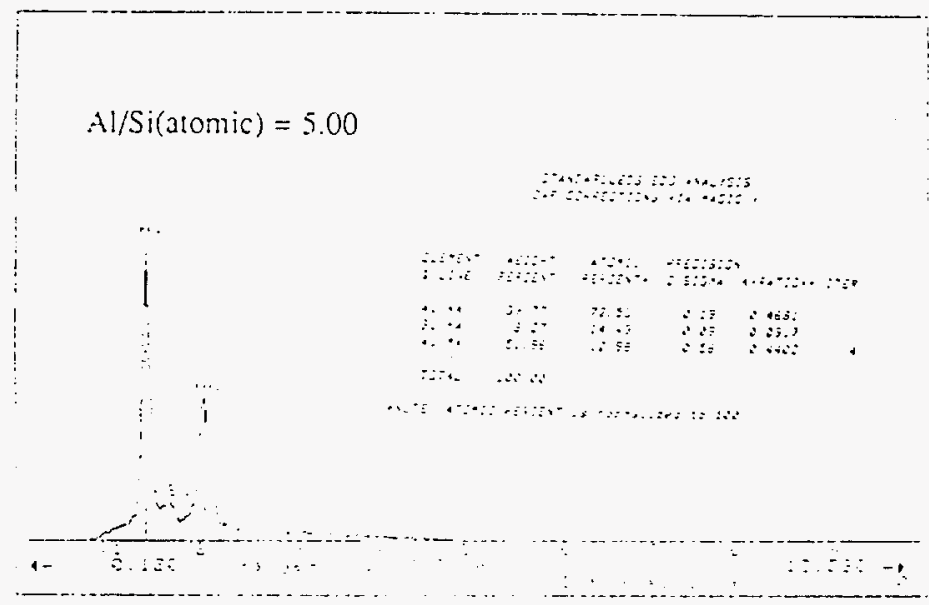

b)

$\mathrm{A} / \mathrm{Si}($ atomic $)=2.73$

s.m.n.

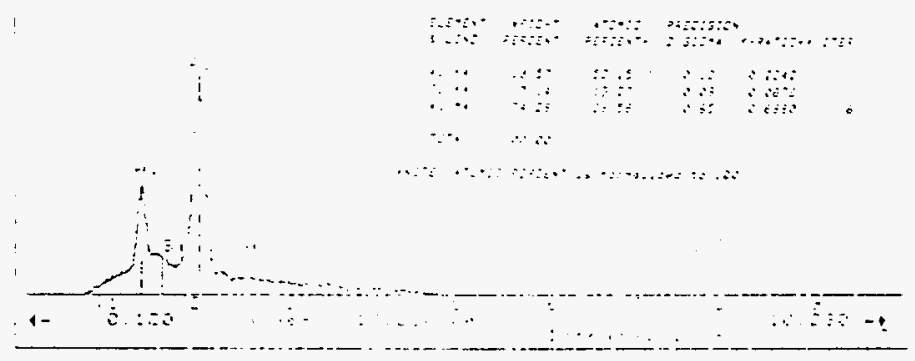

c)

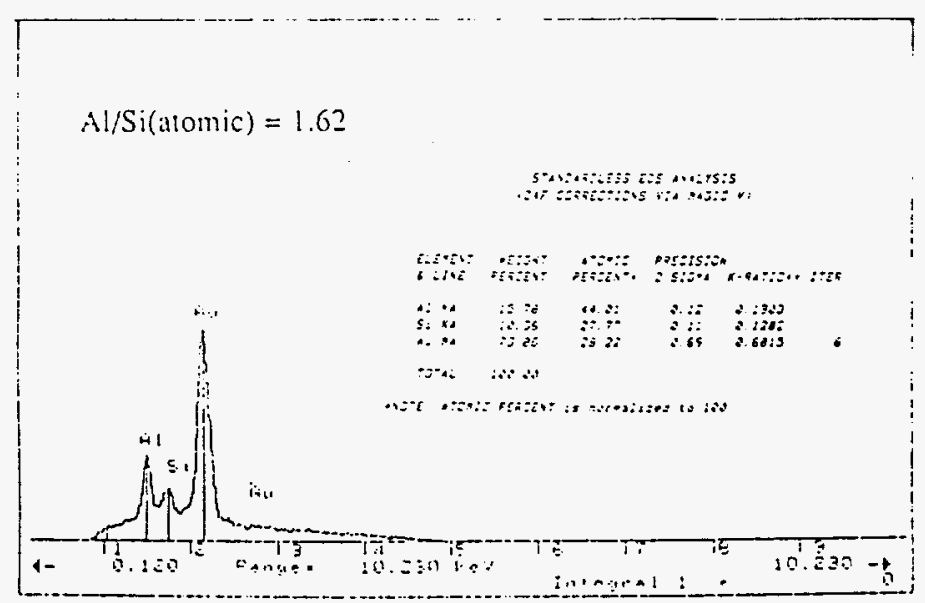

Figure 9 EDS Analysis of Codeposited Coatings With a) Low Si Content, b) Medium Si Content, c) High Si Content 


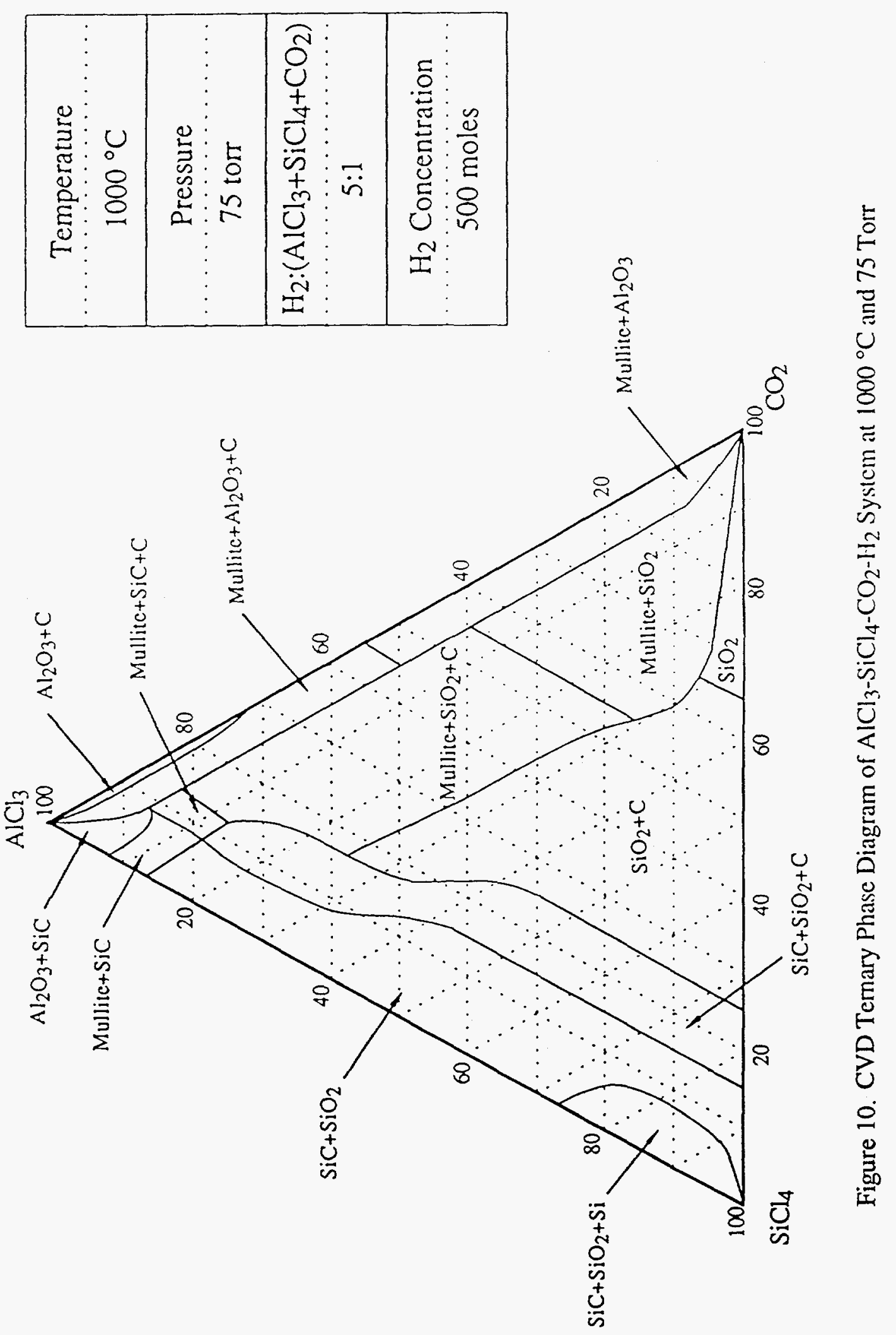




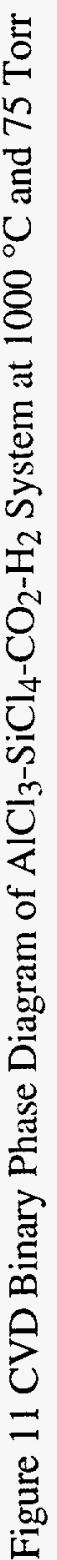


a)

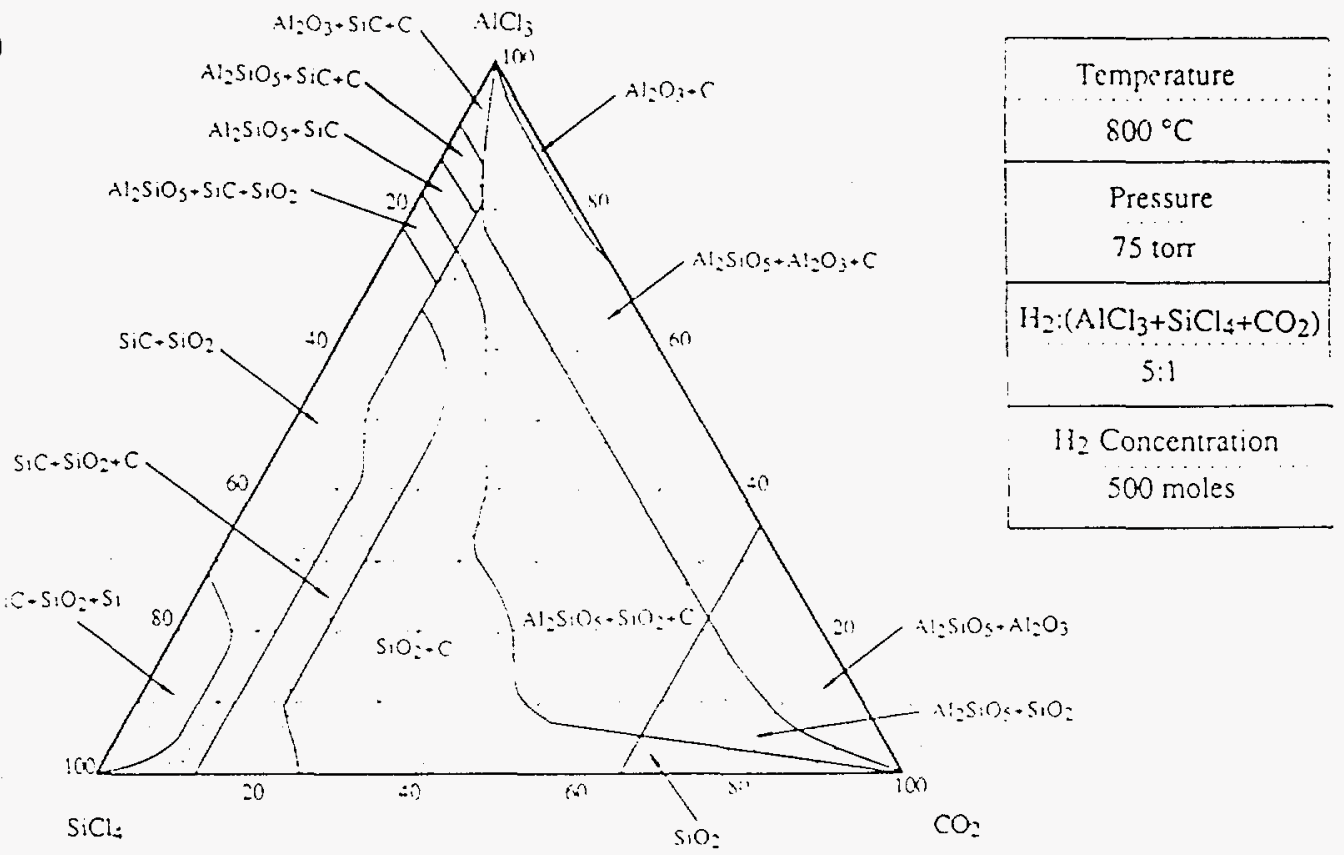

b)

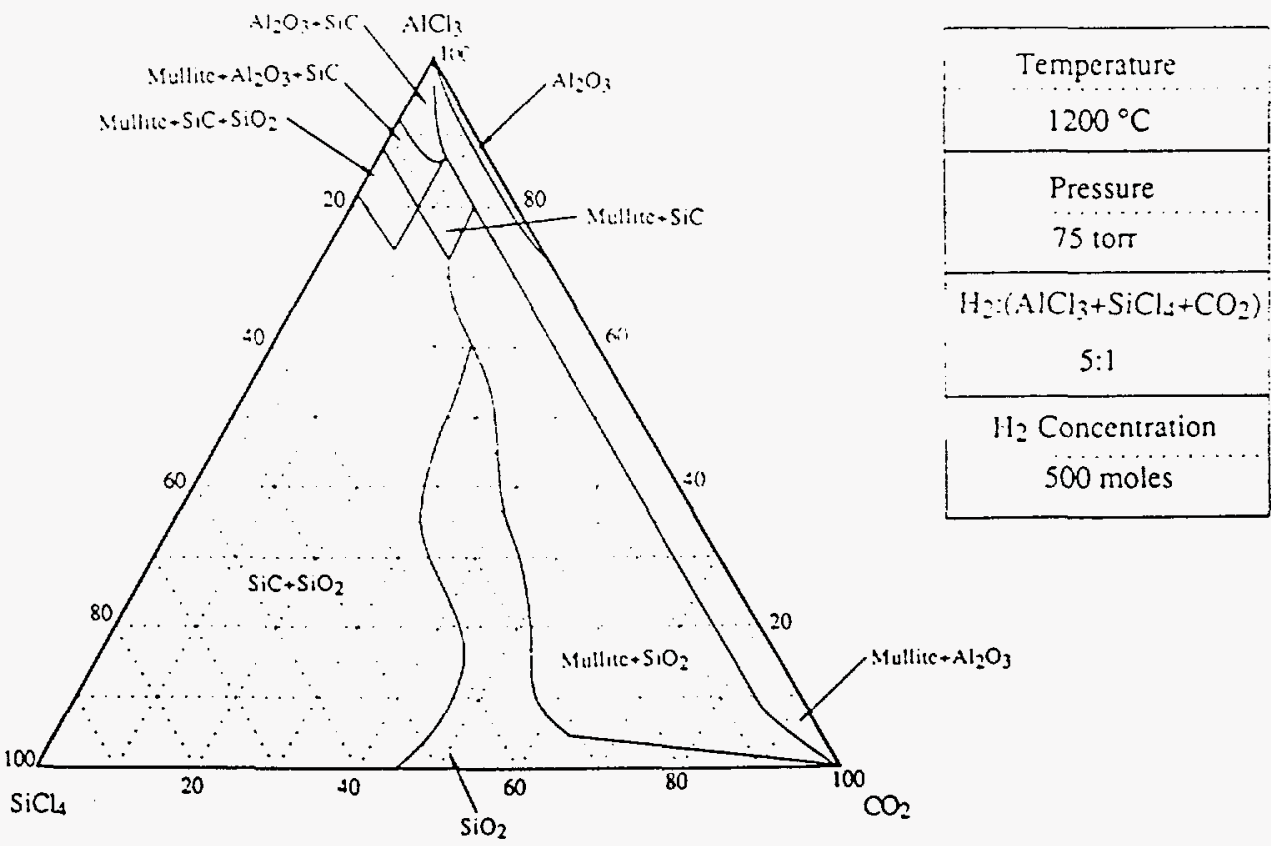

Figure $12 \mathrm{CVD}$ Ternary Phase Diagrams of $\mathrm{AlCl}_{3}-\mathrm{SiCl}_{4}-\mathrm{CO}_{2}-\mathrm{H}_{2}$ System at a) $800{ }^{\circ} \mathrm{C}$, and b) $1200^{\circ} \mathrm{C}$, both at 75 Torr 


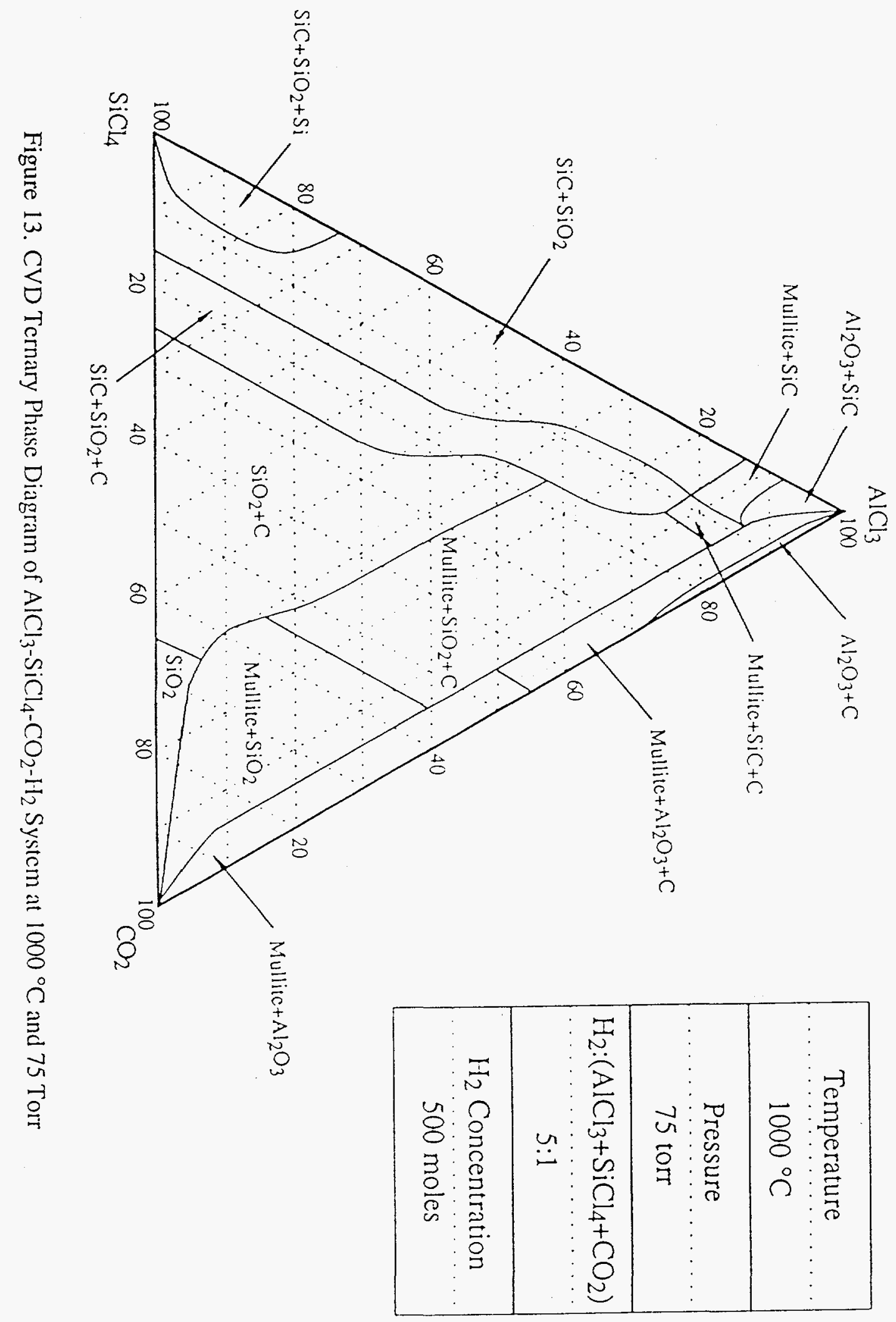


a)
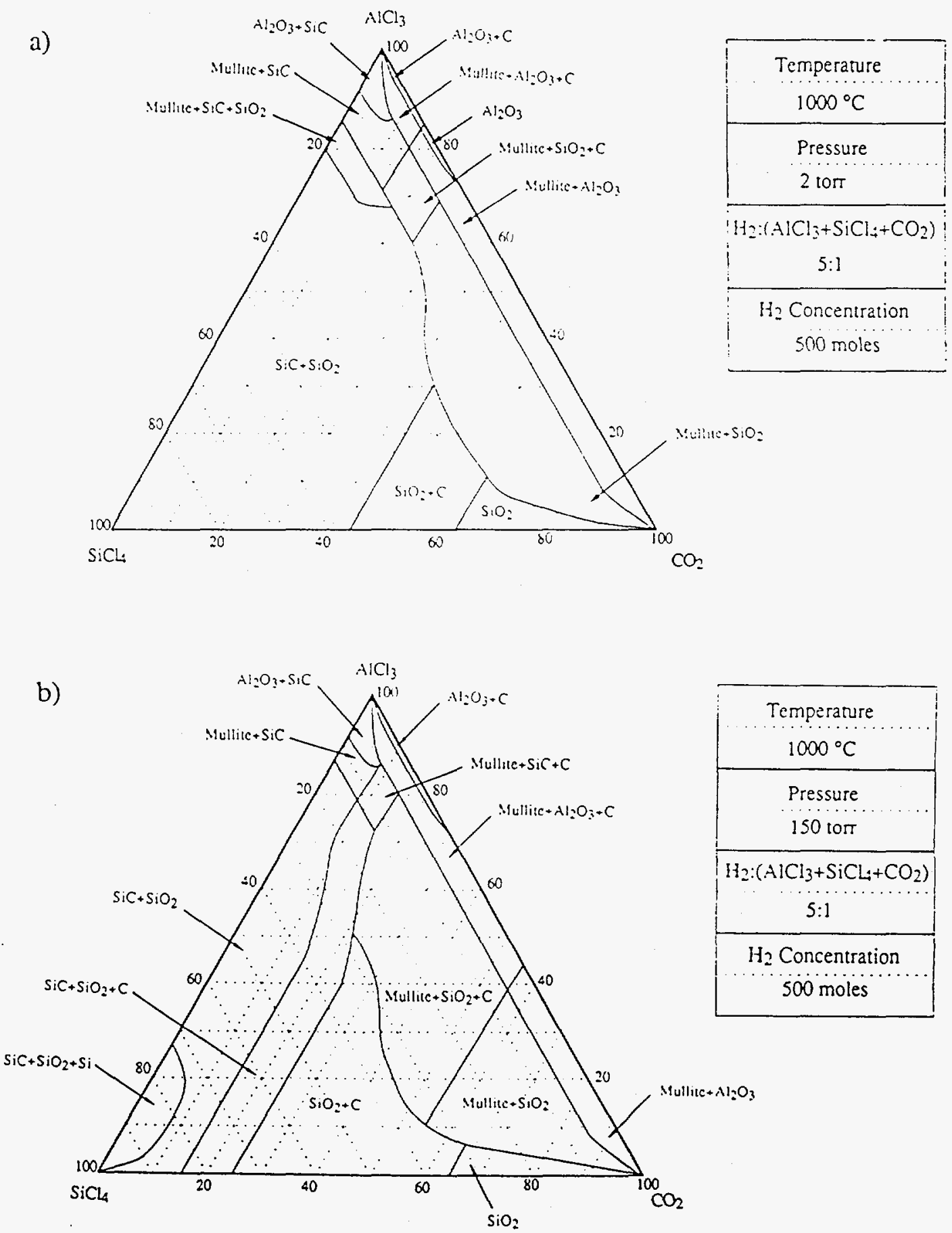

Figure $14 \mathrm{CVD}$ Ternary Phase Diagram of $\mathrm{AlCl}_{3}-\mathrm{SiCl}_{4}-\mathrm{CO}_{2}-\mathrm{H}_{2}$ System at $1000{ }^{\circ} \mathrm{C}$ and a) 2 Torr, and b) 150 Torr 


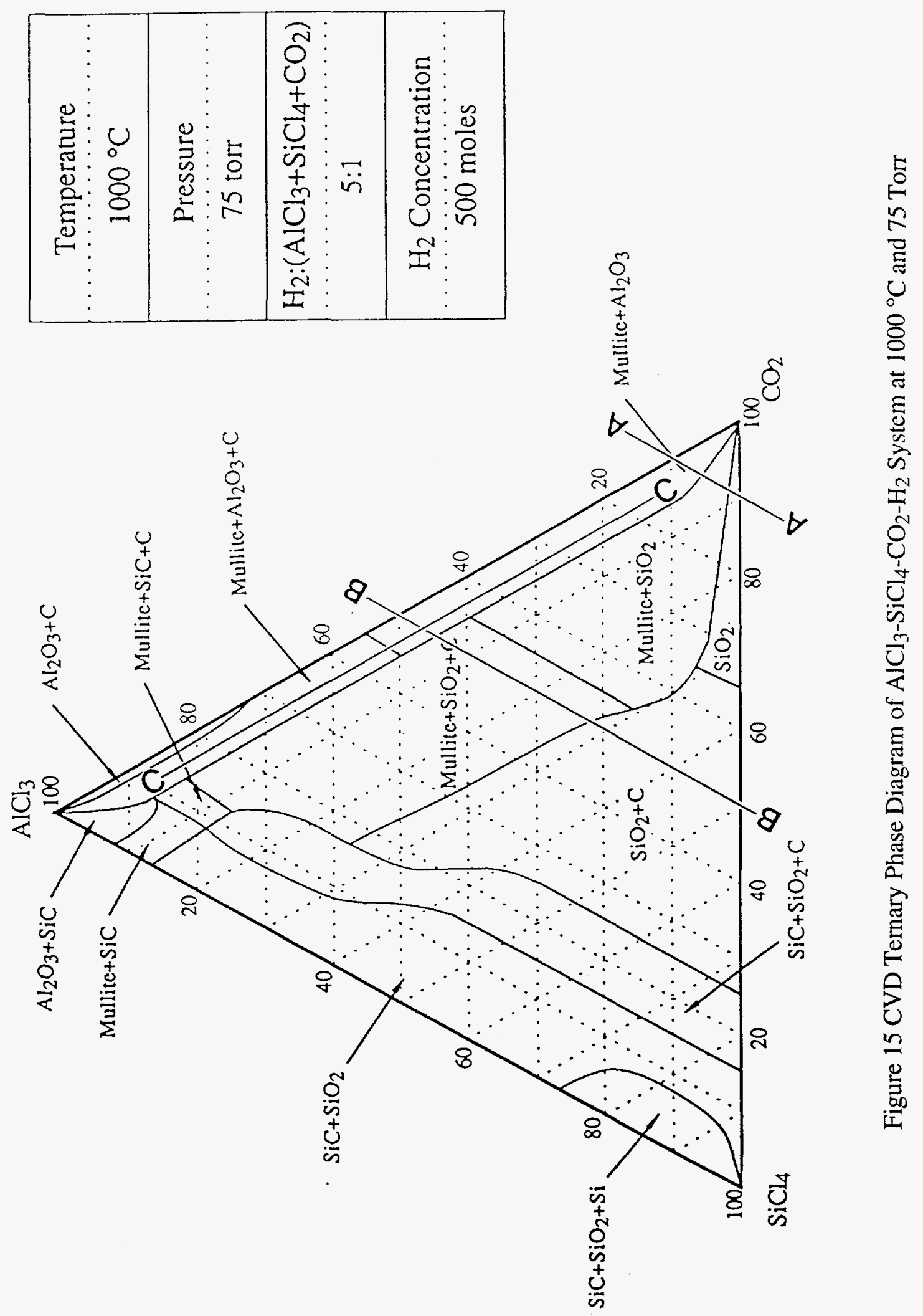


a)

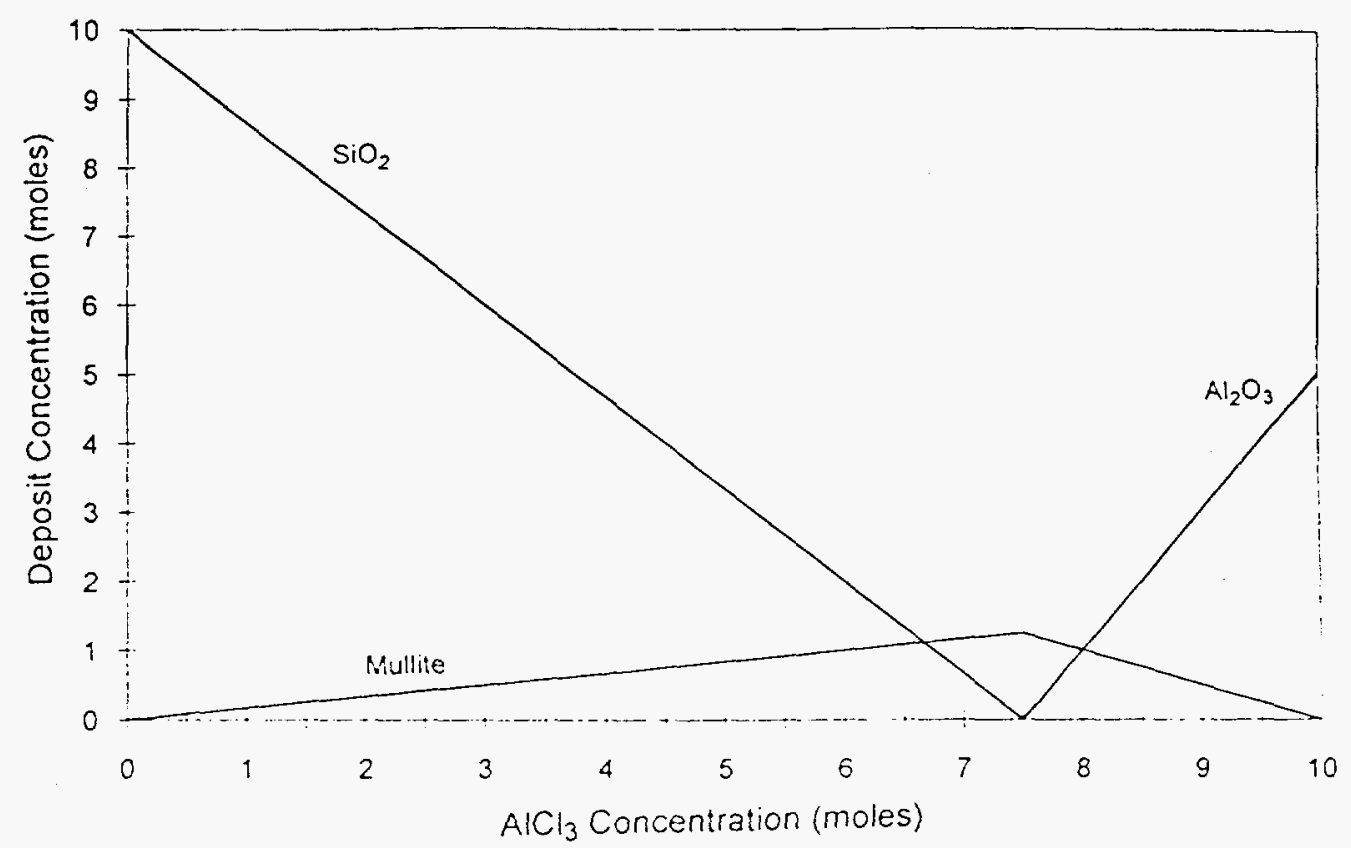

b)

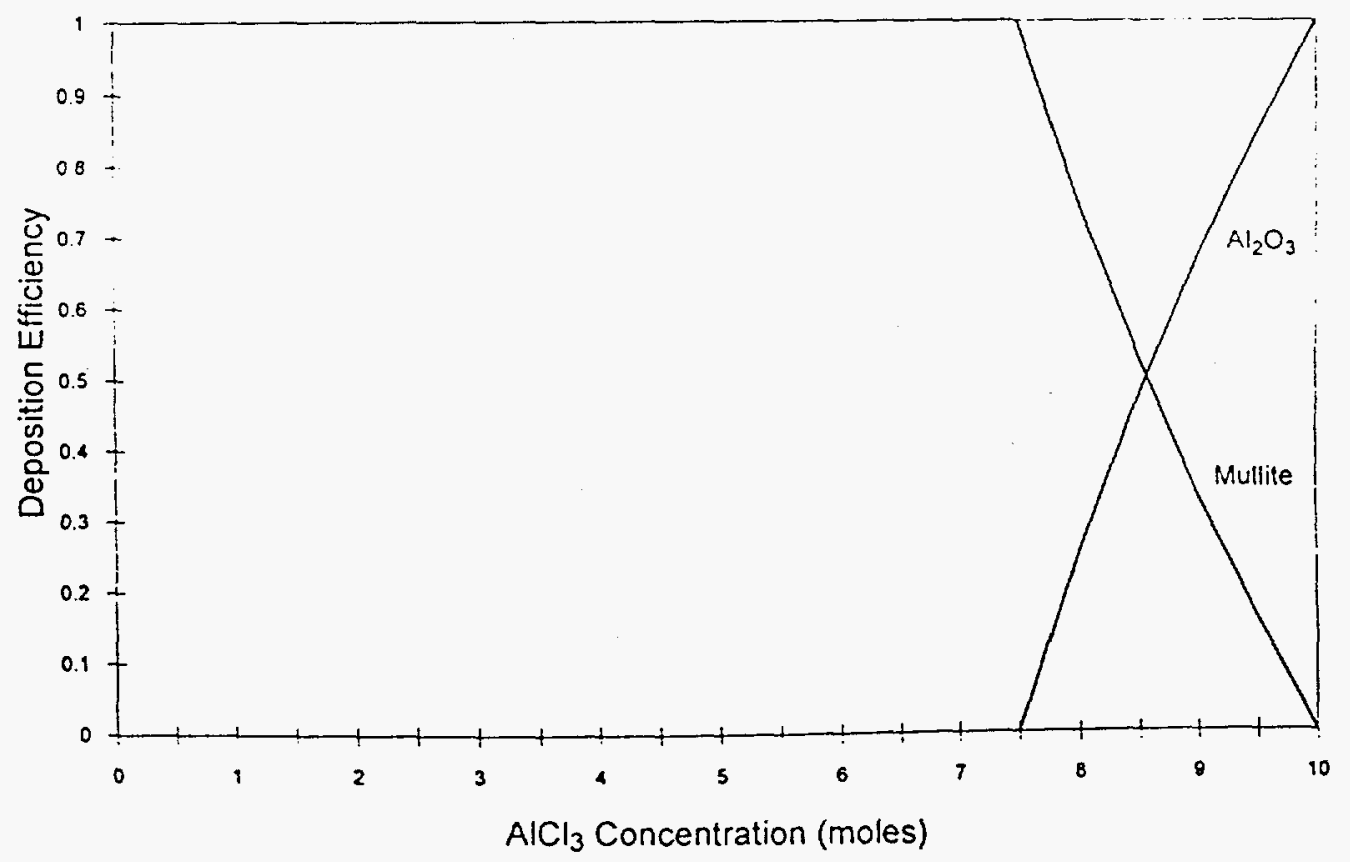

Figure 16 a) Concentration, and b) Efficiency Curves at Section AA in Figure 15 
a)

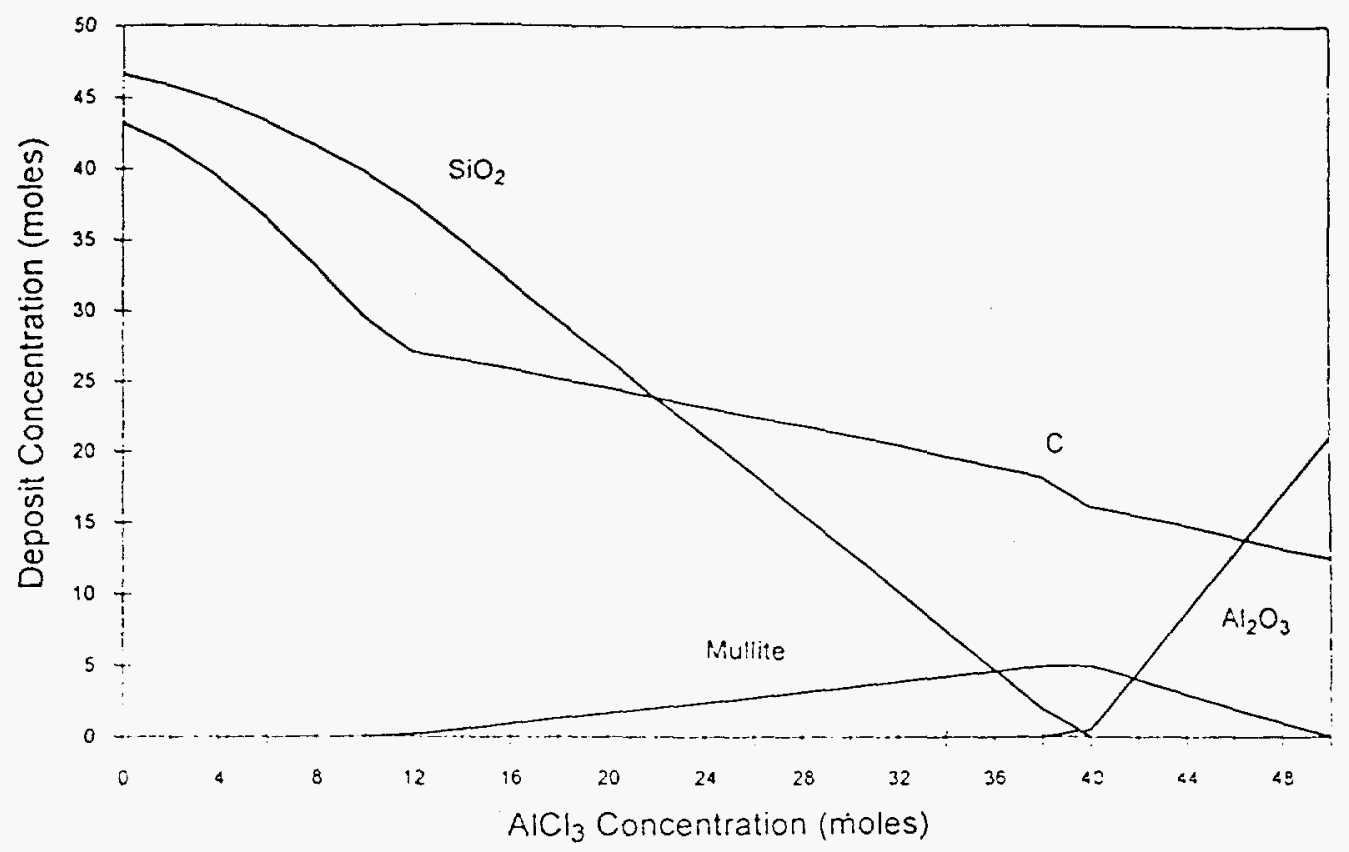

b)

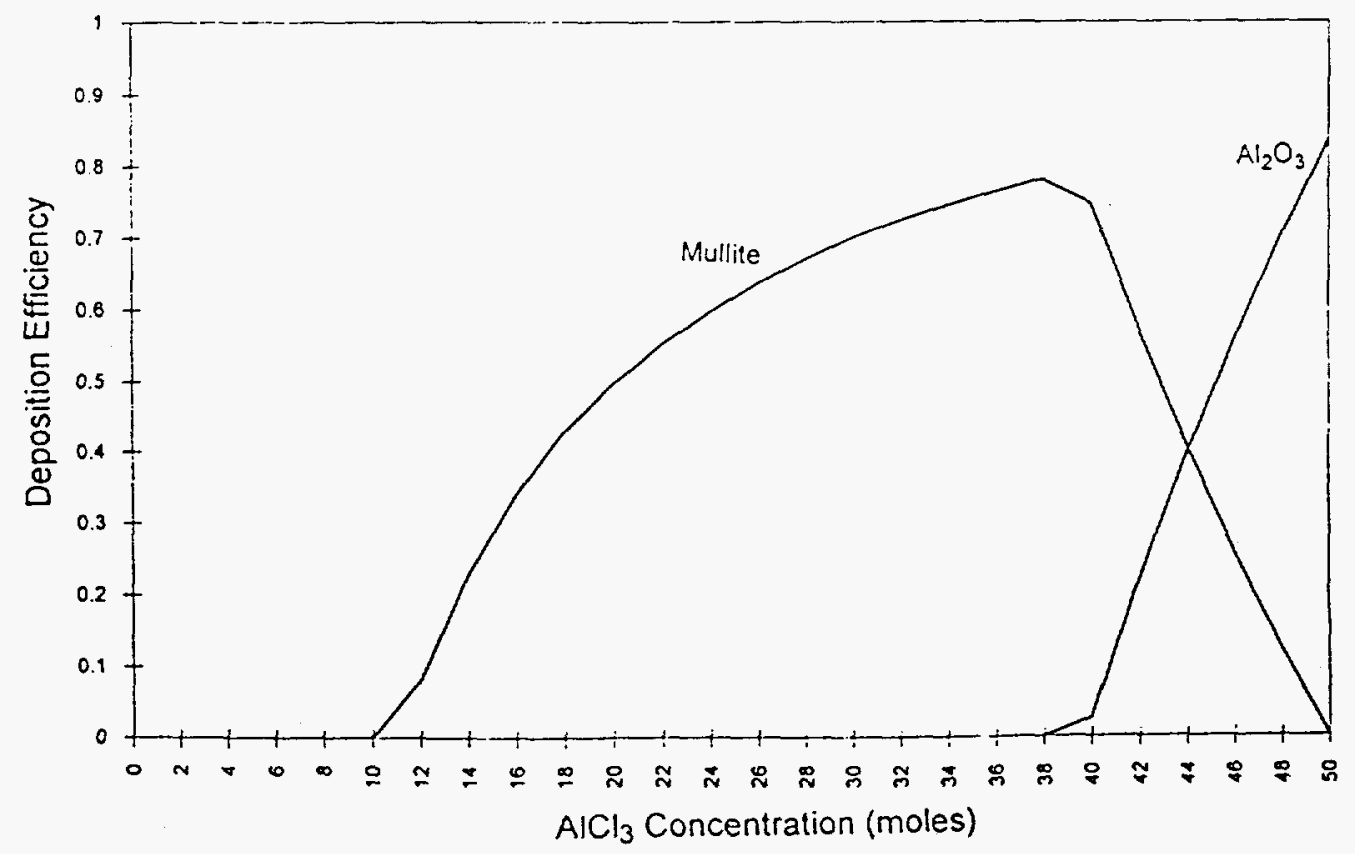

Figure 17 a) Concentration, and b) Efficiency Curves at Section BB in Figure 15 
a)

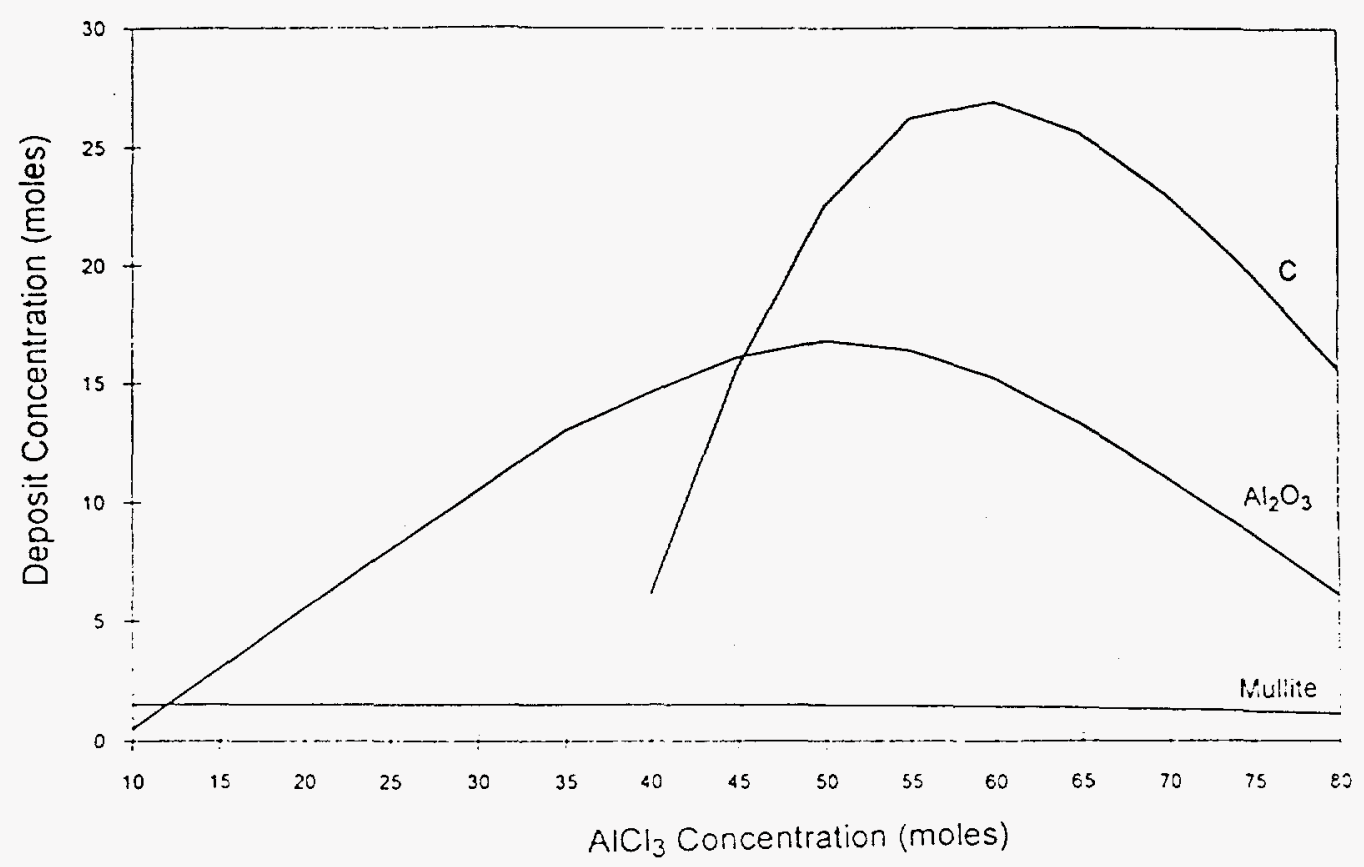

b)

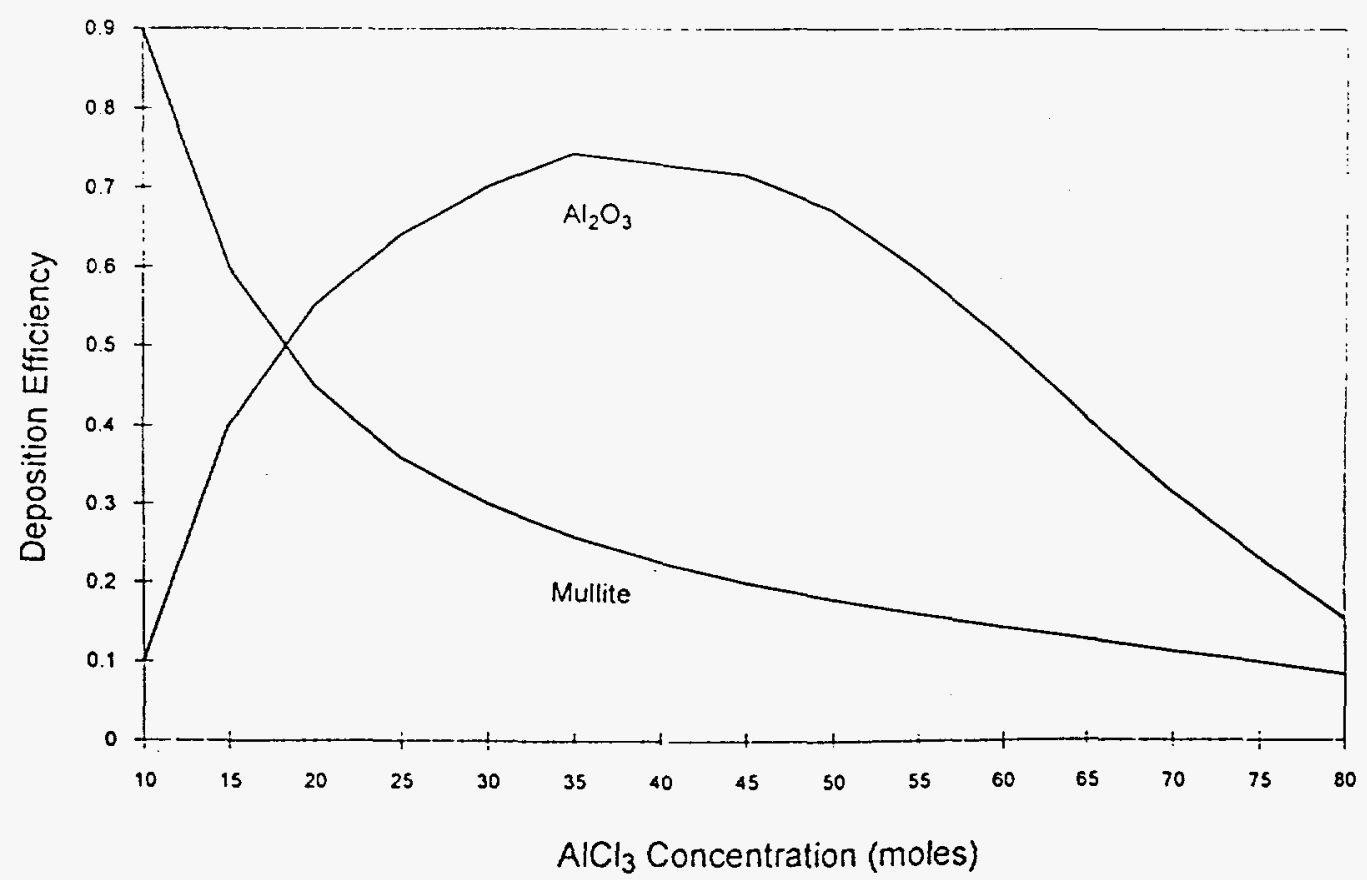

Figure 18 a) Concentration, and b) Efficiency Curves at Section CC in Figure 15 
a)
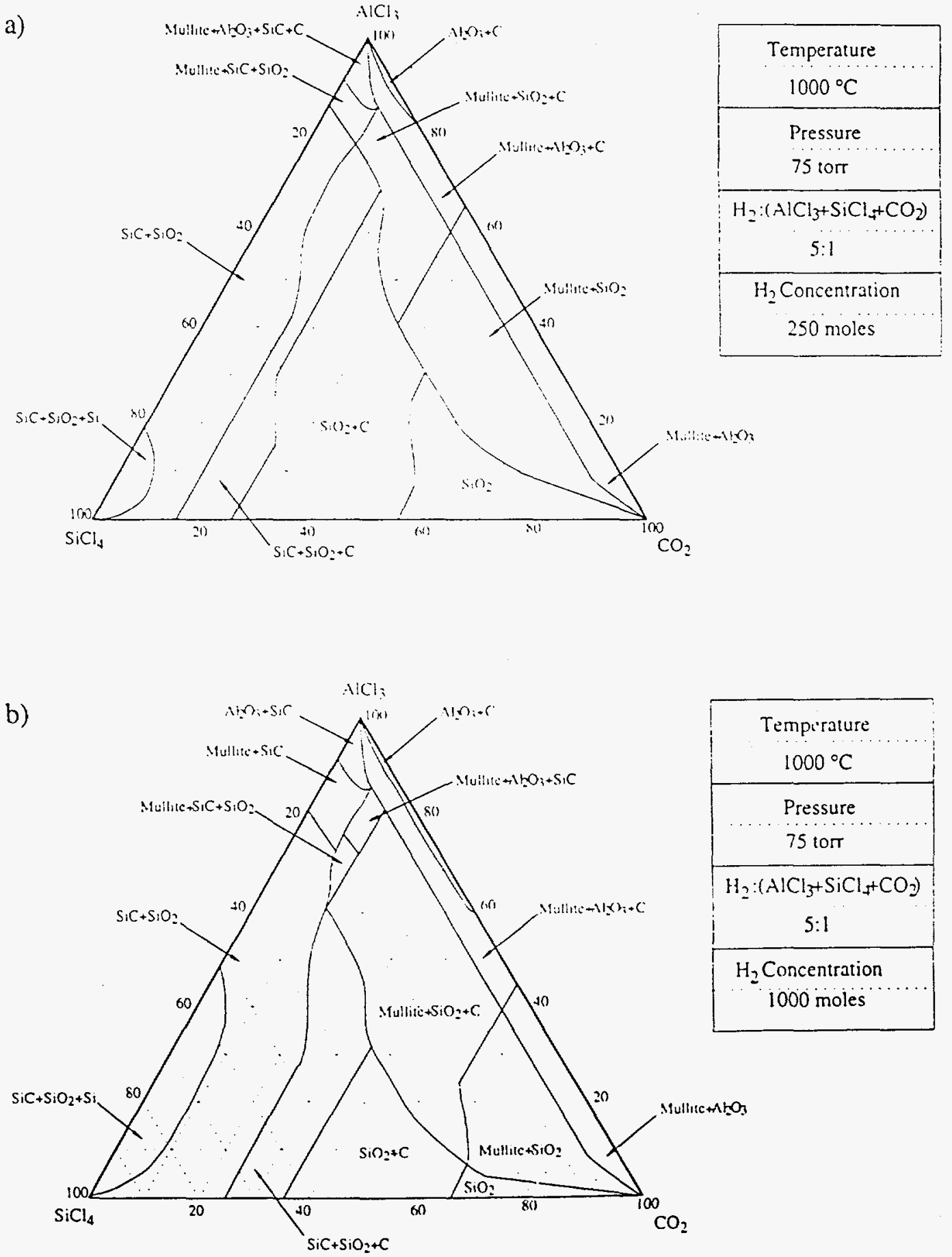

Figure $19 \mathrm{CVD}$ Ternary Phase Diagram of $\mathrm{AlCl}_{3}-\mathrm{SiCl}_{4}-\mathrm{CO}_{2}-\mathrm{H}_{2}$ System at $1000^{\circ} \mathrm{C}$ and 75 Torr; $\mathrm{H}_{2}$ Concentration: a) 1000 Moles, b) 250 Moles 
a)
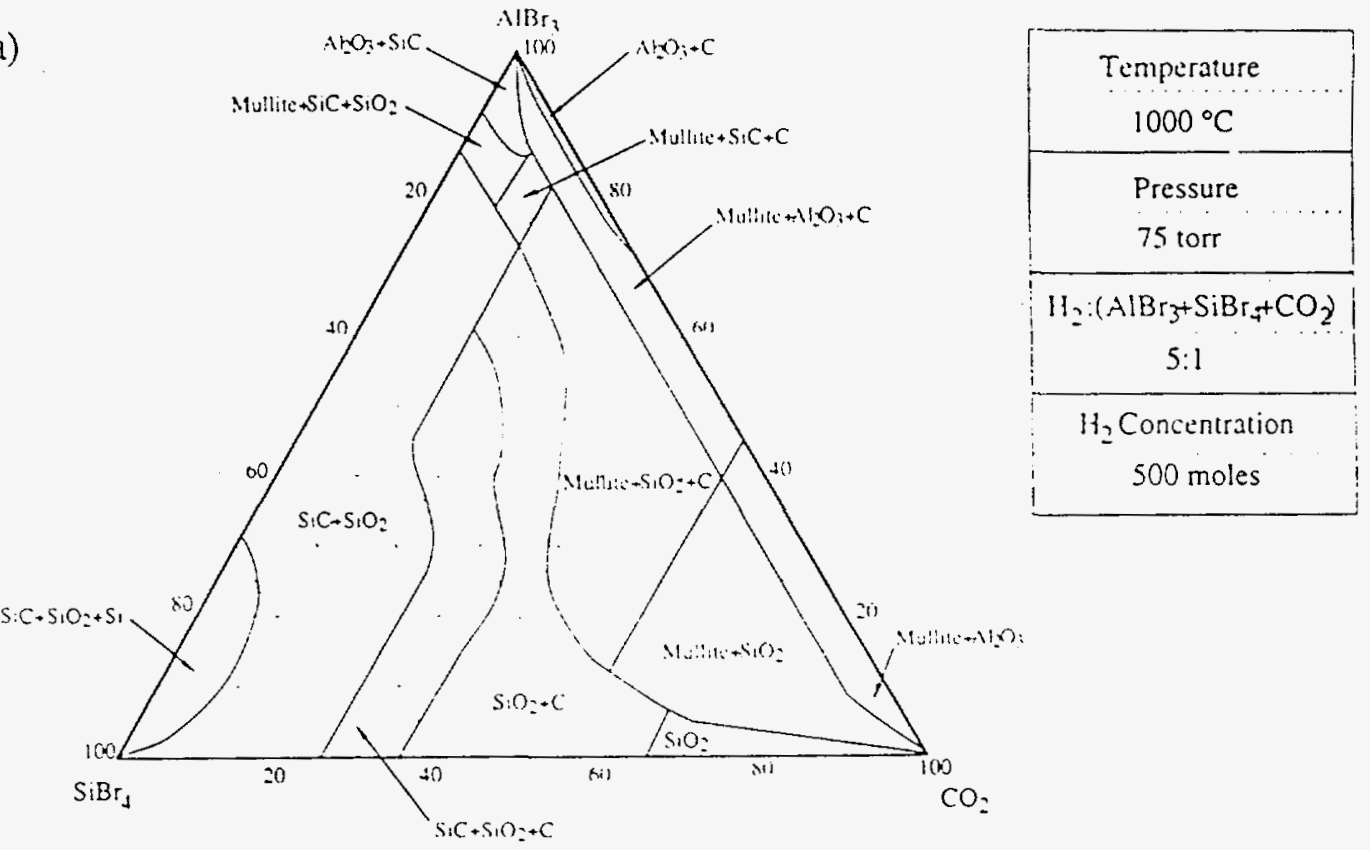

b)
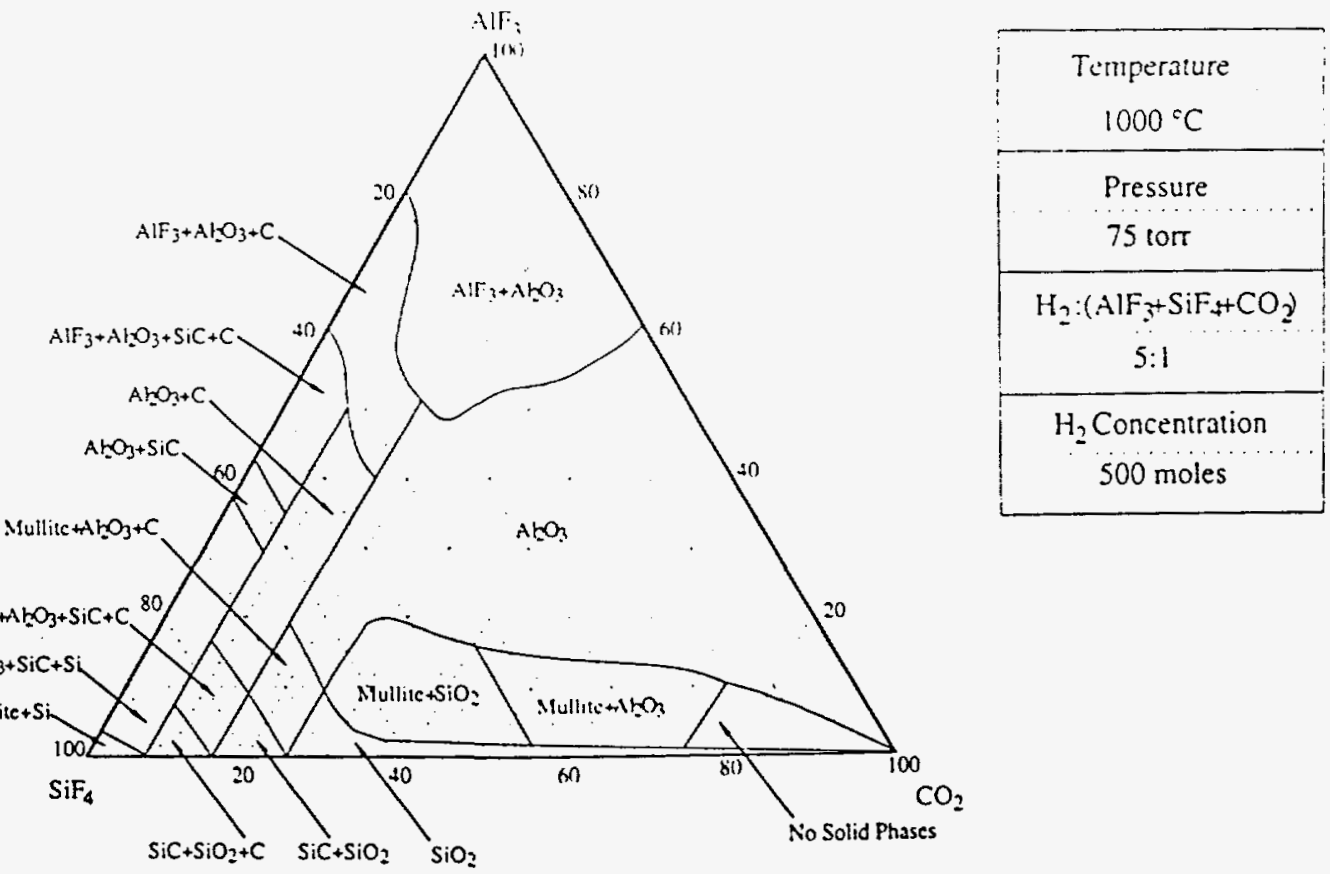

Figure 20 CVD Ternary Phase Diagram of a) $\mathrm{AlBr}_{3}-\mathrm{SiBr}_{4}-\mathrm{CO}_{2}-\mathrm{H}_{2}$ System, and b) $\mathrm{AlF}_{3}-$ $\mathrm{SiF}_{4}-\mathrm{CO}_{2}-\mathrm{H}_{2}$ System at $1000^{\circ} \mathrm{C}$ and 75 Torr 


\begin{tabular}{llll} 
Number & Temperature & Pressure & Reactant Mixture \\
\hline & ${ }^{\circ} \mathrm{C}$ & torr & \\
1. & 1000 & 75 & $\mathrm{AlCl}_{3}-\mathrm{SiCl}_{4}-\mathrm{CO}_{2}-\mathrm{H}_{2}$ \\
2. & 1000 & 2 & \\
3. & 1000 & 25 & \\
4. & 1000 & 150 & \\
5. & 800 & 2 & \\
6. & 800 & 25 & \\
7. & 800 & 75 & \\
8. & 800 & 150 & \\
9. & 1200 & 2 & \\
10. & 1200 & 25 & \\
11. & 1200 & 75 & \\
12. & 1200 & 150 & \\
13. & 1000 & 75 & $\mathrm{H}_{2}: 1000$ moles \\
14. & 1000 & 75 & $\mathrm{H}_{2}: 250 \mathrm{moles}^{2}$ \\
15. & 1000 & 75 & $\mathrm{AlBr}_{3}-\mathrm{SiBr}_{4}-\mathrm{CO}_{2}-\mathrm{H}_{2}$ \\
16. & 1000 & 75 & $\mathrm{AlF}_{3}-\mathrm{SiF}_{4}-\mathrm{CO}_{2}-\mathrm{H}_{2}$
\end{tabular}

Table 1 Deposition Conditions Used in the Thermodynamic Analysis of the $\mathrm{AlCl}_{3}-\mathrm{SiCl}_{4}$ $\mathrm{CO}_{2}-\mathrm{H}_{2}$ System 


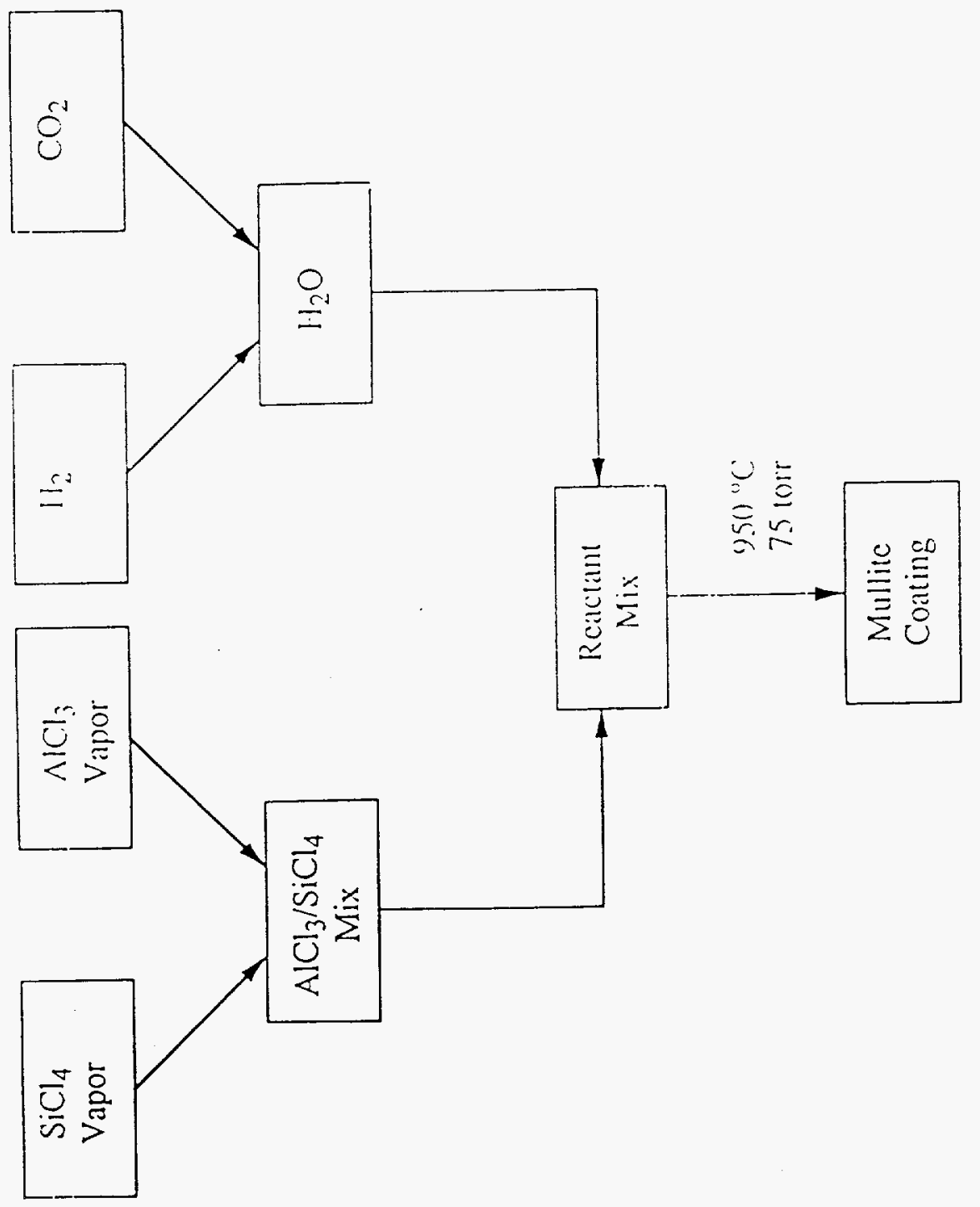

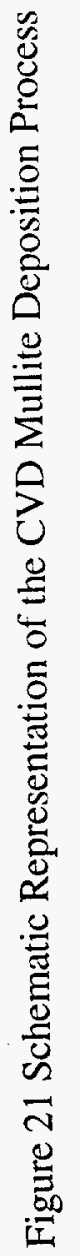



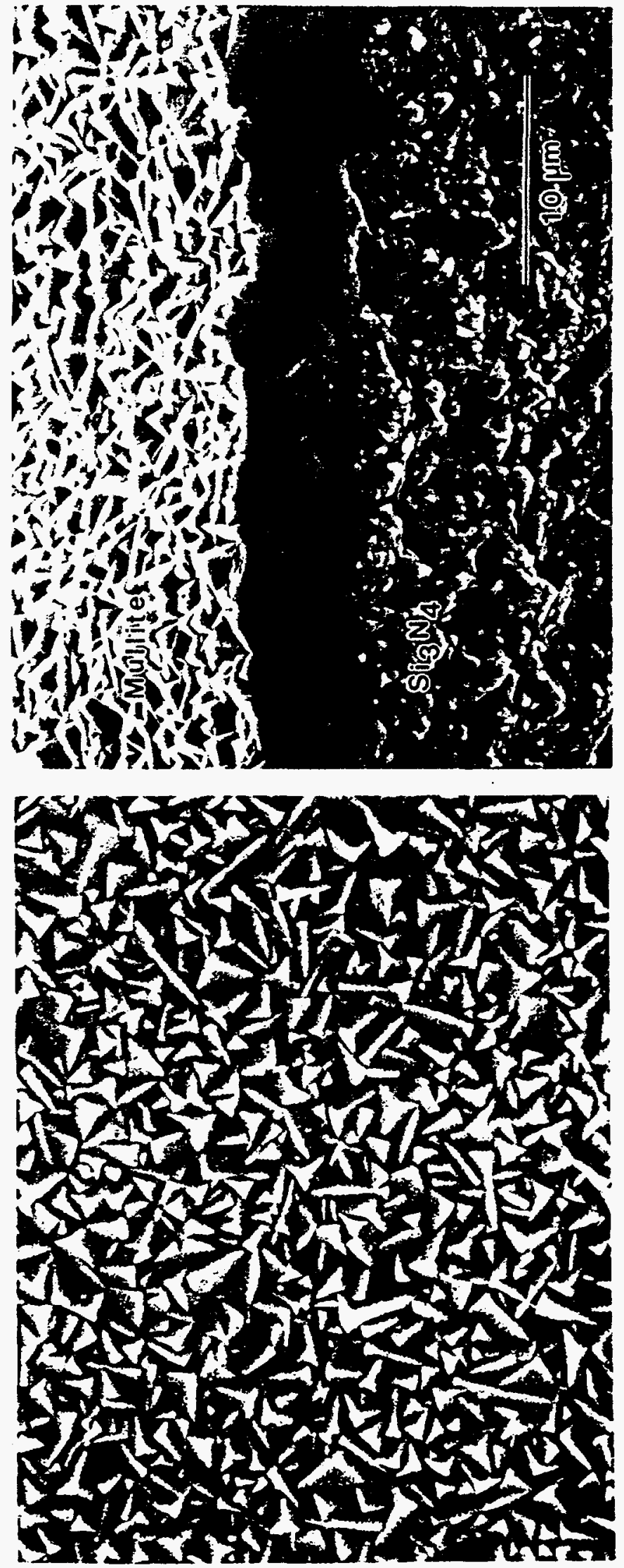


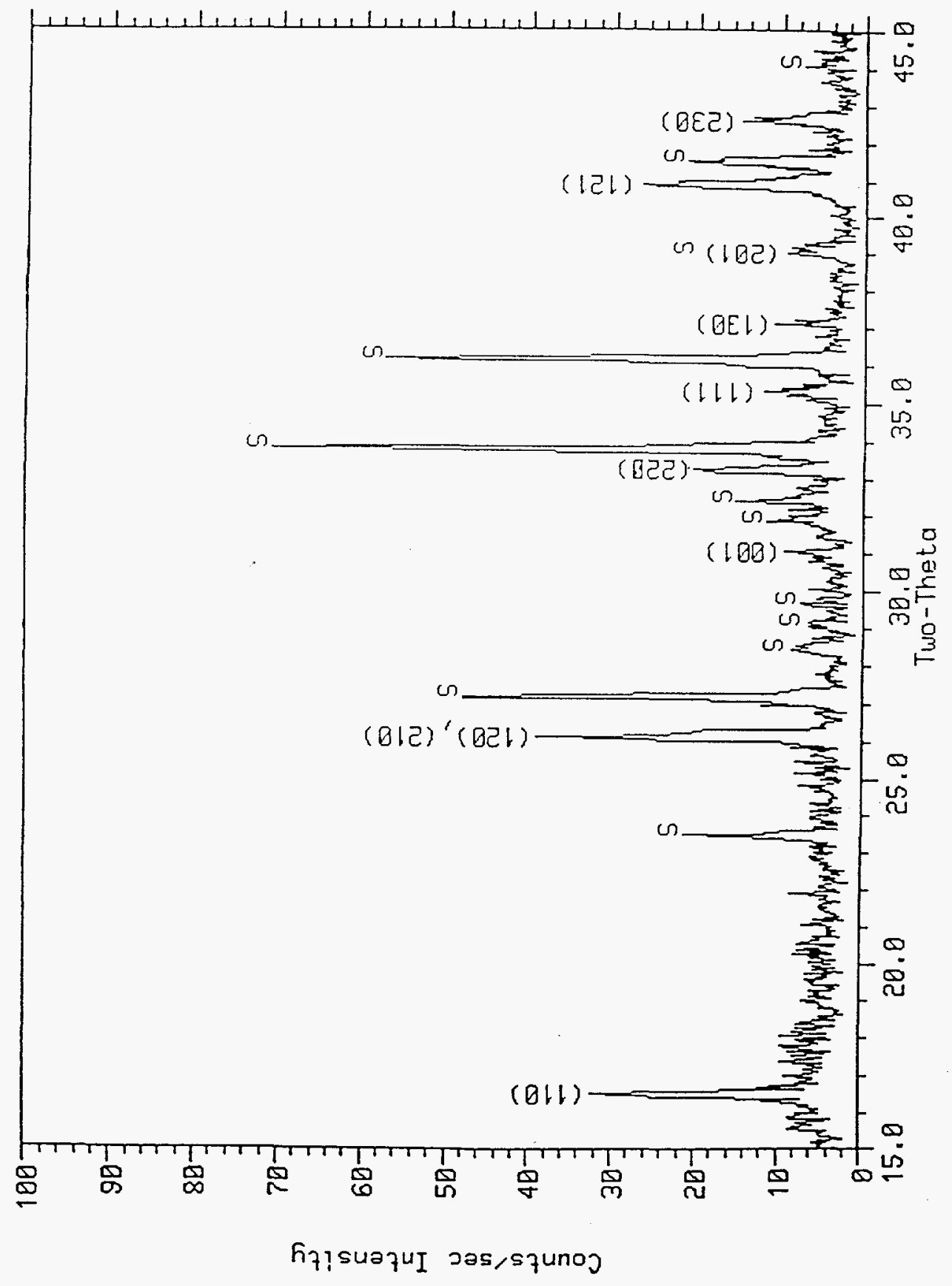

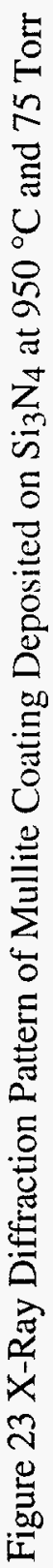




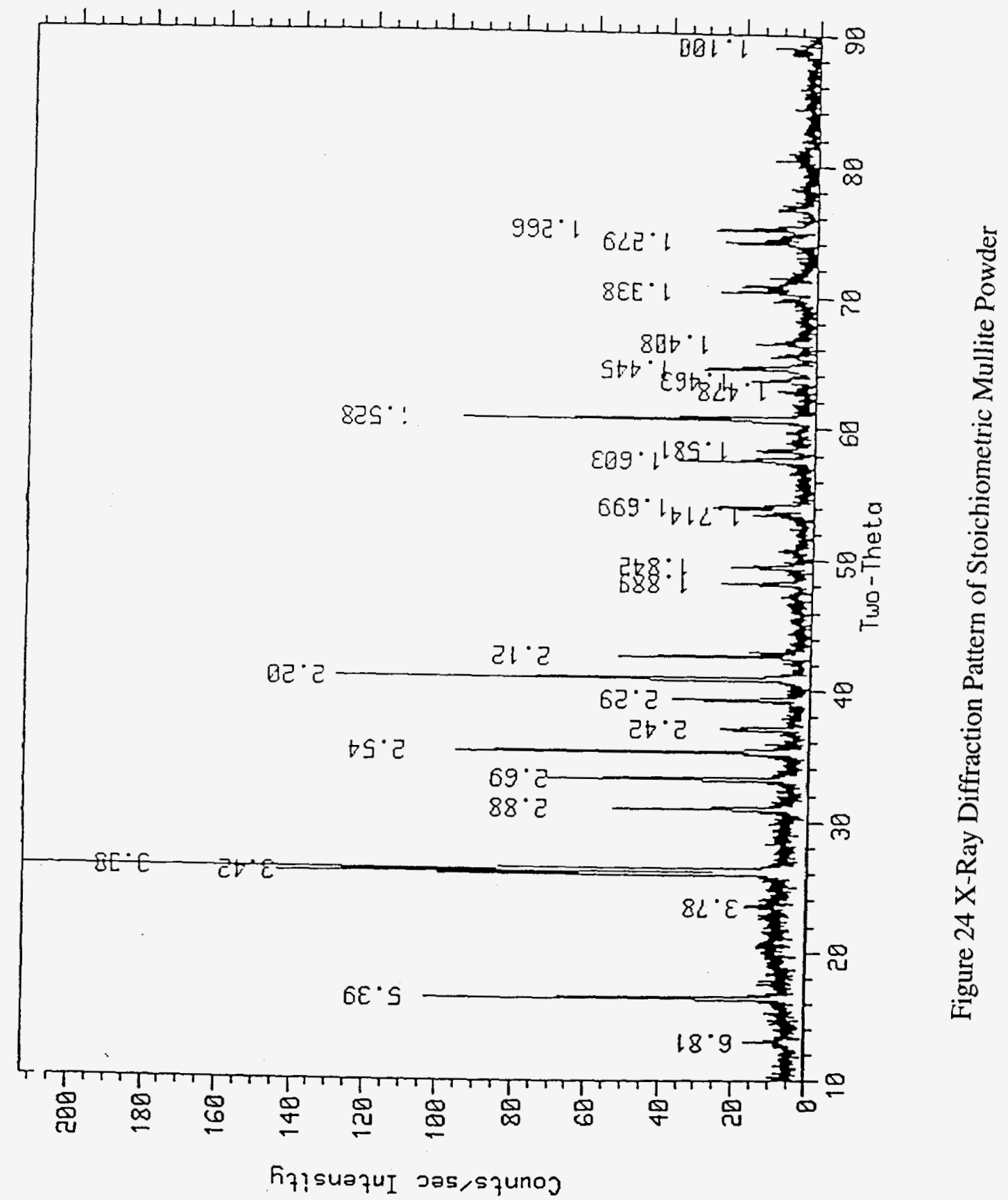



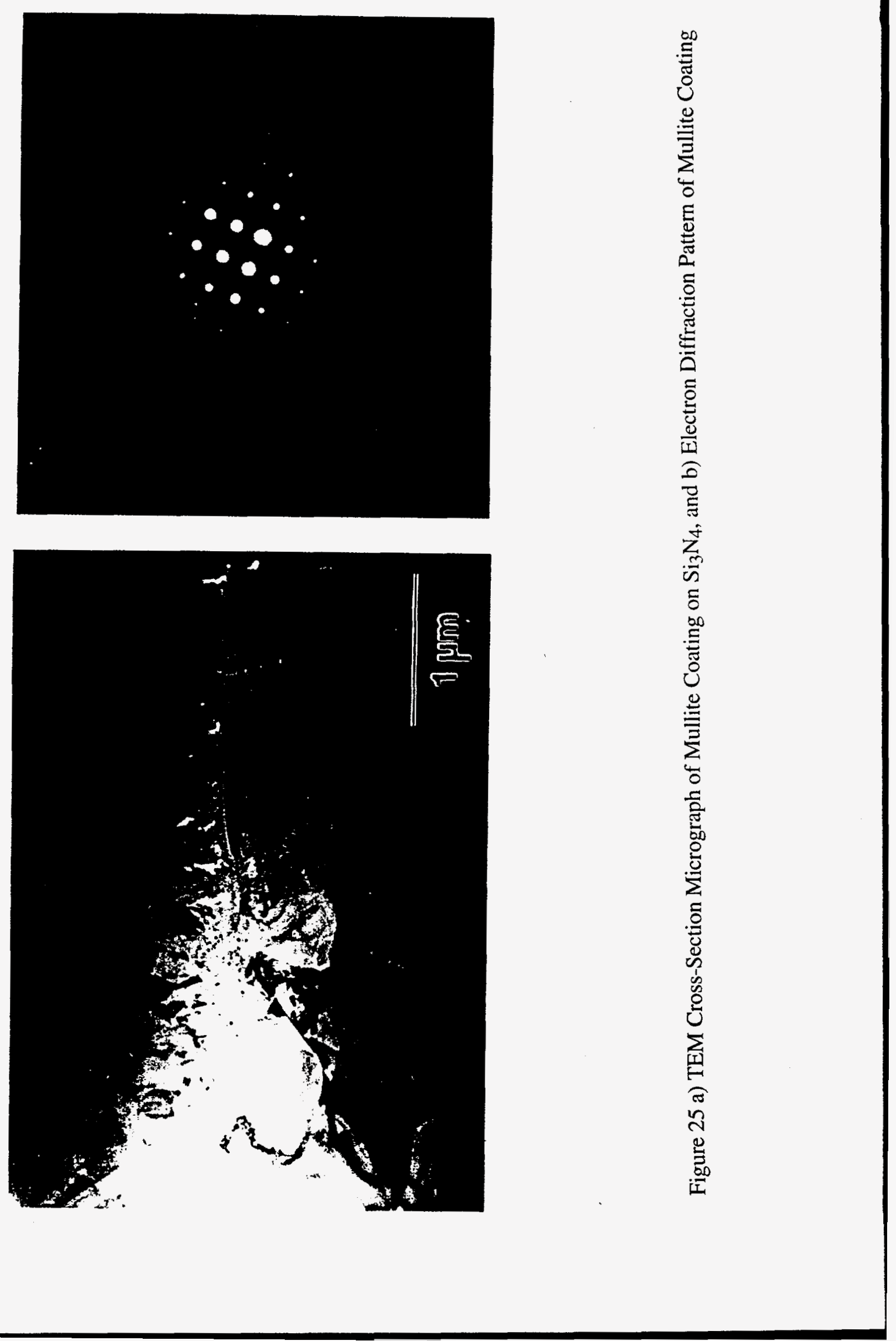


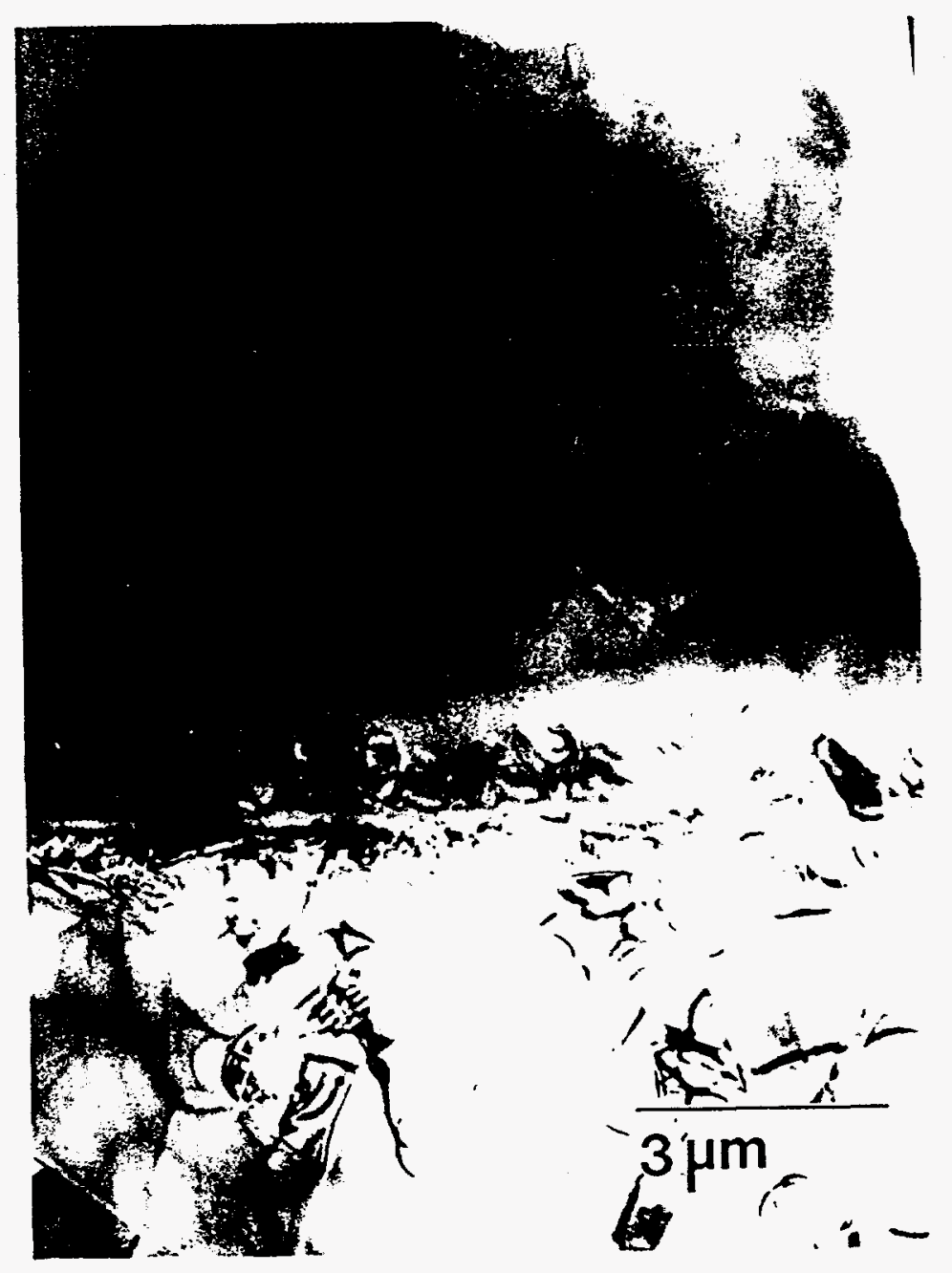

Figure 26 TEM Cross-Section Micrograph of Mullite Coating on SiC Showing Details of the Nanocrystalline and Columnar Regions 

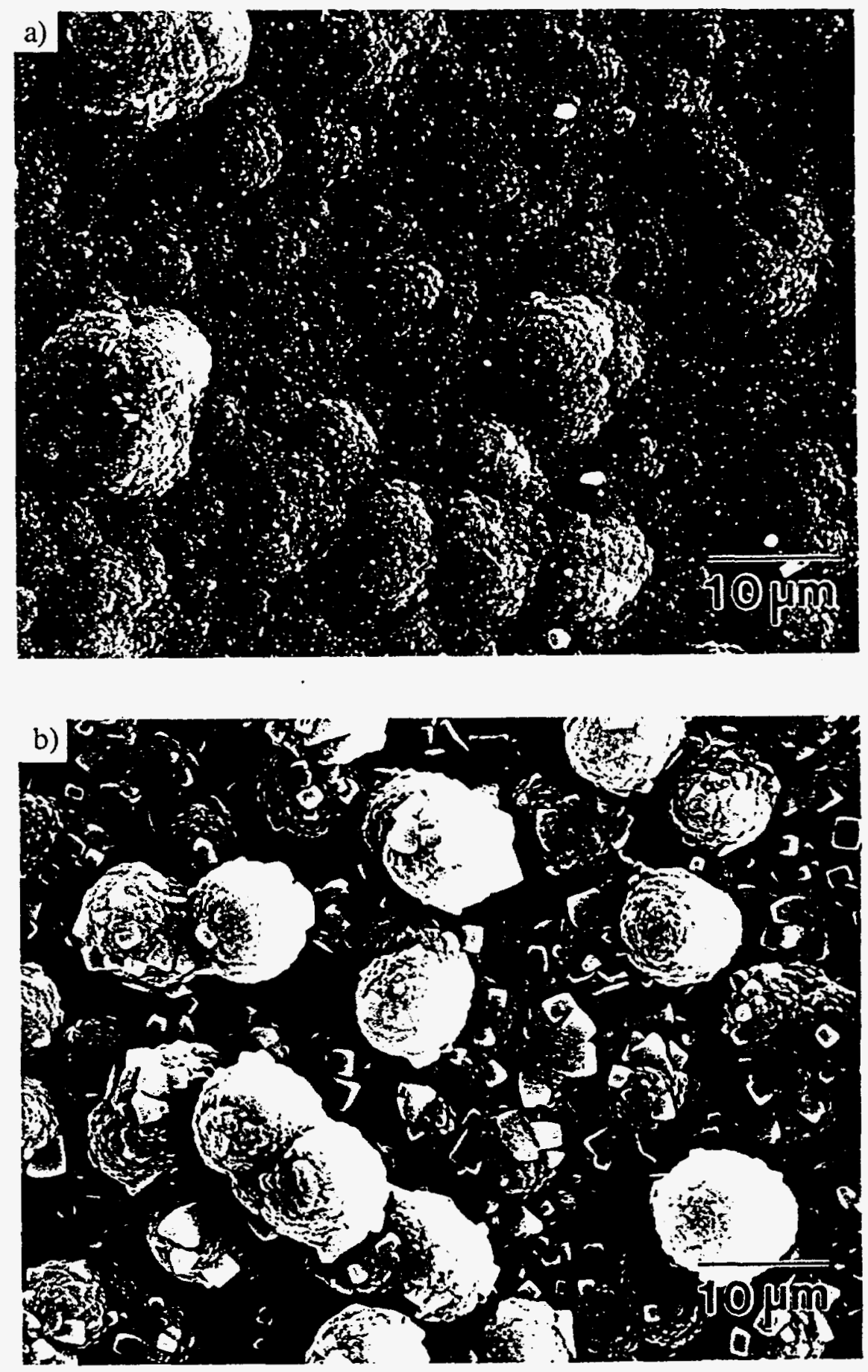

Figure 27 SEM Micrograph of Mullite Coating Deposited on $\mathrm{Si}_{3} \mathrm{~N}_{4}$ at 75 Torr and a) 800 ${ }^{\circ} \mathrm{C}$, b) $850^{\circ} \mathrm{C}$, c) $900^{\circ} \mathrm{C}$, d) $950^{\circ} \mathrm{C}$, e) $1000^{\circ} \mathrm{C}$, and f) $1050^{\circ} \mathrm{C}$ 

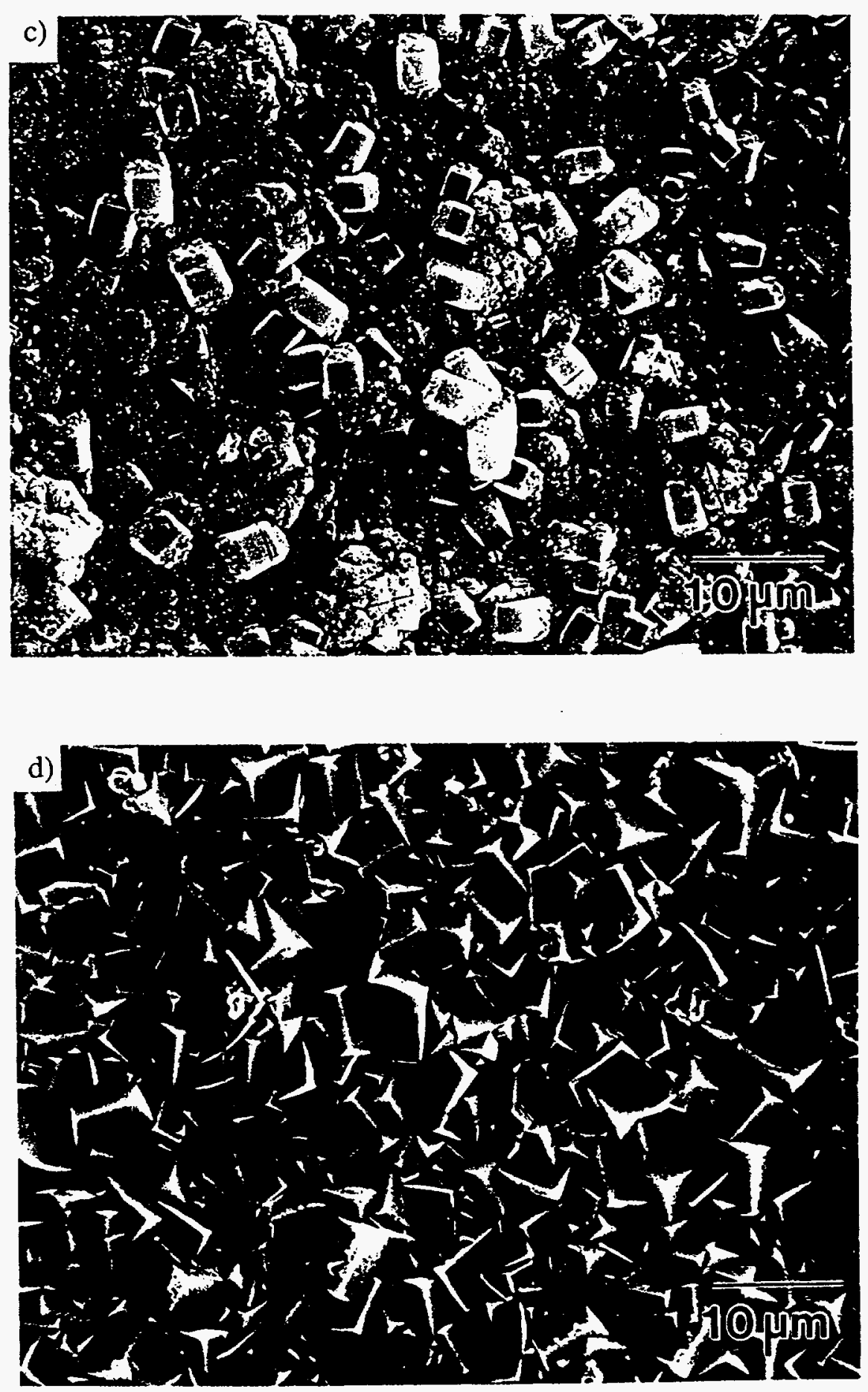

Figure 27 SEM Micrograph of Mullite Coating Deposited on $\mathrm{Si}_{3} \mathrm{~N}_{4}$ at 75 Torr and a) 800 ${ }^{\circ} \mathrm{C}$, b) $850^{\circ} \mathrm{C}$, c) $900^{\circ} \mathrm{C}$, d) $950^{\circ} \mathrm{C}$, e) $1000^{\circ} \mathrm{C}$, and f) $1050^{\circ} \mathrm{C}$ (Contd.....) 

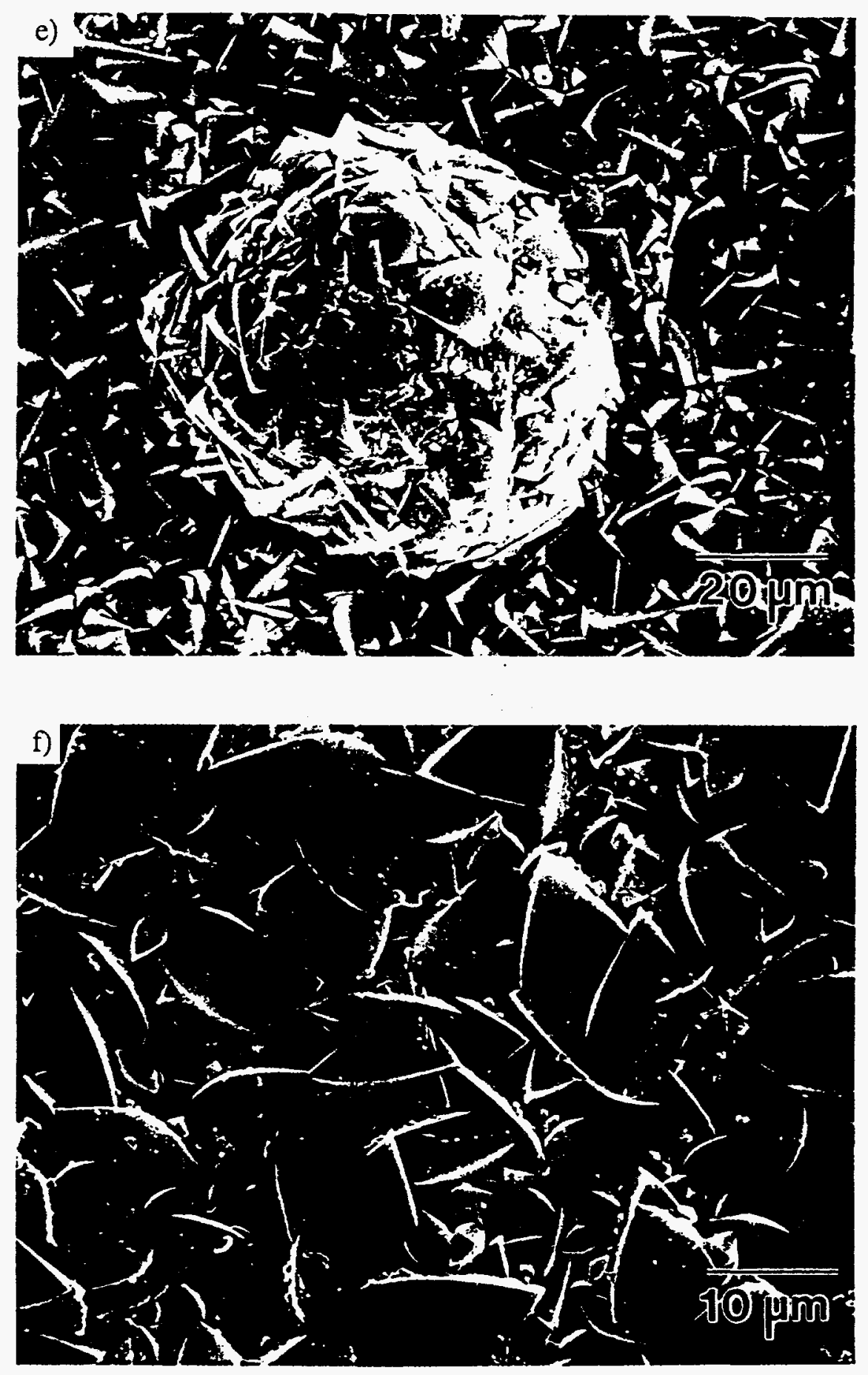

Figure 27 SEM Micrograph of Mullite Coating Deposited on $\mathrm{Si}_{3} \mathrm{~N}_{4}$ at 75 Torr and a) 800 ${ }^{\circ} \mathrm{C}$, b) $850^{\circ} \mathrm{C}$, c) $900^{\circ} \mathrm{C}$, d) $950^{\circ} \mathrm{C}$, e) $1000^{\circ} \mathrm{C}$, and f) $1050^{\circ} \mathrm{C}$ (Contd.....) 
a)

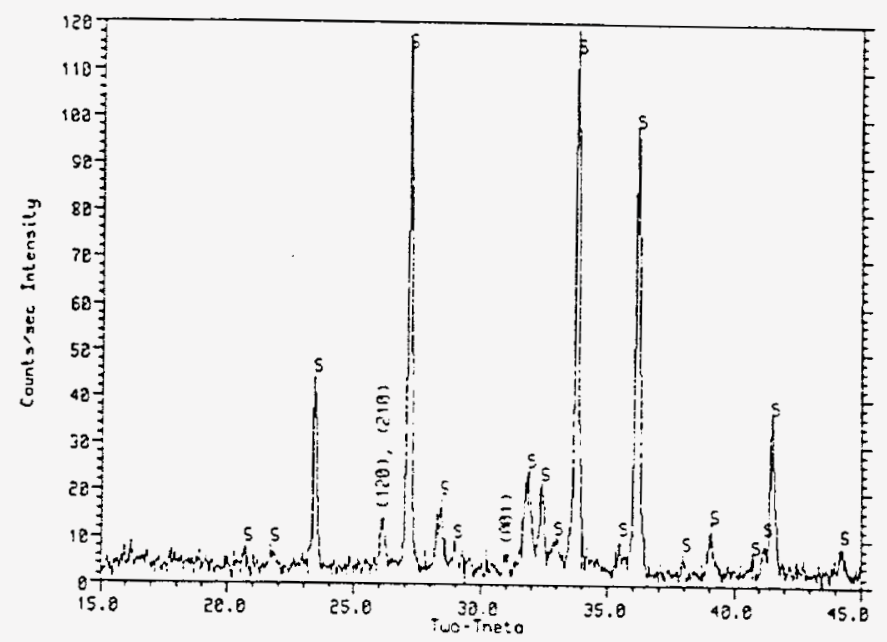

b)

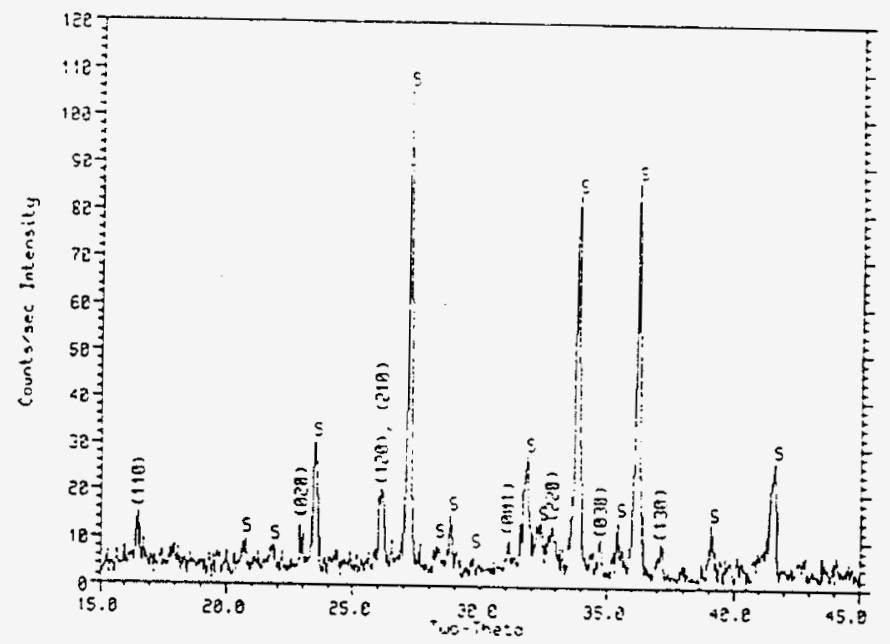

c)

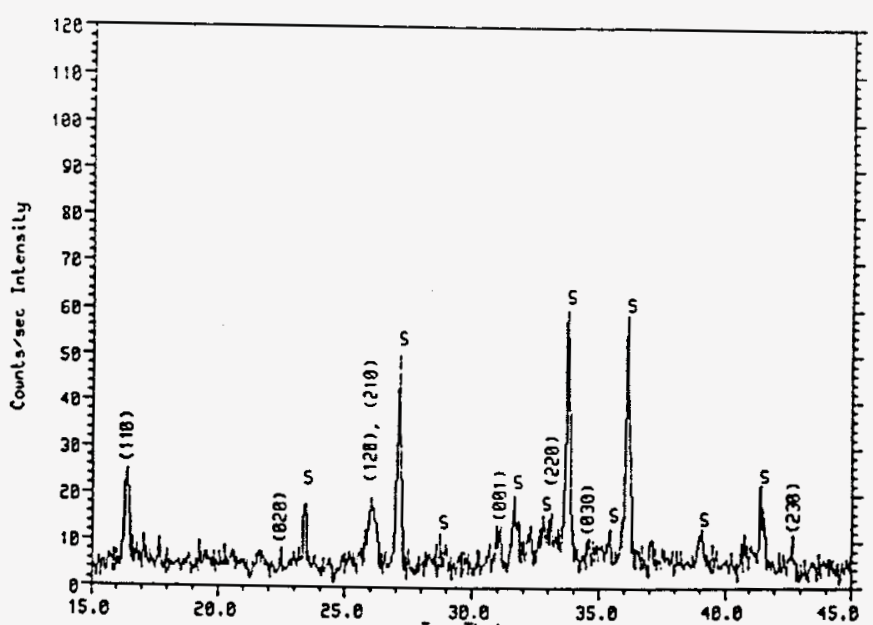

Figure $28 \mathrm{X}$-Ray Diffraction Pattern of Mullite Coating on $\mathrm{Si}_{3} \mathrm{~N}_{4}$ at 75 Torr and a) $850^{\circ} \mathrm{C}$, b) $900^{\circ} \mathrm{C}$, and c) $1000^{\circ} \mathrm{C}$ 
a)

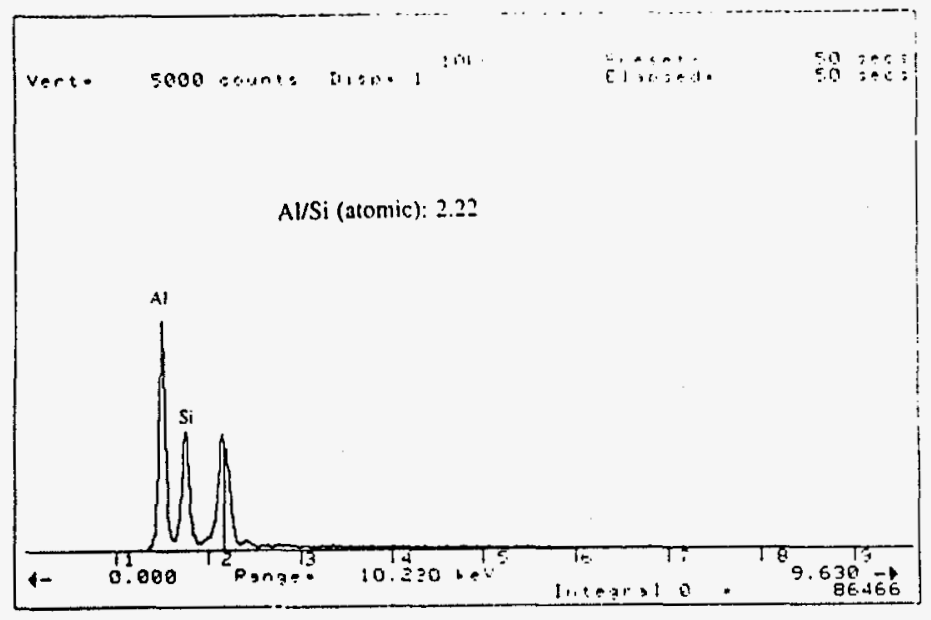

c)

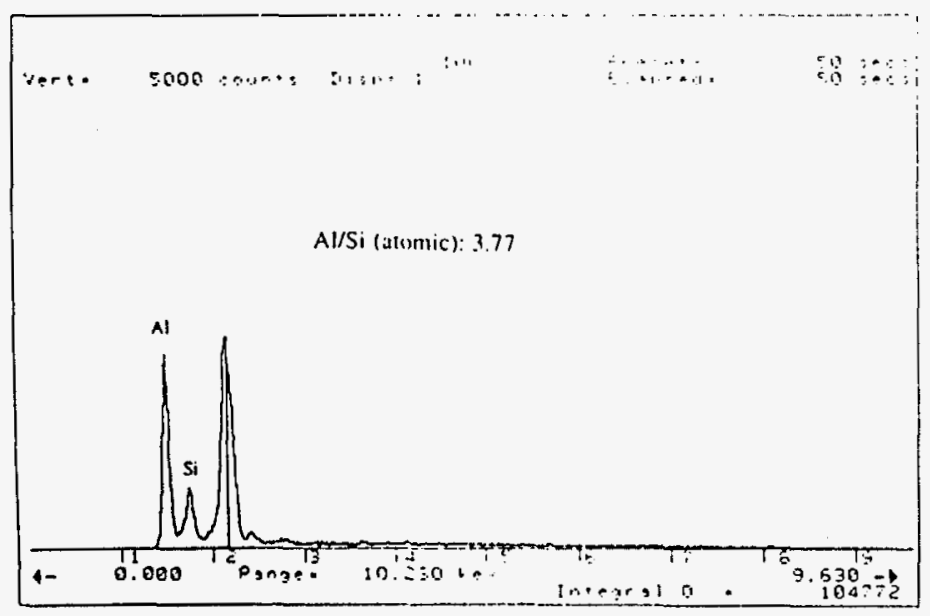

b)

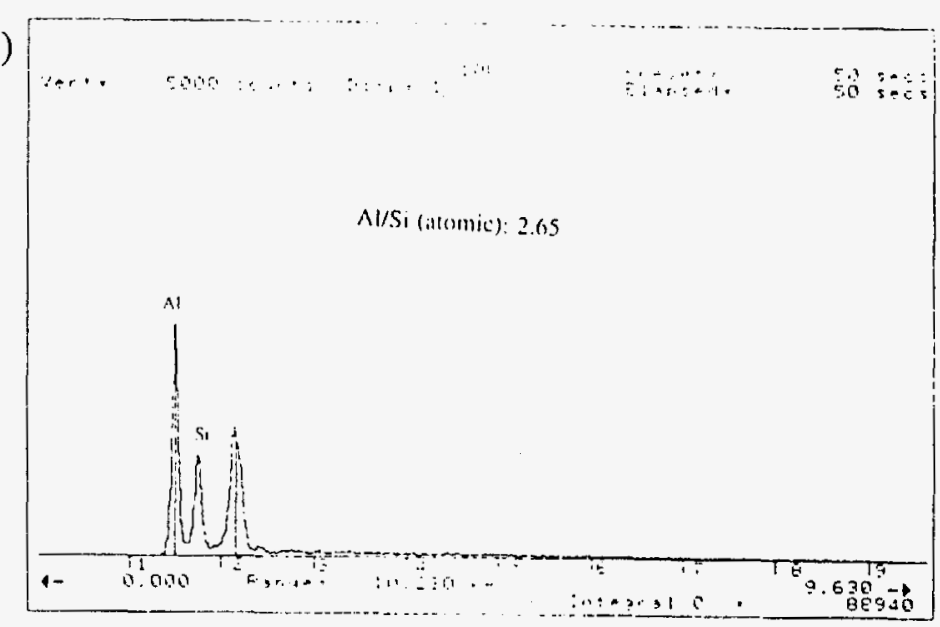

d)

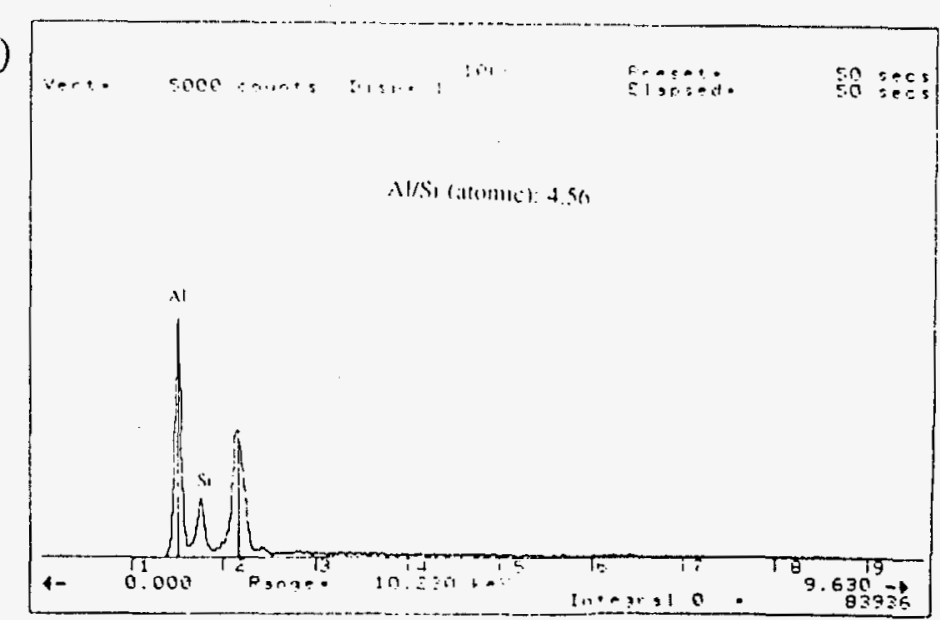

Figure 29 EDS Analysis of Mullite Coating on $\mathrm{Si}_{3} \mathrm{~N}_{4}$ at 75 Torr and a) $800^{\circ} \mathrm{C}$, b) $850^{\circ} \mathrm{C}$, c) $900^{\circ} \mathrm{C}$, and d) $1000^{\circ} \mathrm{C}$; The Unidentified Peak is Conductive Au Coating on the Sample 


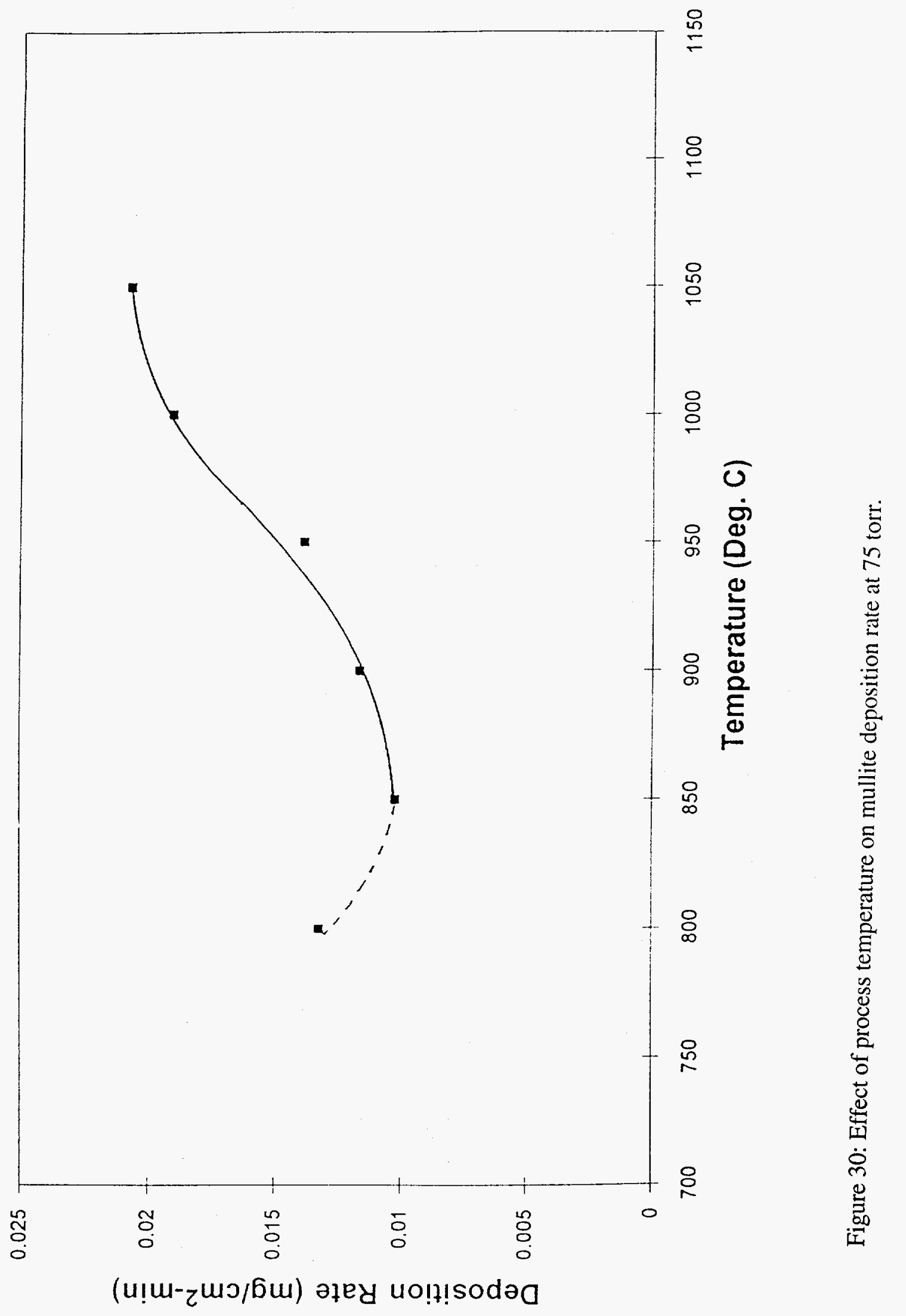




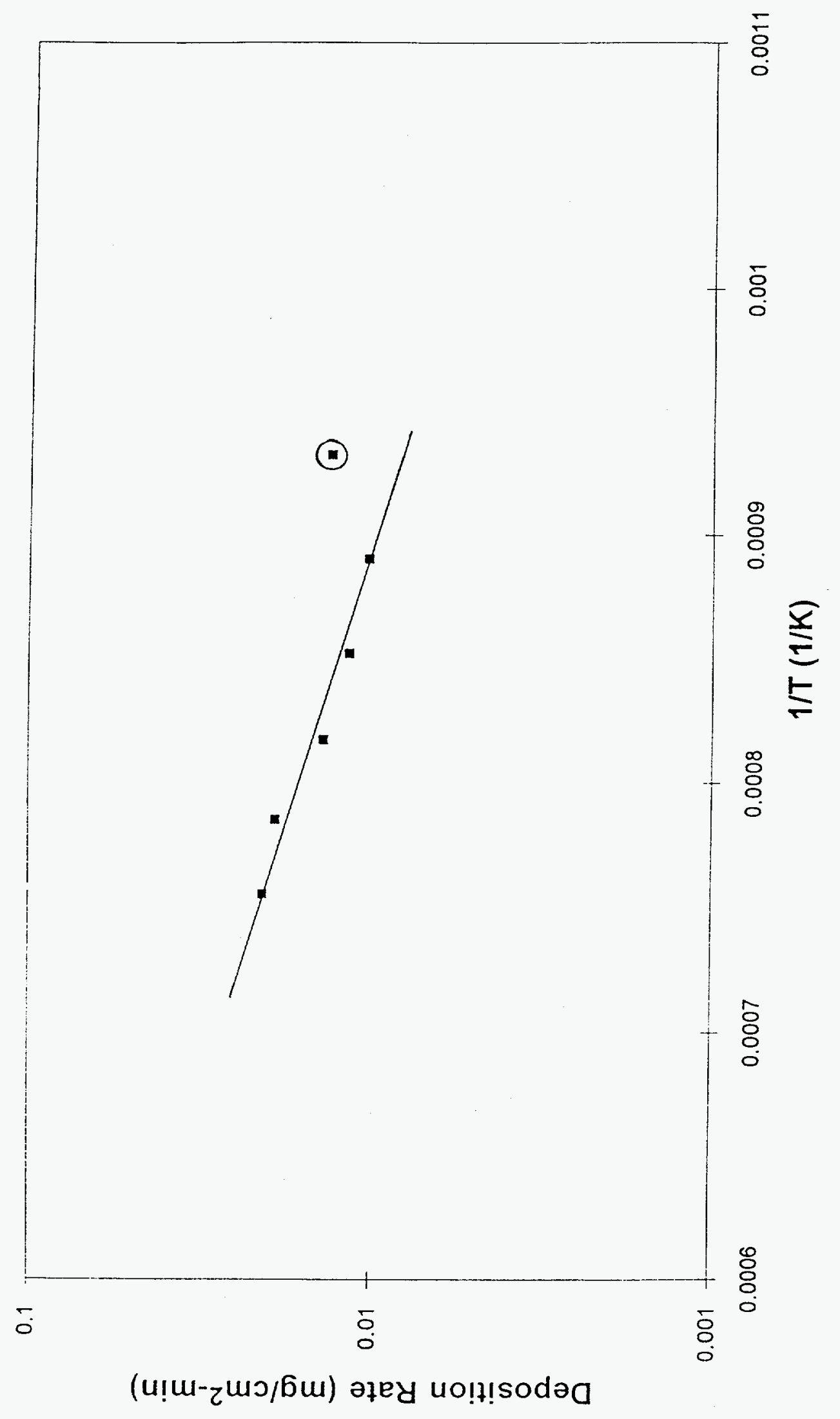

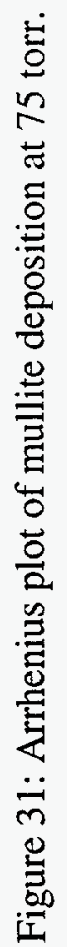



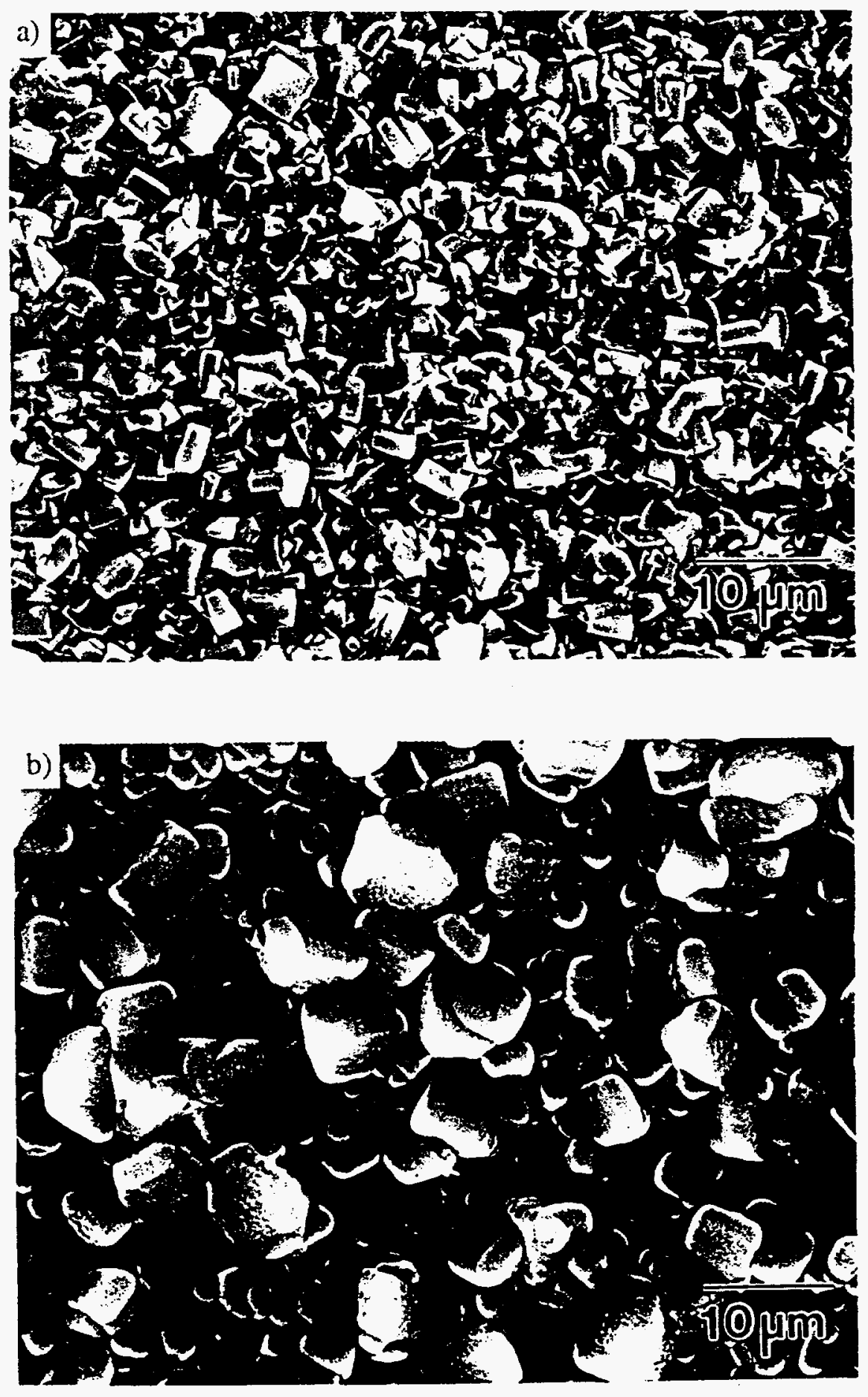

Figure 32 SEM Micrograph of Mullite Coating Deposited on $\mathrm{Si}_{3} \mathrm{~N}_{4}$ at $950{ }^{\circ} \mathrm{C}$ and a) 50 Torr, b) 100 Torr, c) 150 Torr, and d) 200 Torr 

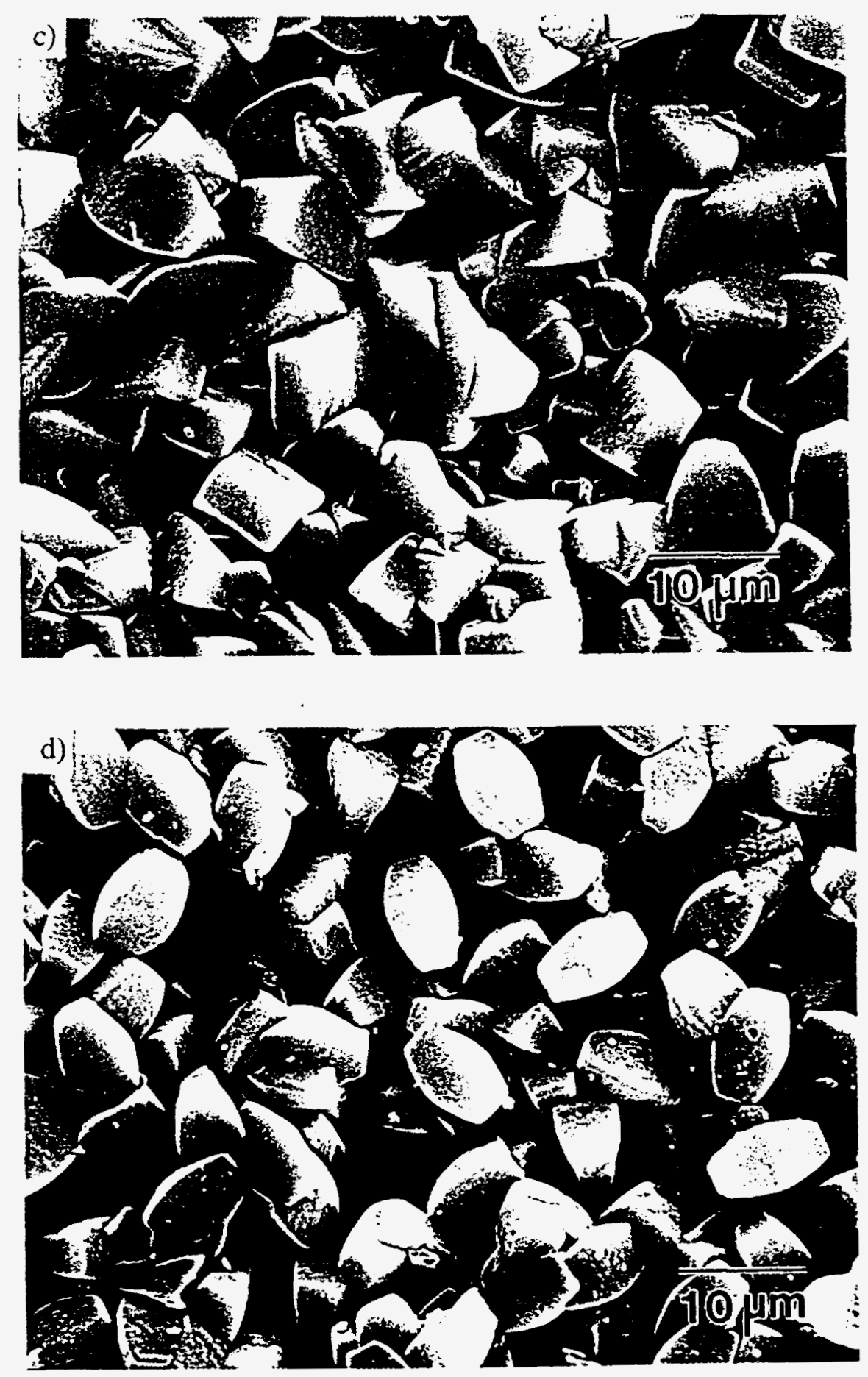

Figure 32 SEM Micrograph of Mullite Coating Deposited on $\mathrm{Si}_{3} \mathrm{~N}_{4}$ at $950{ }^{\circ} \mathrm{C}$ and a) 50 Torr, b) 100 Torr, c) 150 Torr, and d) 200 Torr (Contd.....) 
a)

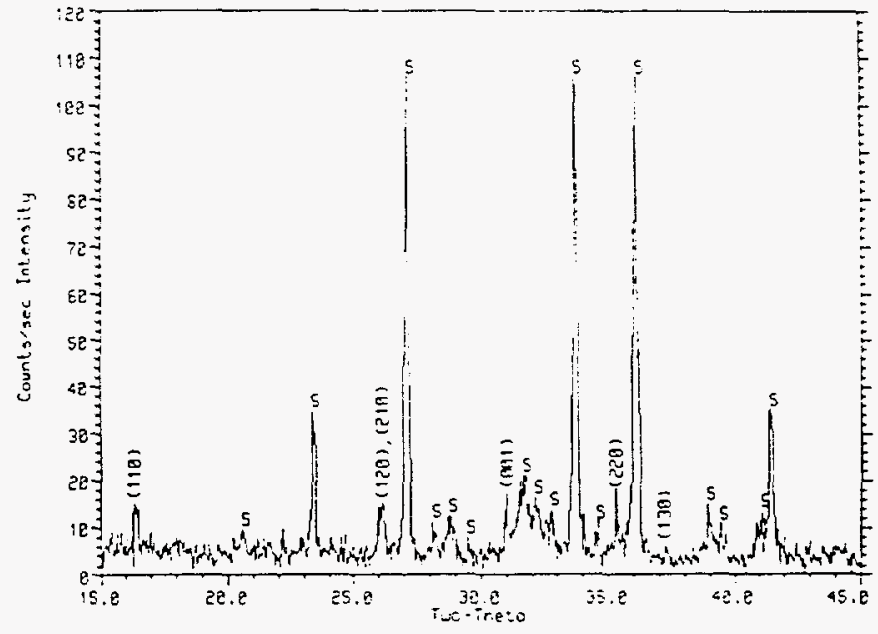

b)

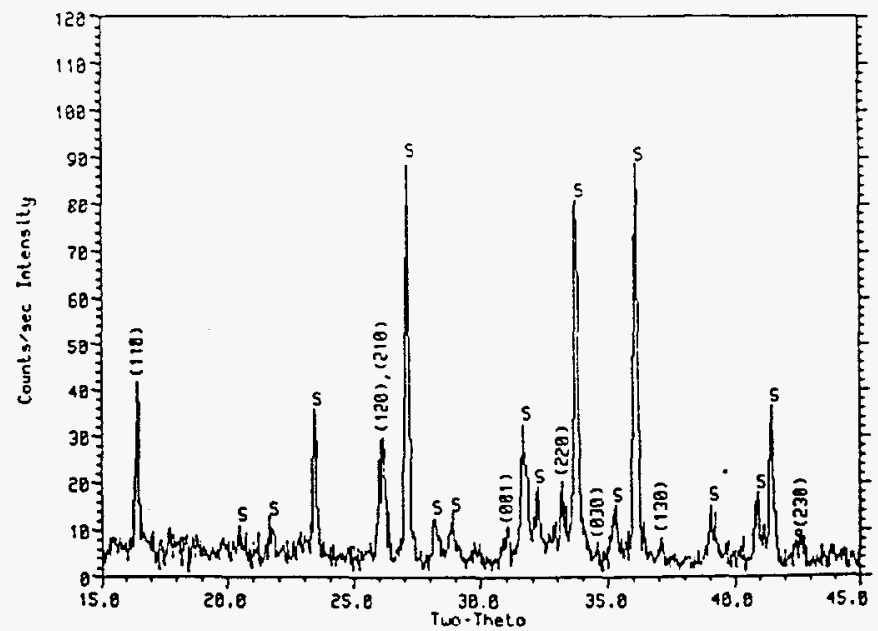

Figure $33 \mathrm{X}$-Ray Diffraction Pattern of Mullite Coating on $\mathrm{Si}_{3} \mathrm{~N}_{4}$ at $950{ }^{\circ} \mathrm{C}$ and a) 50 Torr, and b) 200 Torr 
a)

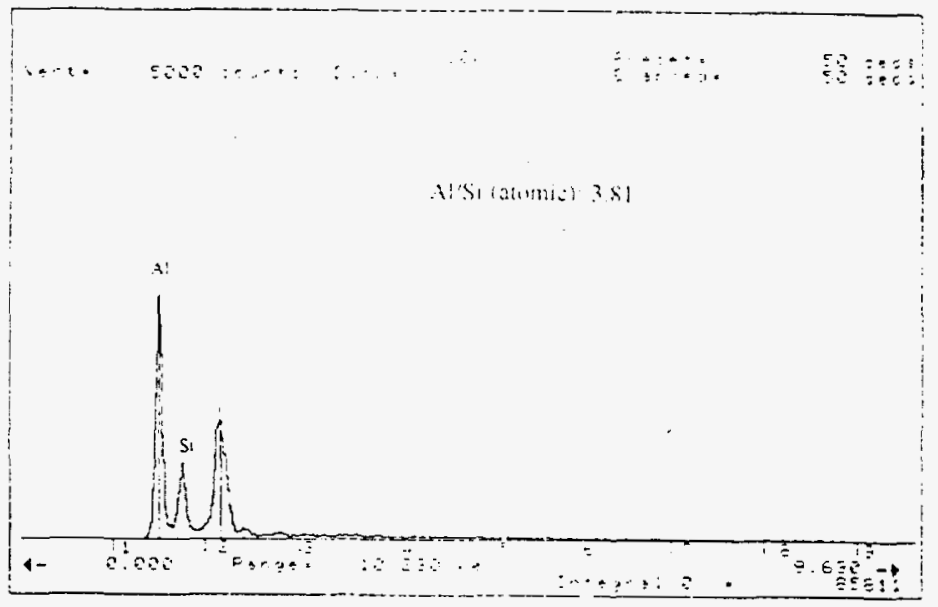

b)

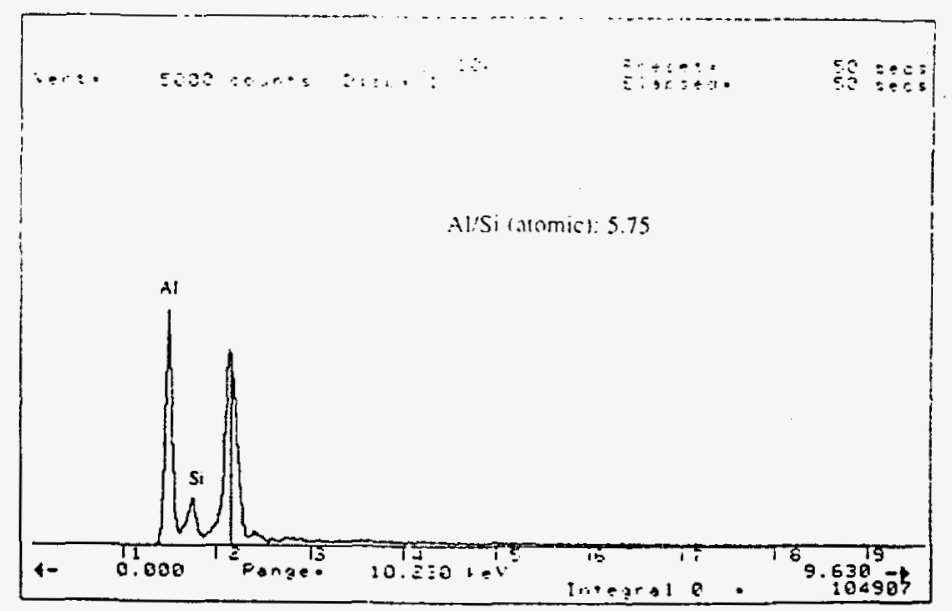

Figure 34 EDS Analysis of Mullite Coating on $\mathrm{Si}_{3} \mathrm{~N}_{4}$ at $950^{\circ} \mathrm{C}$ and a) 50 Torr, and b) 200 Torr; The Unidentified Peak is Conductive Au Coating on the Sample 


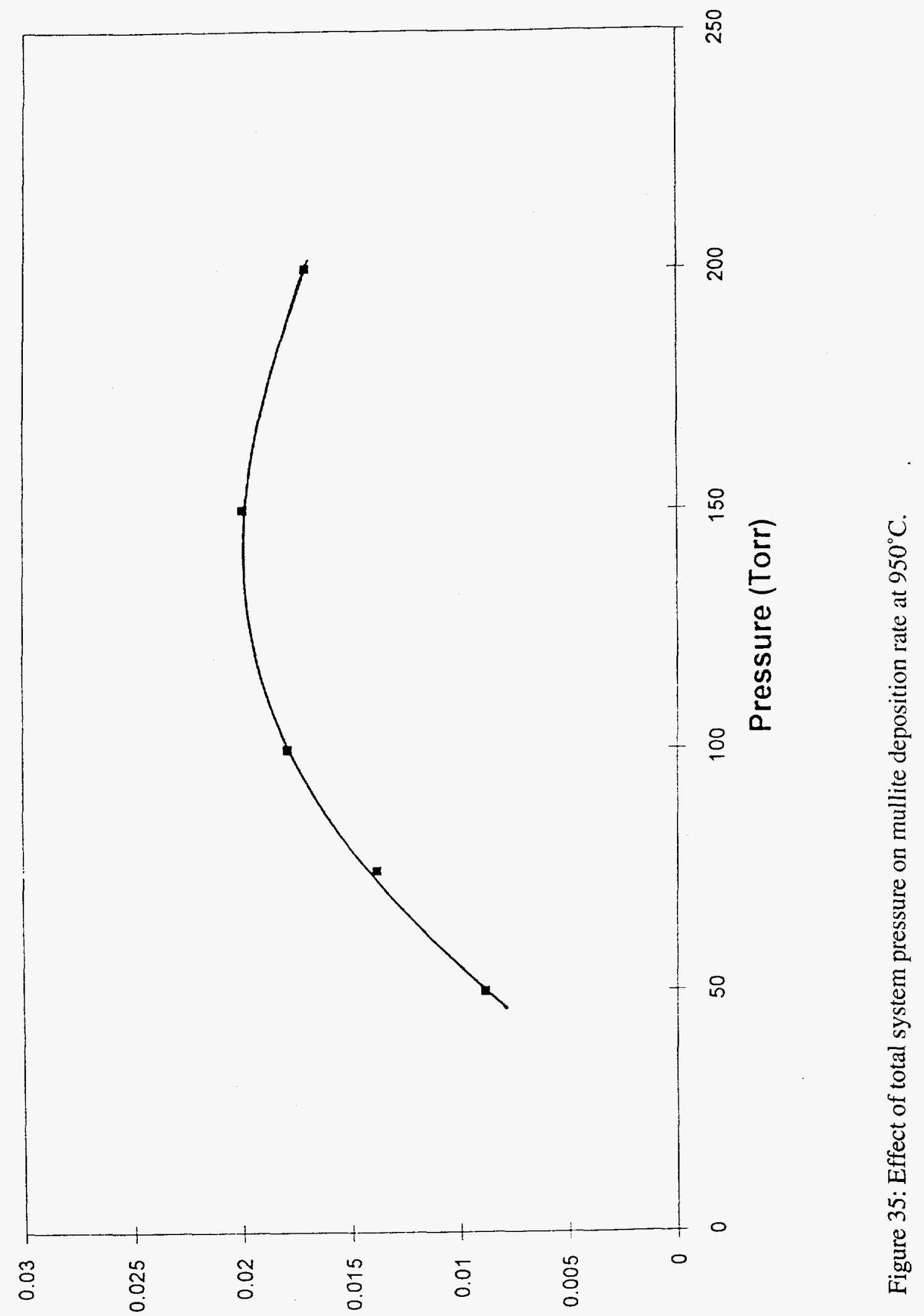

(u!u-zسว/Бw) әреу uo!ł!sodəa 

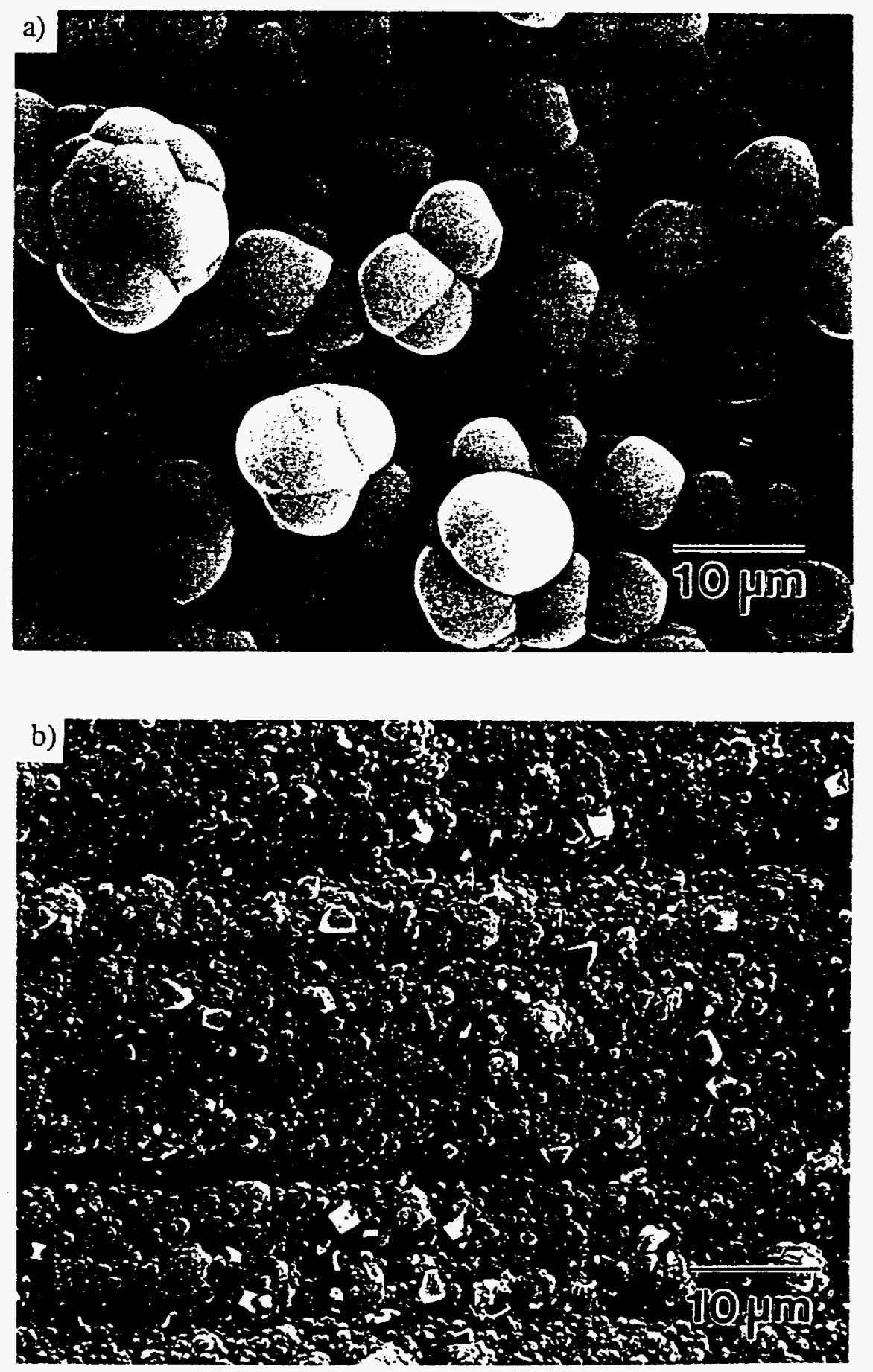

Figure 36 SEM Micrograph of Mullite Coating Deposited on $\mathrm{Si}_{3} \mathrm{~N}_{4}$ at $950{ }^{\circ} \mathrm{C}$ and 75 Torr; Al:Si Ratio in the Input Gas Composition a) $0: 1$, b) $1: 2$, c) $2: 3$, d) $1: 1$, e) $3: 1$, and f) $4: 1$ 

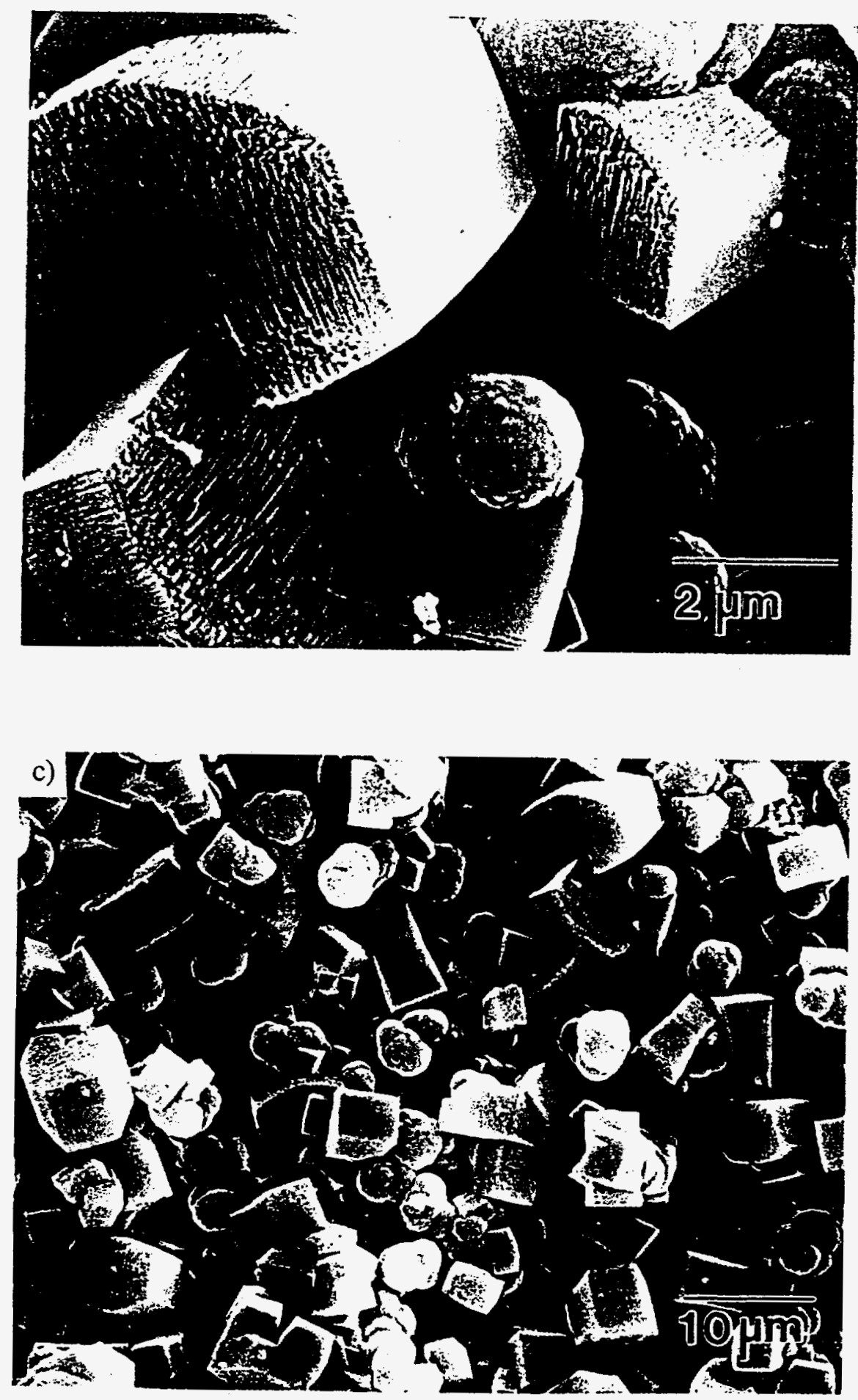

Figure 36 SEM Micrograph of Mullite Coating Deposited on $\mathrm{Si}_{3} \mathrm{~N}_{4}$ at $950{ }^{\circ} \mathrm{C}$ and 75 Torr; Al:Si Ratio in the Input Gas Composition a) 0:1, b) 1:2, c) 2:3, d) 1:1, e) 3:1, and f) 4:1 (Contd.....) 

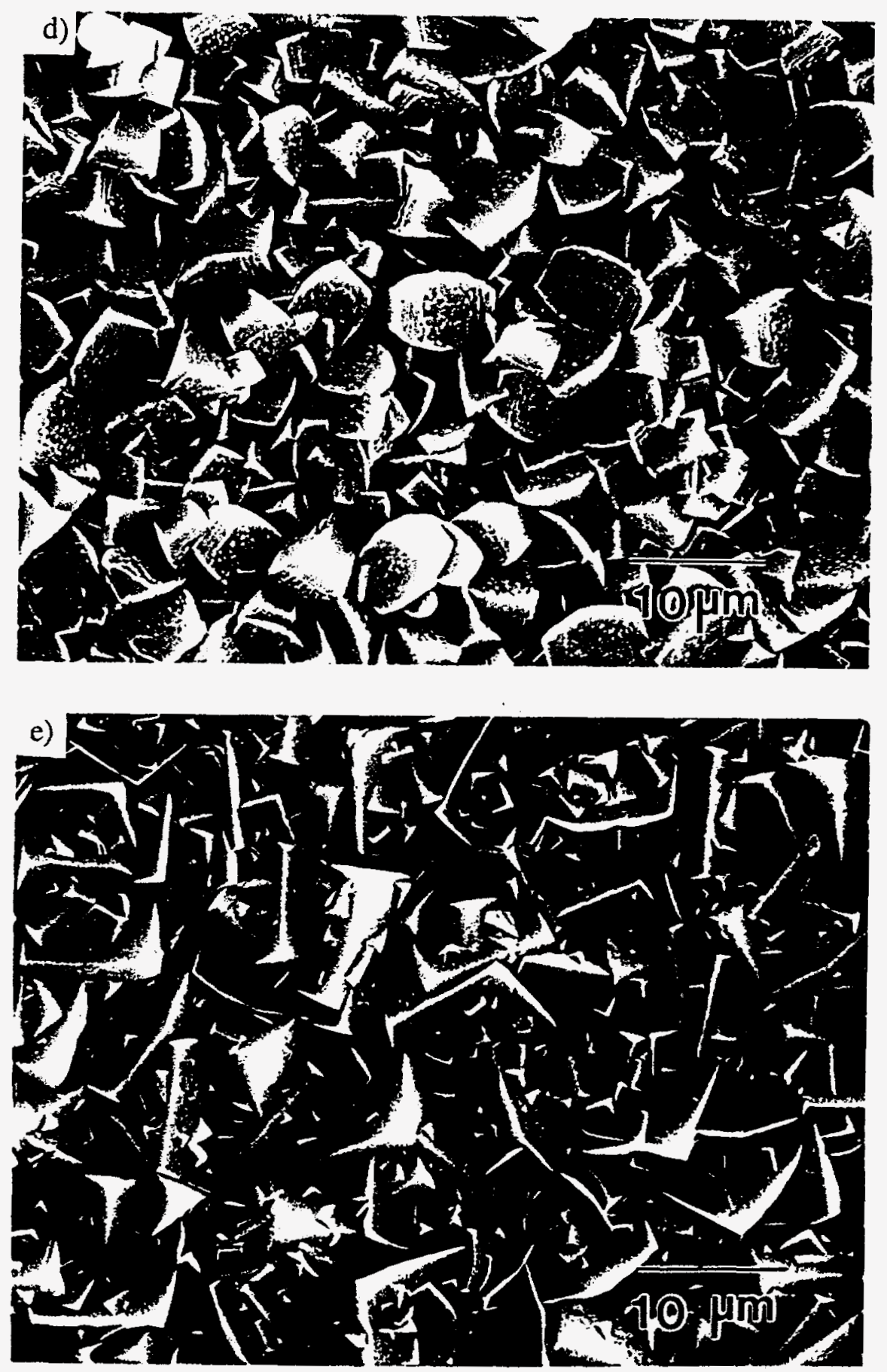

Figure 36 SEM Micrograph of Mullite Coating Deposited on $\mathrm{Si}_{3} \mathrm{~N}_{4}$ at $950{ }^{\circ} \mathrm{C}$ and 75 Torr; Al:Si Ratio in the Input Gas Composition a) 0:1, b) 1:2, c) 2:3, d) 1:1, e) 3:1, and f) 4:1 (Contd.....) 


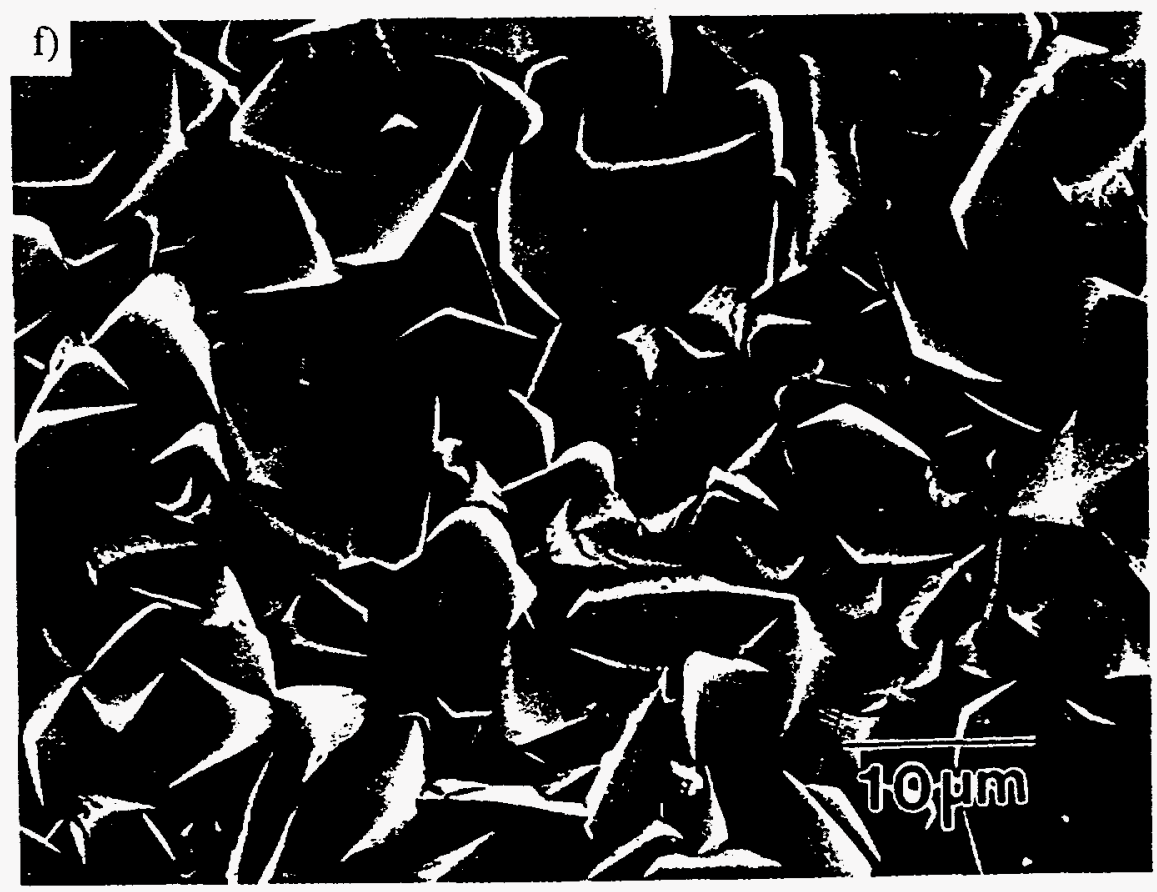

Figure 36 SEM Micrograph of Mullite Coating Deposited on $\mathrm{Si}_{3} \mathrm{~N}_{4}$ at $950^{\circ} \mathrm{C}$ and 75 Torr; Al:Si Ratio in the Input Gas Composition a) $0: 1$, b) $1: 2$, c) $2: 3$, d) $1: 1$, e) $3: 1$, and f) $4: 1$ (Contd.....) 
a)

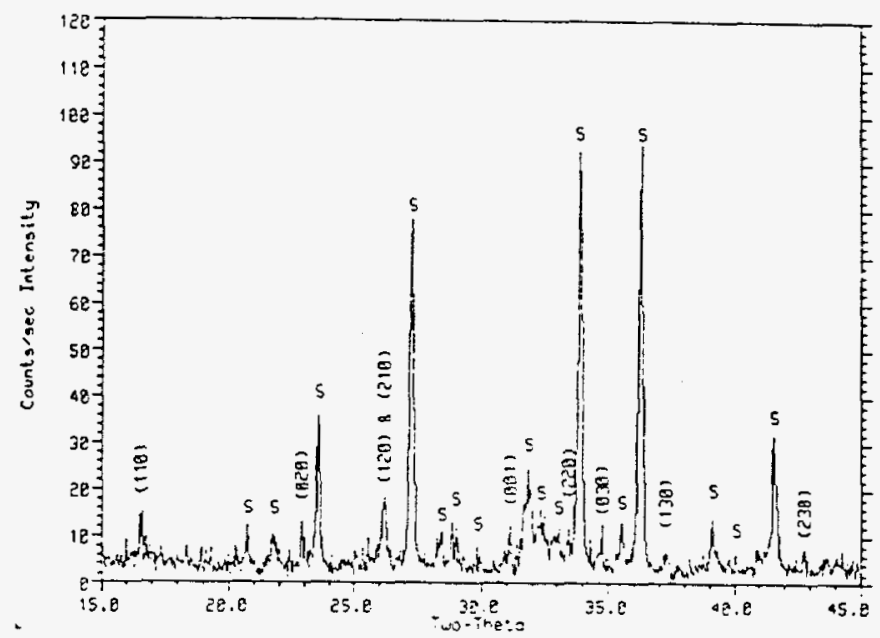

b)

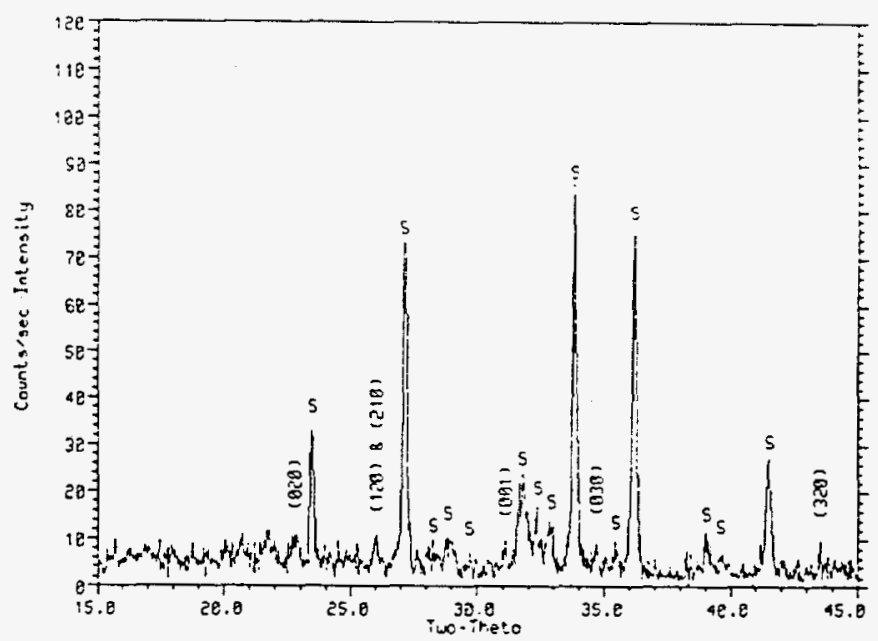

c)

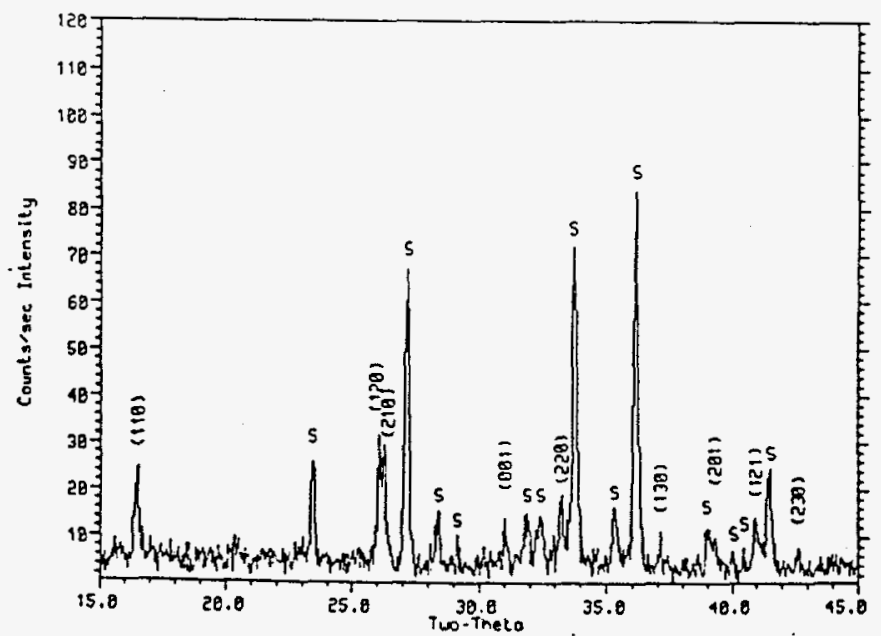

Figure 37. X-Ray Diffraction Pattern of Mullite Coating on $\mathrm{Si}_{3} \mathrm{~N}_{4}$ at $950^{\circ} \mathrm{C}$ and 75 Torr; Al/Si Ratio in the Input Gas Composition: a) 1:2, b) 2:3, and c) $4: 1$ 
a)

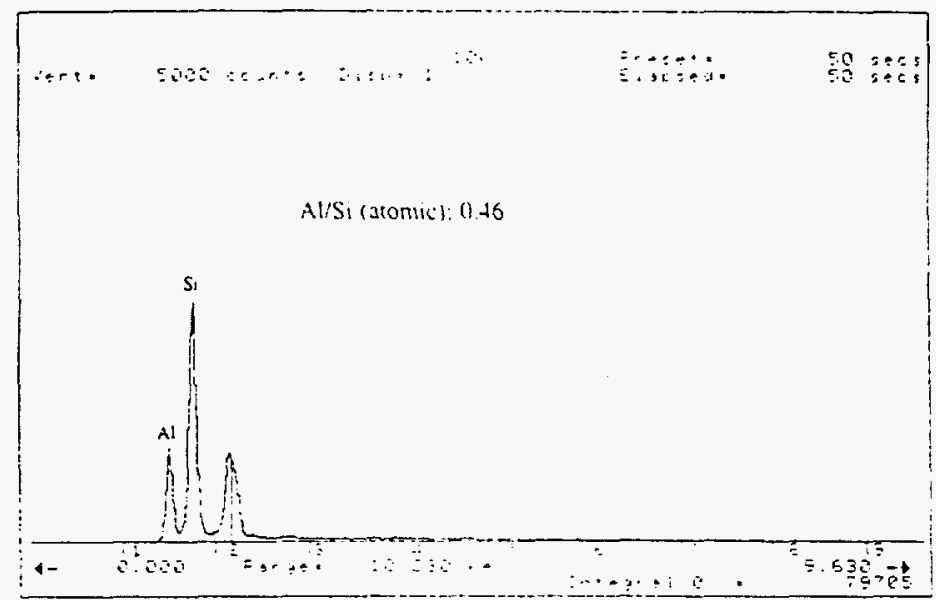

b)

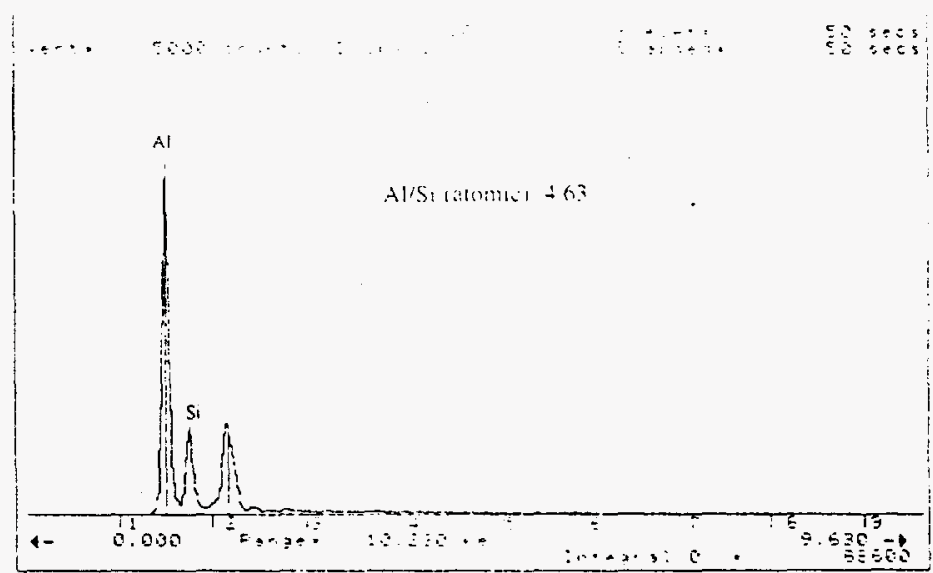

c)

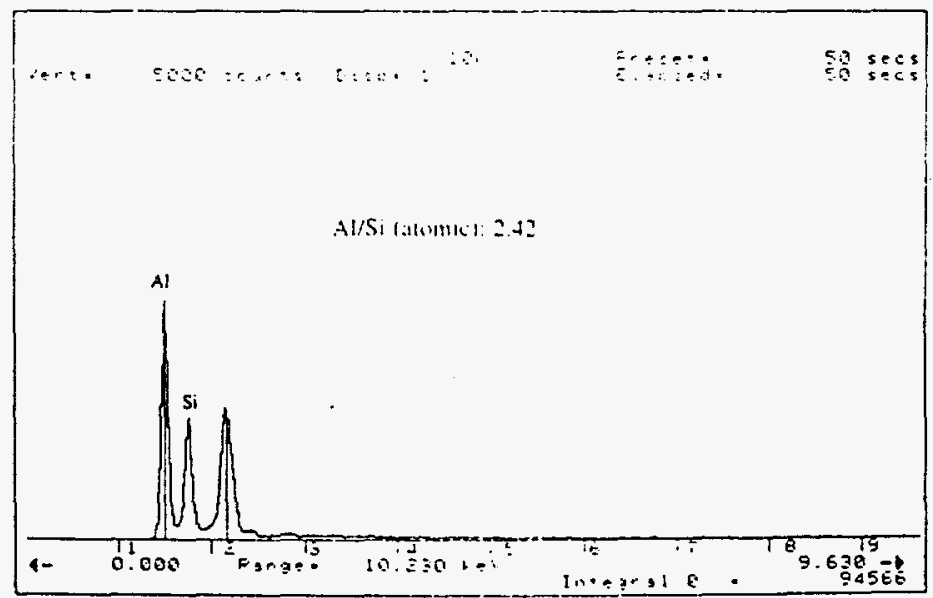

Figure 38 EDS Analysis of Mullite Coating on $\mathrm{Si}_{3} \mathrm{~N}_{4}$ at $950^{\circ} \mathrm{C}$ and $75 \mathrm{Torr}$; Al/Si Ratio in the Input Gas Composition: a) $1: 2$, b) $2: 3$ (Crystalline Region), c) $2: 3$ (Amorphous Region), d) $1: 1$, and e) $4: 1$; The Unidentified Peak is Conductive Au Coating on the Sample 
d)

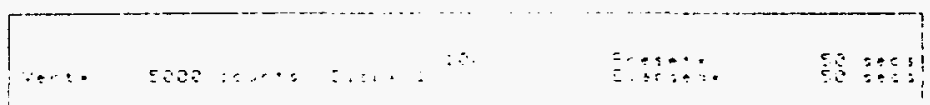

Alisigtomis) : y

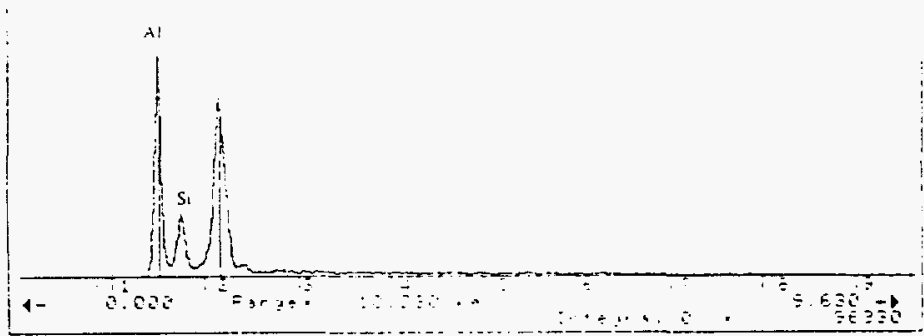

e)

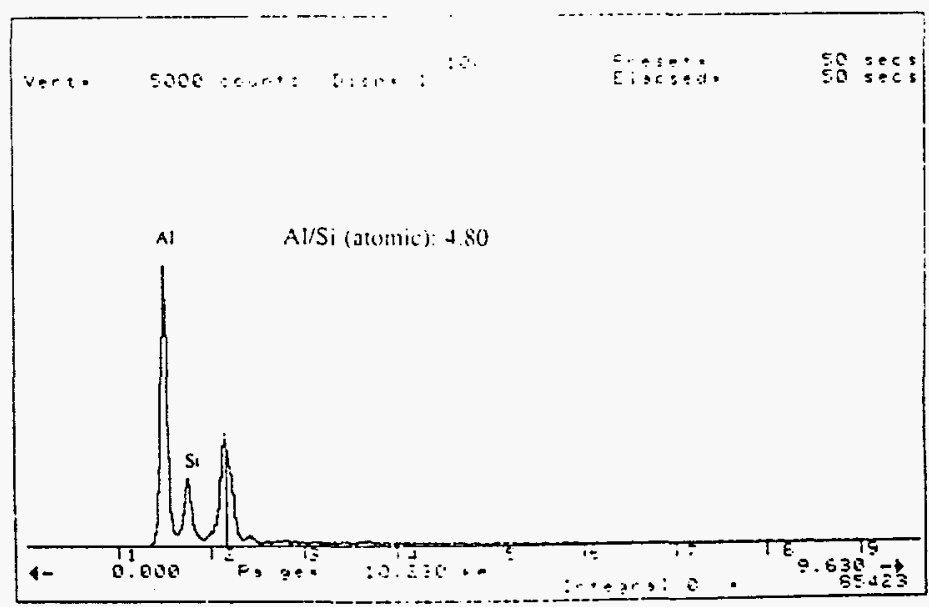

Figure 38 EDS Analysis of Mullite Coating on $\mathrm{Si}_{3} \mathrm{~N}_{4}$ at $950{ }^{\circ} \mathrm{C}$ and $75 \mathrm{Torr} ; \mathrm{Al} / \mathrm{Si}$ Ratio in the Input Gas Composition: a) 1:2, b) 2:3 (Crystalline Region), c) 2:3 (Amorphous Region), d) 1:1, and e) 4:1; The Unidentified Peak is Conductive Au Coating on the Sample (Contd.....) 


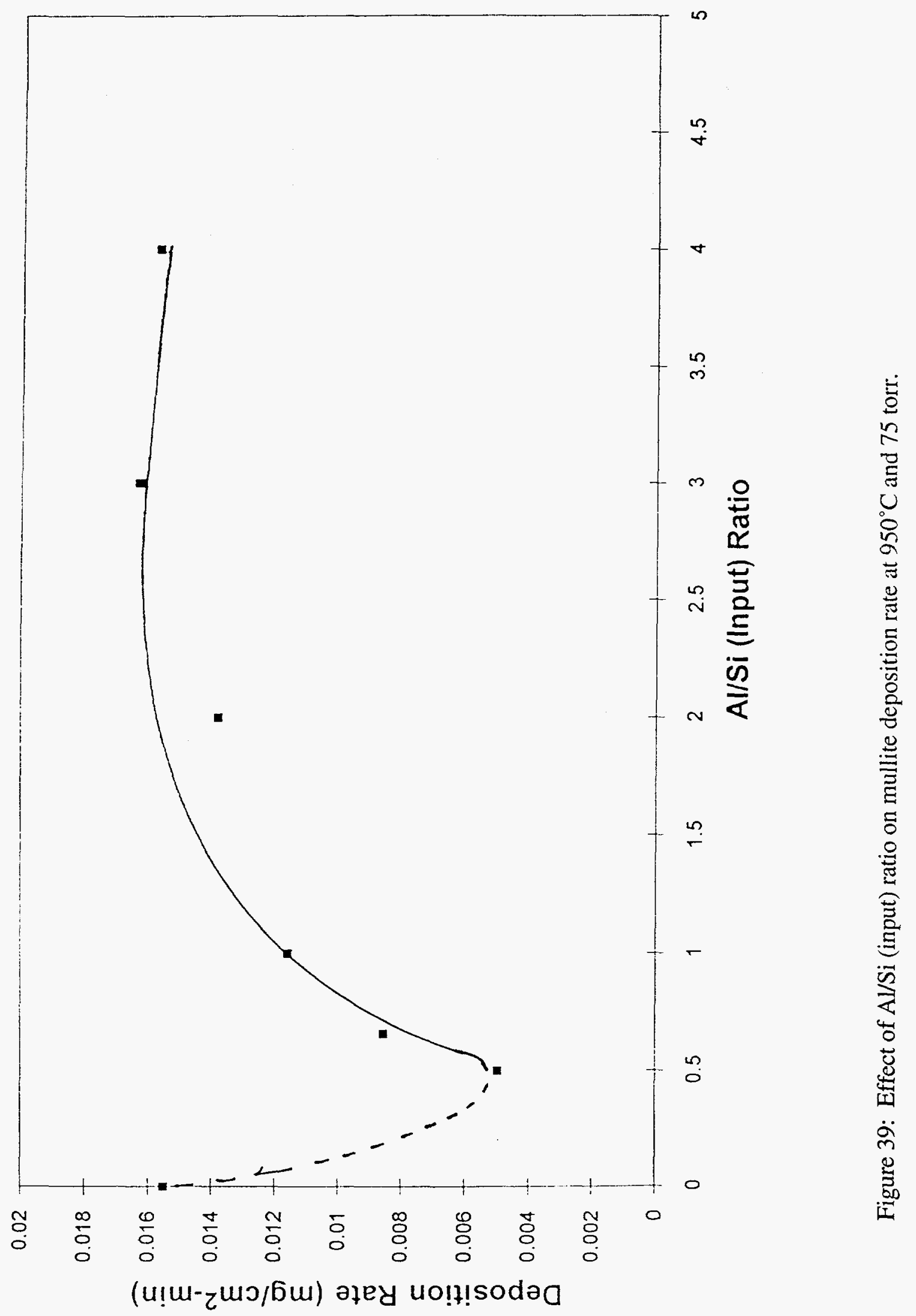



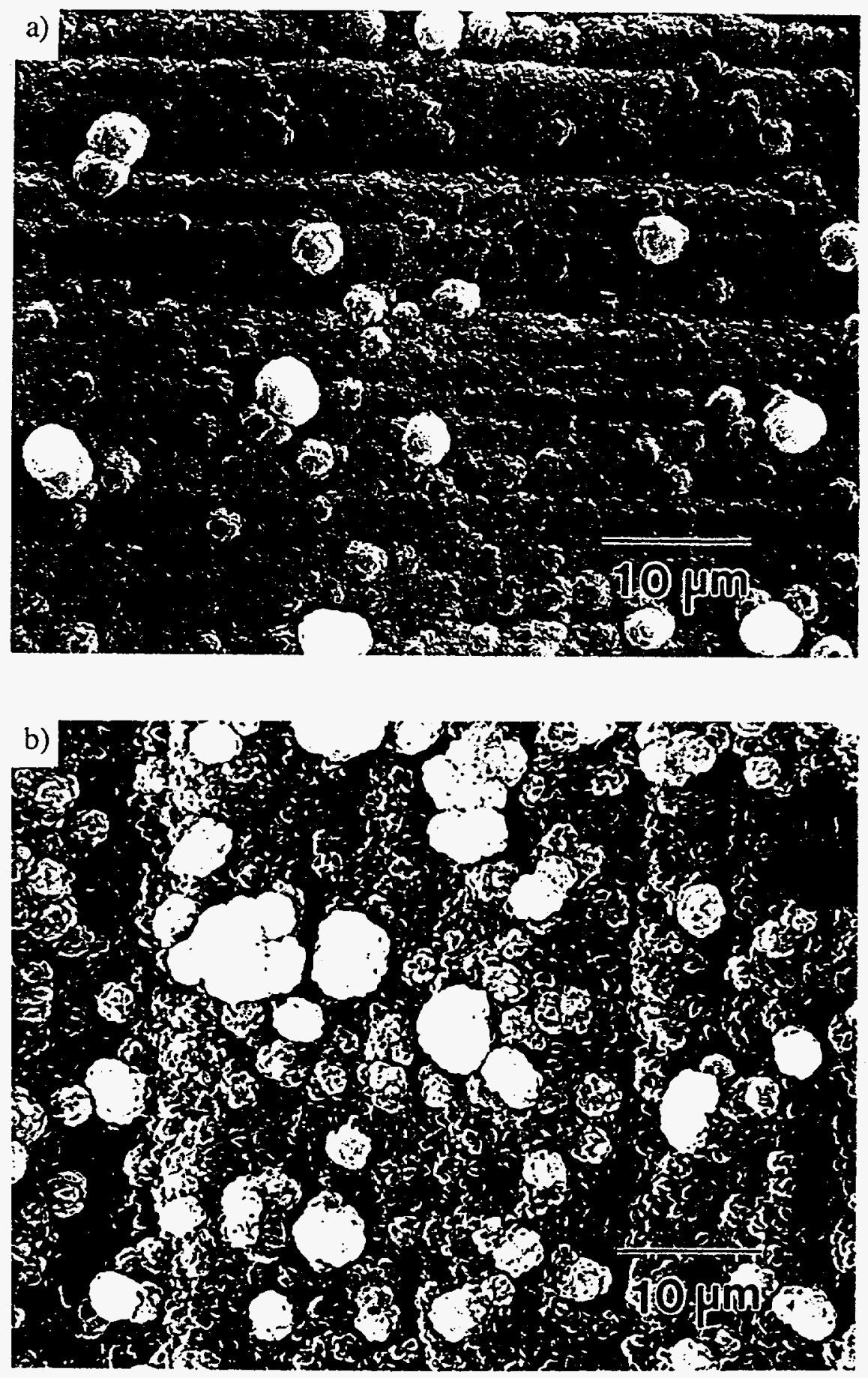

Figure 40 SEM Micrograph of Mullite Coating Deposited on $\mathrm{Si}_{3} \mathrm{~N}_{4}$ at $950^{\circ} \mathrm{C}$ and 75 Torr; Deposition Time: a) 30 Minutes, b) 60 Minutes, c) 90 Minutes, and d) 150 Minutes 


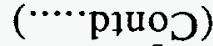

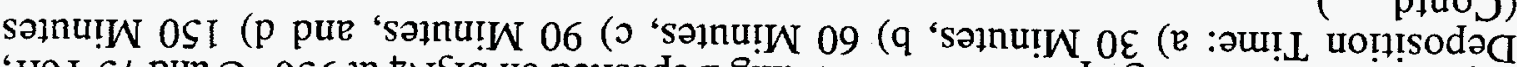

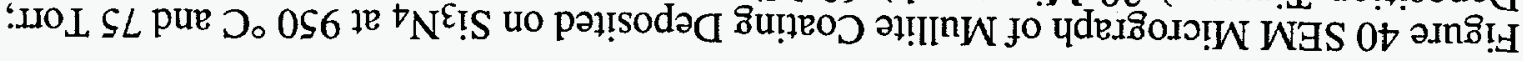
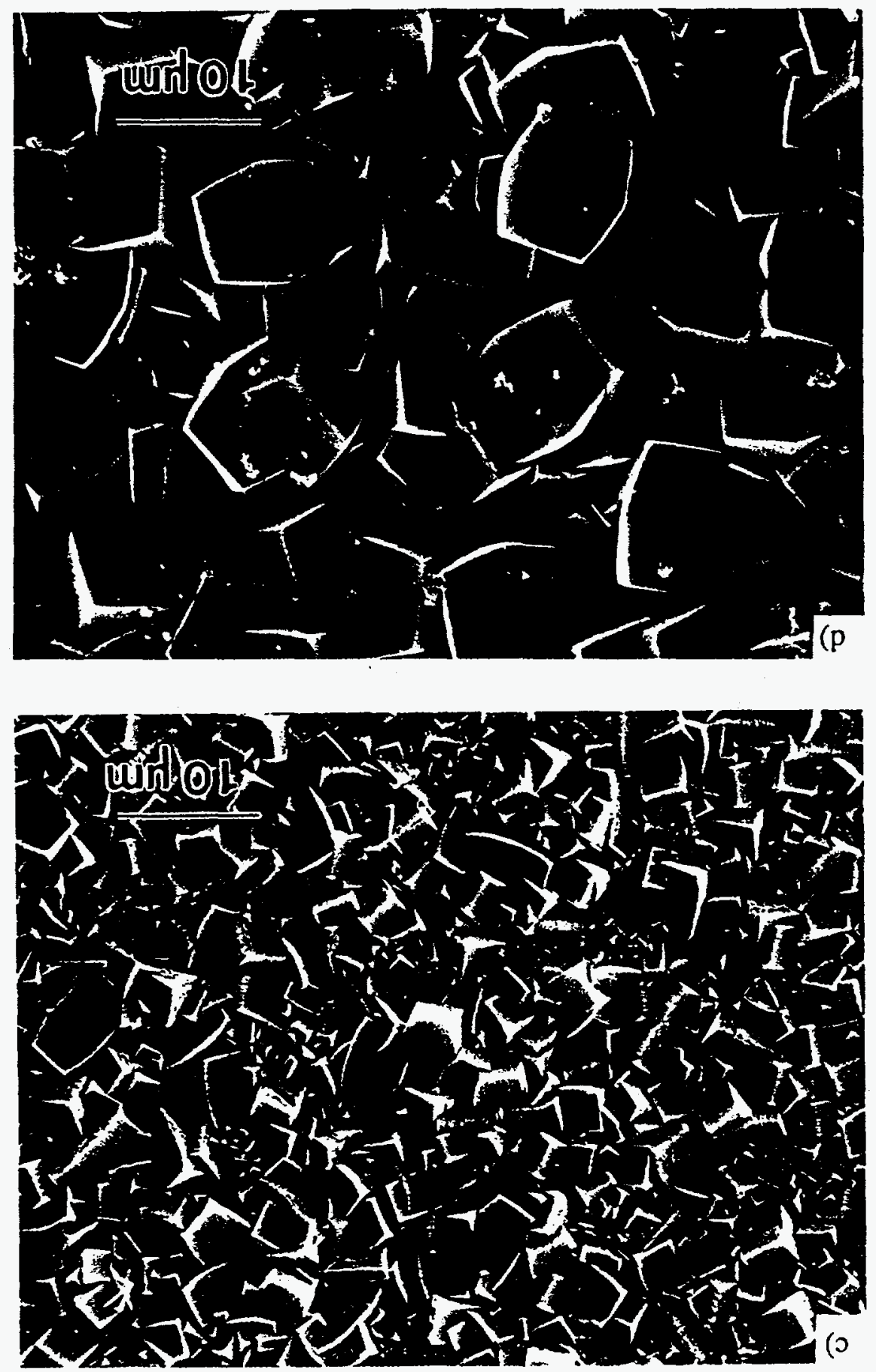
a)

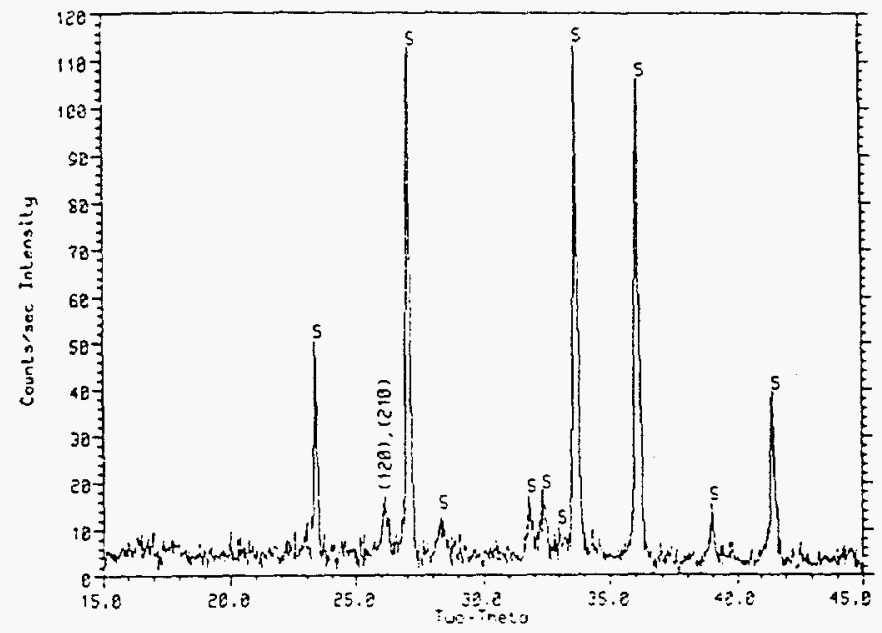

b)

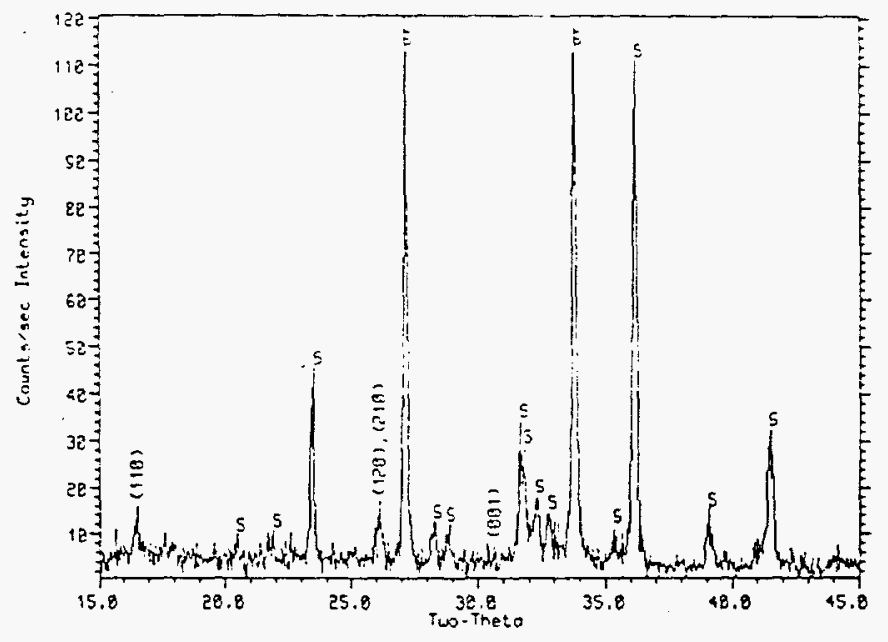

c)

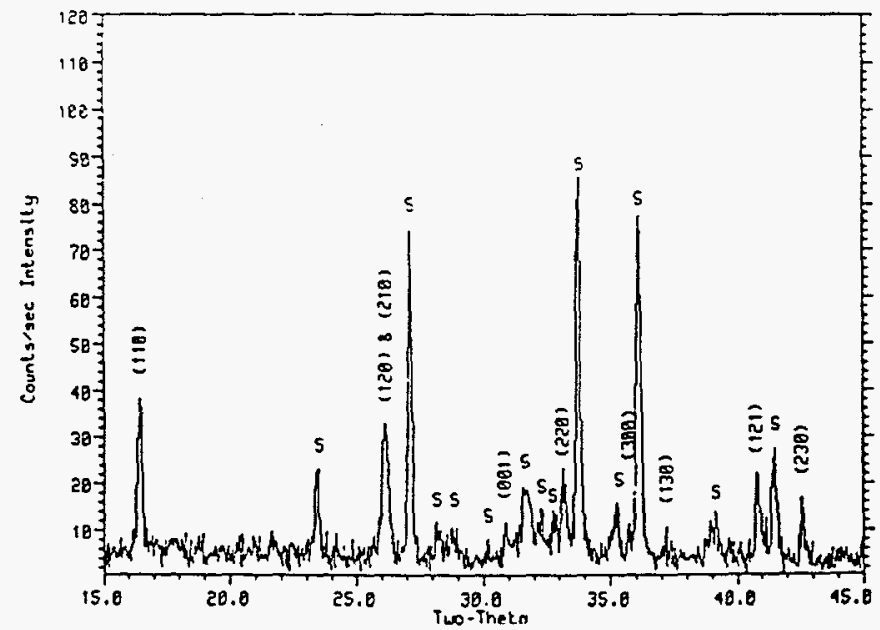

Figure 41 X-Ray Diffraction Pattern of Mullite Coating on $\mathrm{Si}_{3} \mathrm{~N}_{4}$ at $950{ }^{\circ} \mathrm{C}$ and 75 Torr; Deposition Time: a) 60 Minutes, b) 90 Minutes, and c) 150 Minutes 

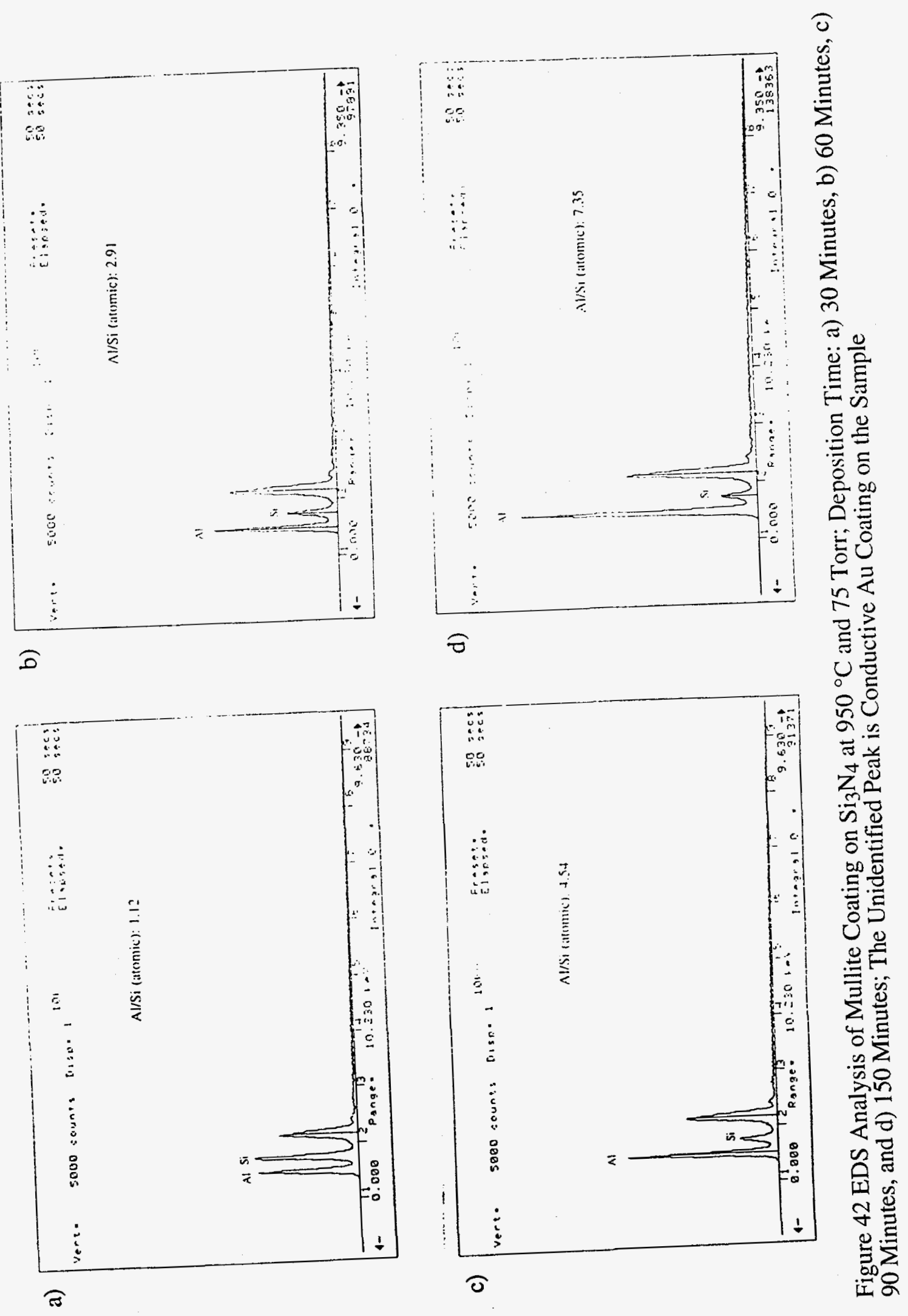


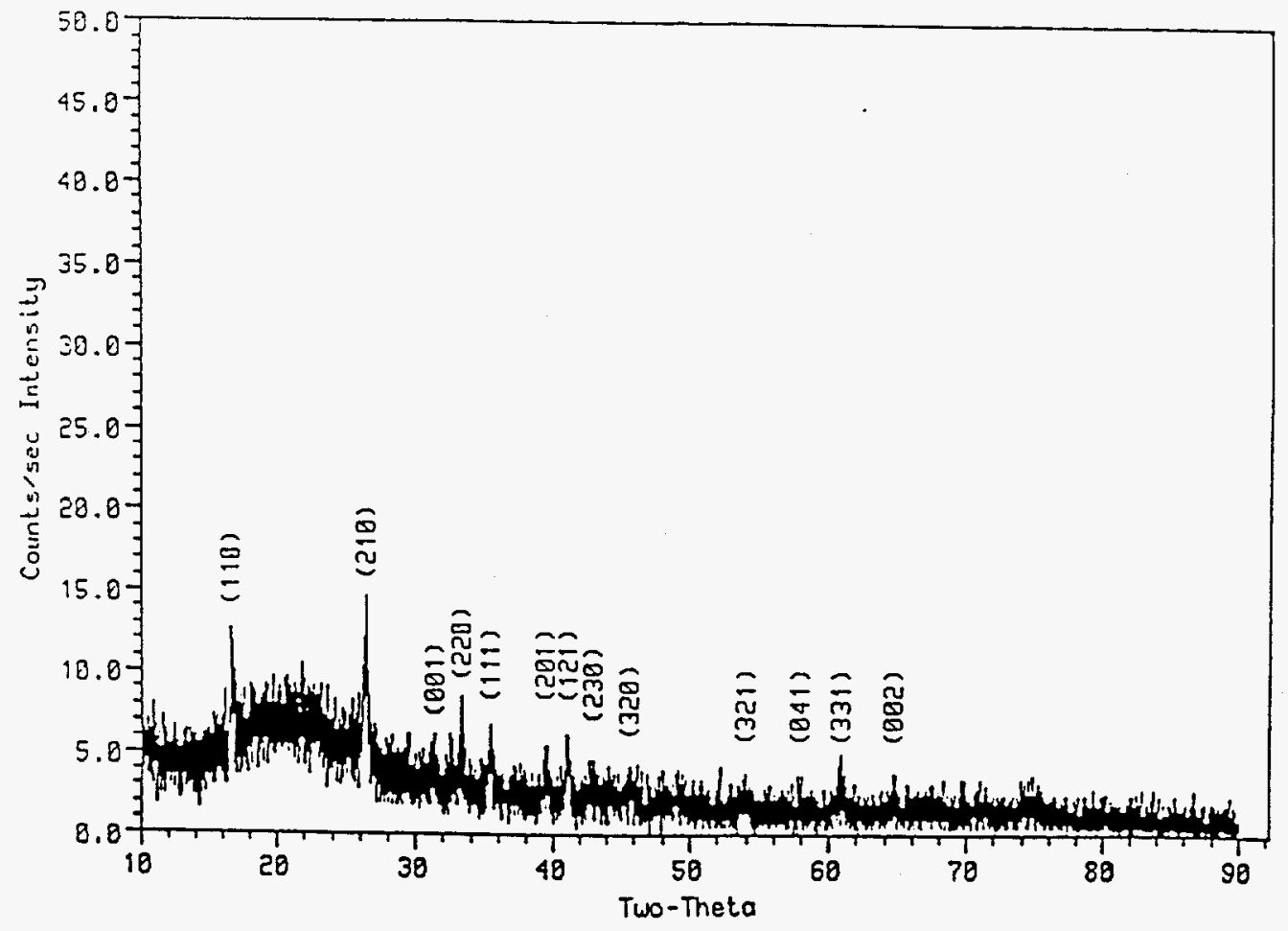

Figure 43 X-Ray Diffraction Pattern of CVD Mullite Powder; The "Hump" in the Lower $2 \theta$ Angles Suggests that there is a Certain Amount of Amorphous Phase 

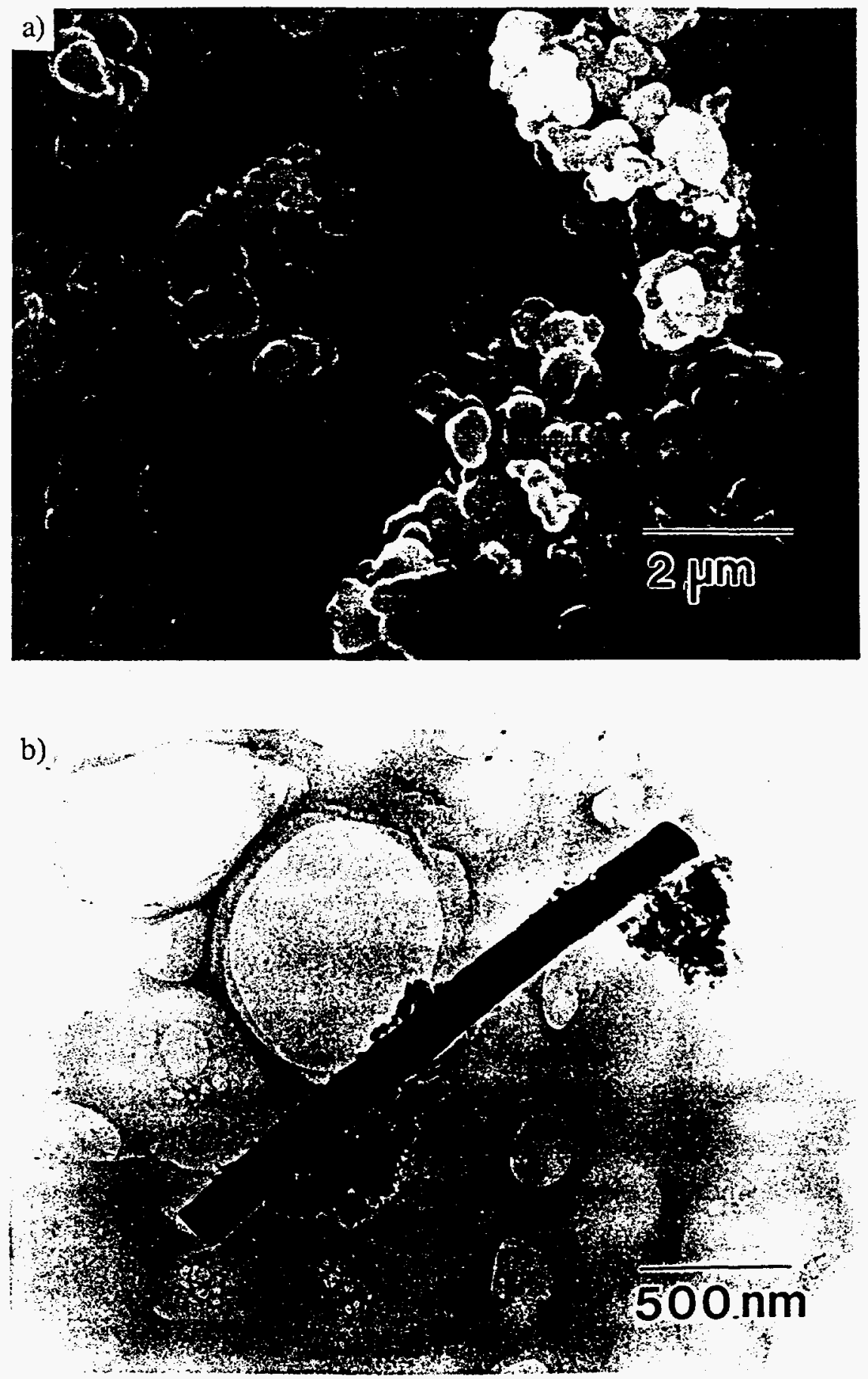

Figure 44 a) SEM Micrograph, and b) TEM Micrograph of Mullite Powder Showing High Orientation Effect 

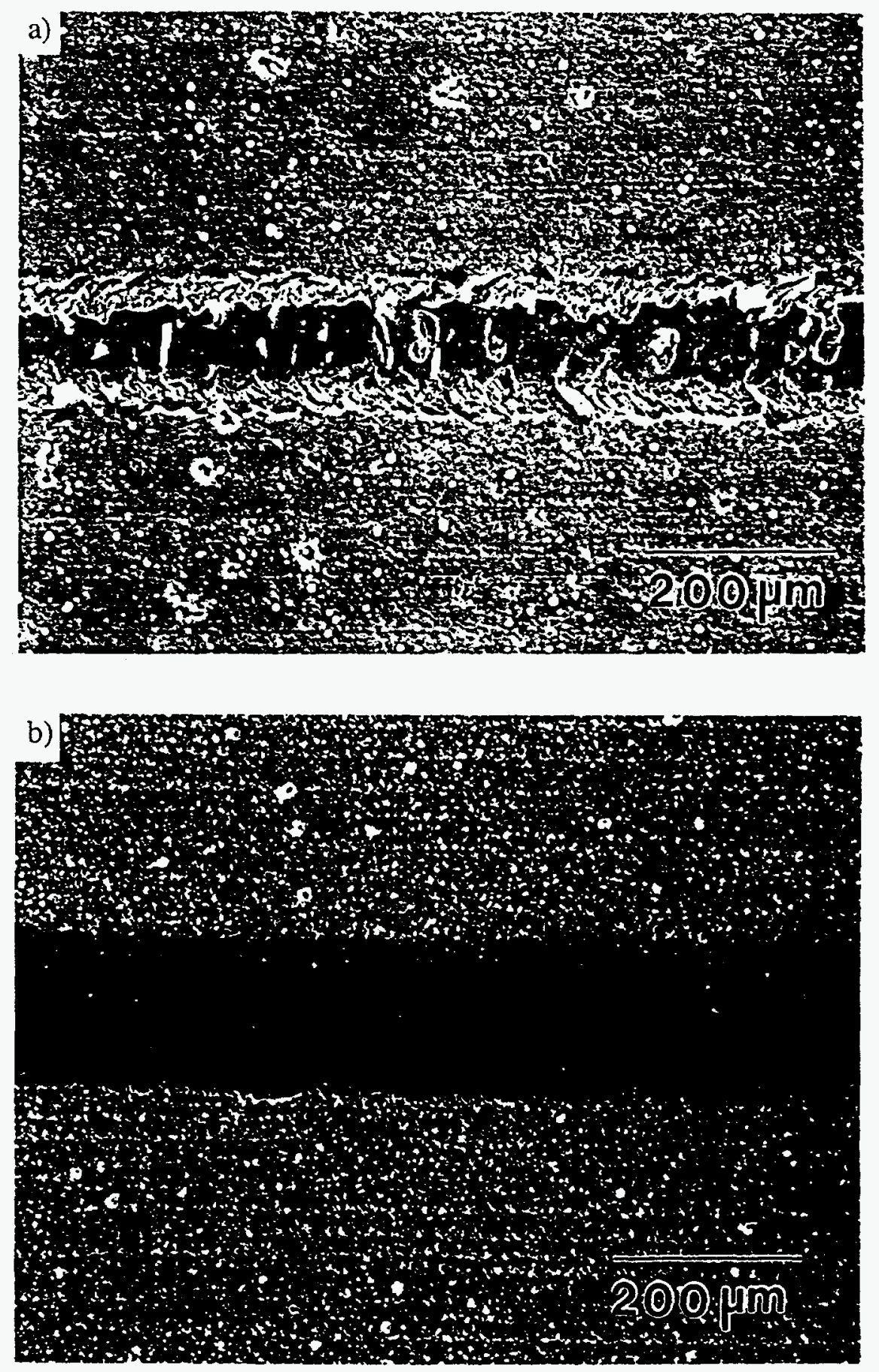

Figure 45 Macro-Scratch Track of Mullite Coating on a) SiC Showing Failure, and b) $\mathrm{Si}_{3} \mathrm{~N}_{4}$ Showing No Failure 


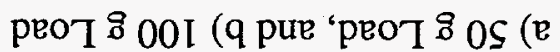

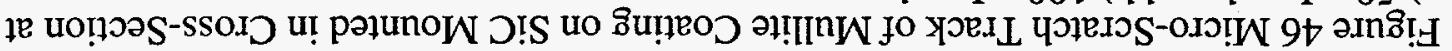
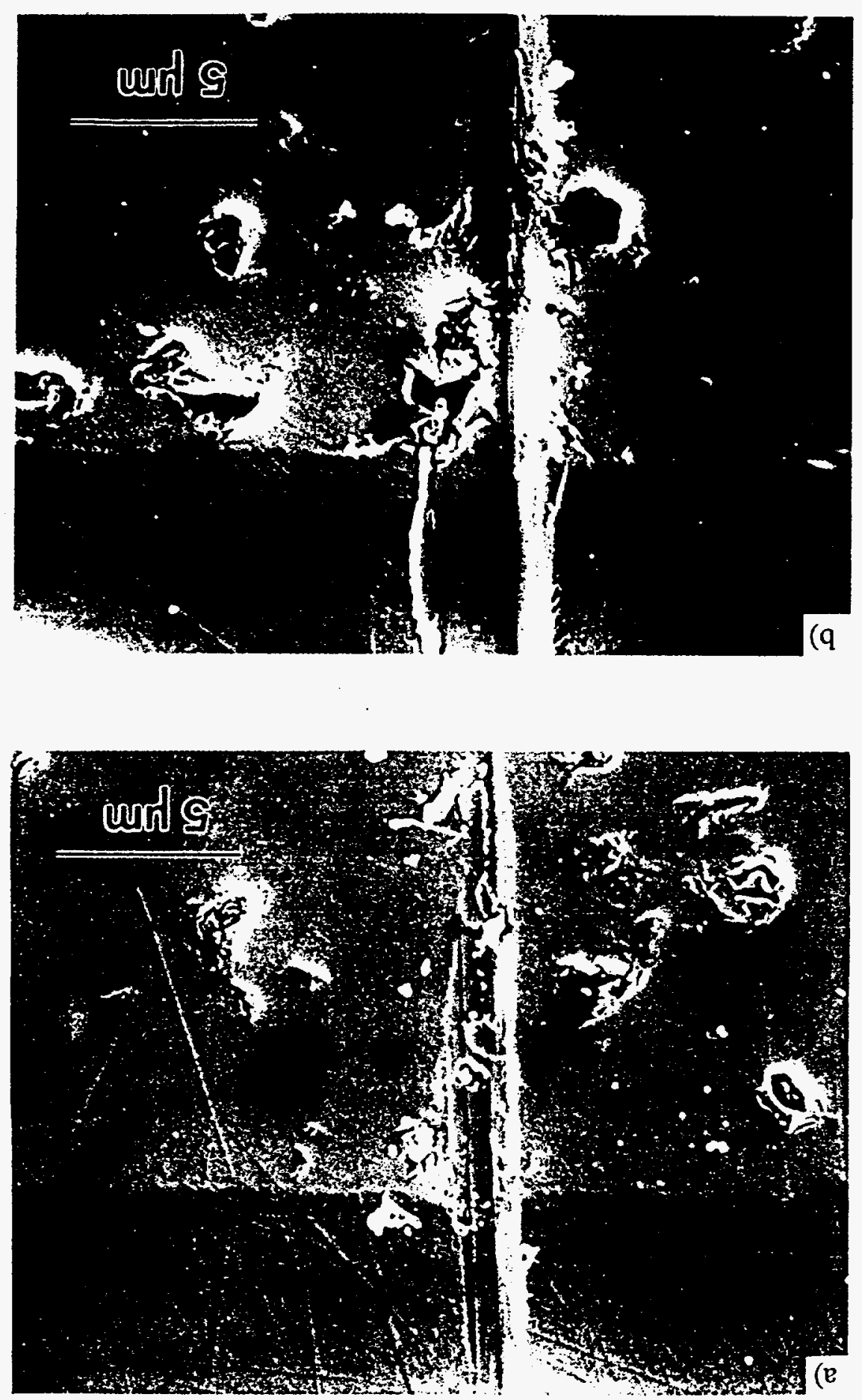

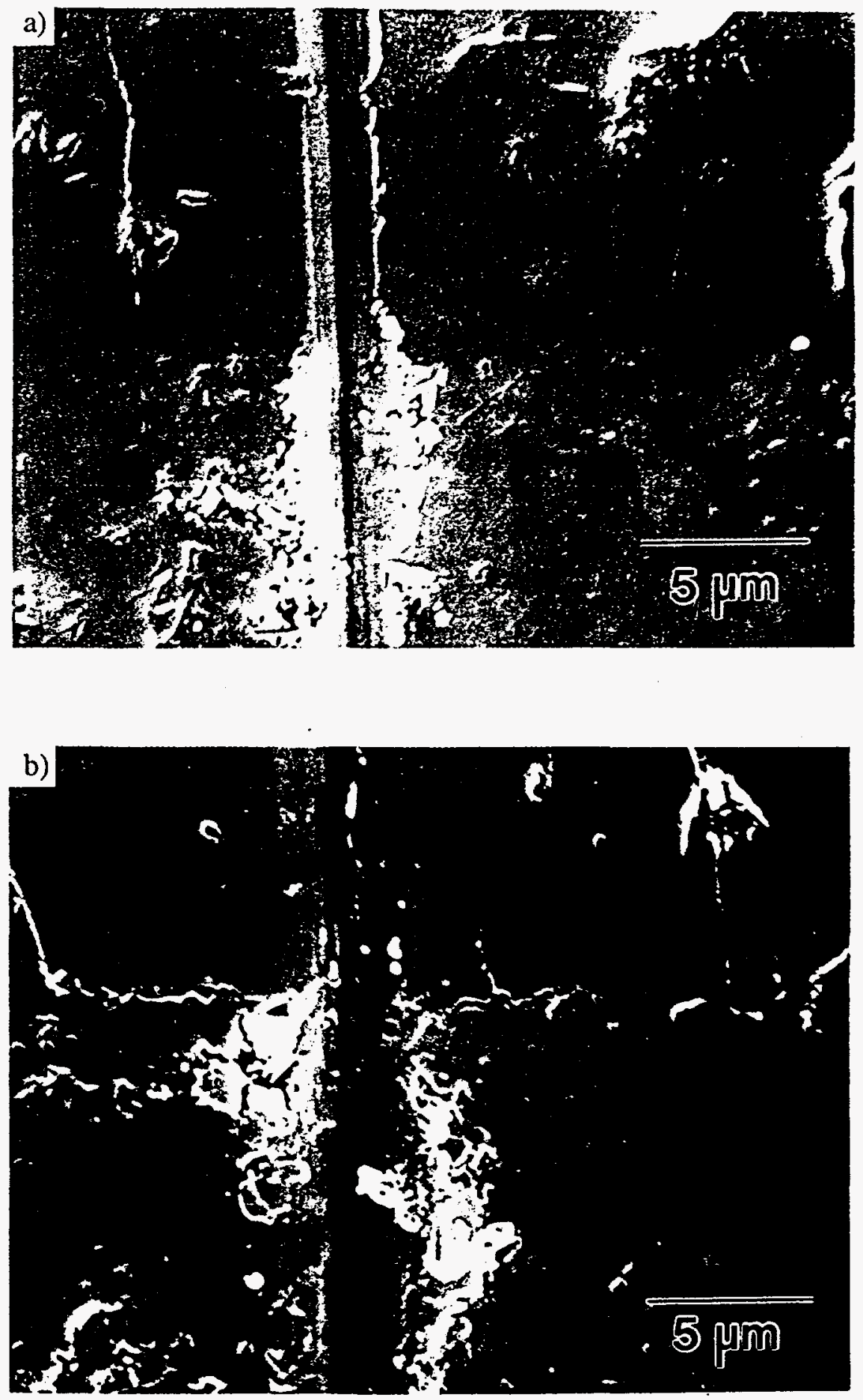

Figure 47 Micro-Scratch Track of Mullite Coating on $\mathrm{Si}_{3} \mathrm{~N}_{4}$ Mounted in Cross-Section at a) $50 \mathrm{~g}$ Load, and b) $100 \mathrm{~g}$ Load 

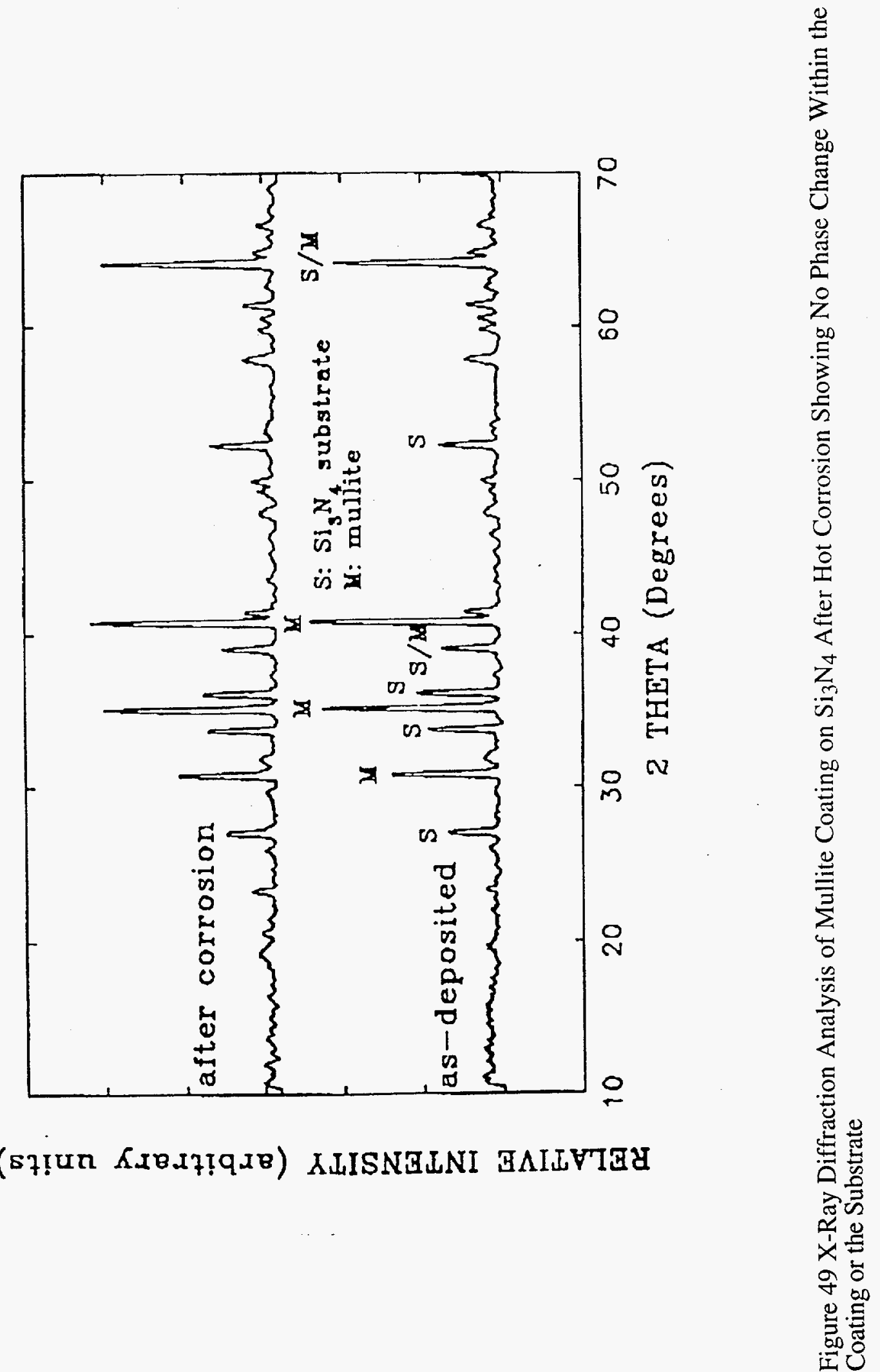


\section{REFERENCES}

1. L.E. Groseclose, and J. Chang, Proc. of the 20th Automotive Technology Development Contractors Coordination Meeting, p. 181, Dearborn, MI (1982)

2. D.W. Richerson, "Modern Ceramic Engineering," pp. 126, Mercel Dekker Inc., New York (1982)

3. G.L. Boyd, and D.M. Kreiner, "AGT101/Advanced Turbine Technology Applications Project (ATTAP)," Proceedings of the Twenty-Sixth Automotive Technology Development Contractors' Coordination Meeting, pp. 275-280, Society of Automotive Engineers, Warrandale, PA, 1989

4. A.F. McLean, "Materials Approach to Engine/Component Design," Ceramic Materials and Components for Engines, Proceedings of the Second International Symposium, W. Bunk, and H. Hausner, Eds., Verlag Deutsche Keramische Gesellschaft, pp. 1023-1034, Bad Honnef, Germany, 1986

5. J.I. Federer, T.N. Tiegs, D.M. Kotchick, and D. Petrak, "Analysis of Candidate Silicon Carbide Recuperator Materials Exposed to Industrial Furnace Environments," Report No. ORNL/TM-9677, Oak Ridge National Laboratory, Oak Ridge, TN, 1985 
6. N.S. Jacobson, and J. Smialek, "Hot Corrosion of Sintered a-SiC at $1000^{\circ} \mathrm{C}$," J. Am. Ceram. Soc., 68 (8) 432-9 (1985)

7. D.W. McKee, and D. Chatterji, "Corrosion of silicon carbide in gases and alkali melts," J. Am. Ceram. Soc. 59 (9-10), 441-4 (1976)

8. Advanced Gas Turbine Powertrain System Development for Automotive Applications, 2nd Semiannual Progress Report, July-Dec 1980, NASA-CR-165329, July 1981, Garrett Turbine Engine Company

9. J. Schienle, and J. Smyth, "High Temperature Coating Study to Reduce Contact Stress Damage of Ceramics," Final Report, ORNL/Sub/84-47992/1 (1987).

10. S. Stecura, "Optimization of the Ni-Cr-Al- ${\mathrm{Y} / Z \mathrm{ZO}_{2}}_{2}-\mathrm{Y}_{2} \mathrm{O}_{3}$ Thermal Barrier System," Adv. Ceram. Mater., 1 [1] 68-76 (1986)

11. W.J. Lackey, D.P. Stinton, G.A. Cerny, L.L. Fehrenbacher, and A.C. Schaffhauser, Oak Ridge National Laboratory Report, ORNL/TM-8959 (1984)

12. C. D'Angelo, H.E. Rebenne, D. Oblas, and V.K. Sarin, Proceedings of the 26th Annual Automotive Technology Development Contractors Coordination Meeting, p. 219, Dearborn, MI, 1988

13. J.I. Federer, "Alumina base coatings for protection of SiC Ceramics," J. Mater. Eng. $12,141-9(1990)$ 
14. K.N. Lee, R.A. Miller, and N.S. Jacobson, "Development of thermal shock resistant mullite coatings on silicon carbide," Advances in Ceramic-Matrix Composites, Ceramic Transactions, Vol. 38, Bansal, N.P., Ed., The American Ceramic Society, Westerville, Ohio, 565-75 (1994)

15. W.E. Sawyer, and A. Man, U.S. Patent 229,335 (June 29, 1880)

16. J.W. Aylsworth. U.S. Patent 553,296 (January 21, 1896)

17. W.A. Bryant, "Chemical Vapor Deposition," Surface Modification Engineering, Volume I: Fundamental Aspects, R. Kassowsky, Ed., pp. 189-229, The CRC Press, Boca Raton, FL (1989)

18. F. Brossa, "Developments and Applications of CVD Ceramic Coatings," Industrial Ceramics, Vol. 9, No. 3 (1989)

19. V.K. Sarin, "Design and Development of Chemically Vapor Deposited Coatings," J. Hard Materials, Vol. 2, No. 1-2 (1991)

20. V.K. Sarin, "Systematic Development of Customized CVD Coatings," Surface and Coatings Technology, Vol. 73, pp. 23-33 (1995)

21. M.A. Gevelber, M.T. Quinones, M.L. Bufano, "Dynamic Modelling of CVD for Real-Time Control of Microstructure," in Chemical Vapor Deposition of Refractory Metals and Ceramics III, pp 33-38, Proceedings of the Materials Research Society, Gallois, et. al., Eds., Vol. 363, Boston, MA, Nov/Dec 1994 
22. W.L. deKaiser, Science of Ceramics, Vol. II, p. 243, Academic Press, NY (1963)

23. W.D. Kingery, H.K. Bowen, and D.R. Uhlmann, Introduction to ceramics, 2nd ed., p. 76, Wiley, New York, NY (1976)

24. M.D. Sacks, N. Bozkurt, and G.W. Scheiffele, "Fabrication of Mullite and MulliteMatrix Composites by Transient Viscous Sintering of Composite Powders," J. Am. Ceram. Soc., 74 [10] 2428-37 (1991)

25. W.Y. Lee, Y.W. Bae, and D.P. Stinton, "Na2 $\mathrm{SO}_{4}$-Induced Corrosion of $\mathrm{Si}_{3} \mathrm{~N}_{4}$ Coated with Chemically Vapor Deposited $\mathrm{Ta}_{2} \mathrm{O}_{5}$," Journal of American Ceramic Society, Vol. 78, No. 7, pp. 1927-1930 (1995)

26. V.K. Sarin, "Micro-scratch test for adhesion evaluation of thin films," Journal of Adhesion Science and Technology, Vol. 7, No. 12, pp. 1265-1278 (1993)

27. V.L. Rabinovich, and V.K. Sarin, "Modelling of Interfacial Fracture," presented at the Fifth International Conference on the Science of Hard Materials, Maui, HI, Feb. 20-24 (1995)

28. G. Oertel, and H. Flietner, "Isolationsschichten Auf Germanium Und Deren Elektrische Eigenschaften," Proceedings of the Second Colloquium on Thin Films, pp. $626-635$ (1967)

29. J.E. Sundgren, and H.G. Hentzell, J. Vac. Sci. Technol., Vol. A4, p. 2259 (1986) 
30. D. Doppalapudi, R. Mulpuri, S.N. Basu, and V.K. Sarin, "Phase Transformations in Multilayered CVD Mullite Coatings," in Chemical Vapor Deposition of Refractory Metals and Ceramics III, pp. 95-100, Proceedings of Materials Research Society, Vol. 363, Boston, MA, Nov/Dec (1994)

31. D. Doppalapudi, "Structure and Phase Transformations in CVD Mullite Coatings," Boston University, MS Thesis (1995)

32. W.Y. Lee, K.L. More, D.P. Stinton, and Y.W. Bae, "Characterization of $\mathrm{Si}_{3} \mathrm{~N}_{4}$ Coated with Chemically Vapor Deposited Mullite after $\mathrm{Na}_{2} \mathrm{SO}_{4}$ Induced Corrosion," to appear as Communication in Journal of the American Ceramic Society (1995) 
3M COMPANY

Ceramic Materials Department

201-4N-01 3M Center,

St. Paul, MN 55144

M. A. Leitheiser

AIR PRODUCTS AND CHEMICALS

P.O. Box 538

Allentown, PA 18105

$S$. W. Dean

\section{ALLISON GAS TURBINE DIVISION}

P.O. Box 420

Indianapolis, IN 46206-0420

P. Khandelwal (Speed Code W-5)

R. A. Wenglarz (Speed Code W-16)

\section{AMA RESEARCH \& DEVELOPMENT}

CENTER

5950 McIntyre Street

Golden, CO 80403

T. B. Cox

ARGONNE NATIONAL LABORATORY 9700 S. Cass Avenue

Argonne, IL 60439

W. A. Ellingson

J. P. Singh

ARGONNE NATIONAL

LABORATORY-WEST

P.O. Box 2528

Idaho Falls, ID 83403-2528

S. P. Henslee

BABCOCK \& WILCOX

Domestic Fossil Operations

20 South Van Buren Avenue

Barberton, $\mathrm{OH} 44023$

M. Gold

\section{BRITISH COAL CORPORATION}

Coal Technology Development Division

Stoke Orchard, Cheltenham

Glocestershire, England GL52 4ZG

J. Oakey

CANADA CENTER FOR MINERAL \& ENERGY TECHNOLOGY

568 Booth Street

Ottawa, Ontario

Canada K1A OG1

R. Winston Revic

Mahi Sahoo

DOE

DOE OAK RIDGE OPERATIONS

P.O.Box 2001

Oak Ridge, TN 37831

Assistant Manager for

Energy Research and Development

DOE

DOE OAK RIDGE OPERATIONS

P. O. Box 2008

Building 4500N, MS 6269

Oak Ridge, TN 37831

M. H. Rawlins

DOE

OFFICE OF BASIC ENERGY SCIENCES

Materials Sciences Division

ER-131

19901 Germantown Road

Germantown, MD 20874-1290

H. M. Kerch

DOE

IDAHO OPERATIONS OFFICE

P. O. Box 1625

Idaho Falls, ID 83415

J. B. Malmo 
DOE

MORGANTOWN ENERGY TECHNOLOGY CENTER

P.O. Box 880

Morgantown, WV 26505

R. C. Bedick

D. C. Cicero

F. W. Crouse, Jr.

R. A. Dennis

N. T. Holcombe

W. J. Huber

T. J. McMahon

J. E. Notestein

DOE

OFFICE OF FOSSIL ENERGY

FE-72

19901 Germantown Road

Germantown, MD 20874-1290

J. P. Carr

DOE

OFFICE OF VEHICLE AND ENERGY R\&D CE-151 Forrestal Building

Washington, DC 20585

R. B. Schulz

DOE

OFFICE OF SCIENTIFIC AND TECHNICAL INFORMATION

P. O. Box 62

Oak Ridge, TN 37831

For distribution by microfiche as shown in DOE/TIC-4500, Distribution Category:

UC-1 14 (Coal Based Materials and

Components)
DOE

PITTSBURGH ENERGY TECHNOLOGY

CENTER

P.O. Box 10940

Pittsburgh, PA 15236
A. L. Baldwin
G. V. McGurl
L. A. Ruth
T. M. Torkos

DOW CORNING CORPORATION

3901 S. Saginaw Road

Midland, MI 48686-0995

H. Atwell

EC TECHNOLOGIES

3614 Highpoint Drive

San Antonio, TX 78217

D. J. Kenton

ELECTRIC POWER RESEARCH

INSTITUTE

P.O. Box 10412

3412 Hillview Avenue

Palo Alto, CA 94303

W. T. Bakker

J. Stringer

EUROPEAN COMMUNITIES JOINT

RESEARCH CENTRE

Petten Establishment

P.O. Box 2

1755 ZG Petten

The Netherlands

M. Van de Voorde

GA TECHNOLOGIES. INC.

P.O. Box 85608

San Diego, CA 92138

T. D. Gulden 
GEORGIA INSTITUTE OF TECHNOLOGY

Materials Science \& Engineering (0245)

Bunger-Henry Building, Room 276

Atlanta, GA 30332-0245

T. L. Starr

IDAHO NATIONAL ENGINEERING

LABORATORY

P. O. Box 1625

Idaho Falls, ID 83415

B. H. Rabin

LAVA CRUCIBLE-REFRACTORIES CO.

P.O. Box 278

Zelienople, PA 16063

T. Mulholland

LAWRENCE LIVERMORE NATIONAL

LABORATORY

P.O. Box 808, L-325

Livermore, CA 94550

W. A. Steele

LOS ALAMOS NATIONAL LABORATORY

P.O. Box 1663

Los Alamos, NM 87545

J. D. Katz

NATIONAL INSTITUTE OF STANDARDS AND TECHNOLOGY

U.S. Dept. of Commerce

Bldg. 220, Rm A215

Gaithersburg, MD 20899

S. G. Malghan

\section{NATIONAL MATERIALS ADVISORY}

BOARD

National Research Council

2101 Constitution Avenue

Washington, DC 20418

K. M. Zwilsky
OAK RIDGE NATIONAL LABORATORY

P.O. Box 2008

Oak Ridge, TN 37831

P. T. Carlson

N. C. Cole

R. R. Judkins

R. A. Lawson (8 copies)

E. L. Long, Jr.

D. P. Stinton

M. R. Upton

OFFICE OF NAVAL RESEARCH

Code 431, 800 N. Quincy Street

Arlington, VA 22217

S. G. Fishman

\section{SANDIA NATIONAL LABORATORIES}

Department 6211, MS 0710

Albuquerque, NM 87185

R. J. Buss

G. A. Carlson

A. G. Sault

SHELL DEVELOPMENT COMPANY

P.O. Box 1380

Houston, TX 77251-1380

L. W. R. Dicks

TENNESSEE VALLEY AUTHORITY

Energy Demonstration \& Technology

MR2N58A

Chattanooga, TN 37402-2801

C. M. Huang

THE JOHNS HOPKINS UNIVERSITY

Materials Science \& Engineering

Maryland Hall

Baltimore, MD 21218

R. E. Green, Jr. 
THE MATERIALS PROPERTIES COUNCIL, INC.

United Engineering Center

345 E. Forty-Seventh Street

New York, NY 10017

M. Prager

THE NORTON COMPANY

High Performance Ceramics Division

Goddard Road

Northborough, MA 01532-1545

N. Corbin

THE TORRINGTON COMPANY

Advanced Technology Center

59 Field St.

Torrington, CT 06790

W. J. Chmura

UNION CARBIDE CORPORATION

Linde Division

P.O. Box 44

175 East Park Drive

Tonawanda, NY 14151-0044

Harry Cheung

UNITED TECHNOLOGIES RESEARCH

CENTER

MS 24, Silver Lane

East Hartford, CT 06108

K. M. Prewo

UNIVERSITY OF WASHINGTON

Department of Materials Science and

Engineering

101 Wilson, FB-10

Seattle, WA 98195

T. G. Stoebe

VIRGINIA POLYTECHNIC INSTITUTE \&

STATE UNIVERSITY

Department of Materials Engineering

Blackburg, VA 24601

W. A. Curtin

K. L. Reifsnider
WESTERN RESEARCH INSTITUTE

365 N. 9th Street

P.O. Box 3395

University Station

Laramie, WY 82071

V. K. Sethi

WESTINGHOUSE ELECTRIC

CORPORATION

Research and Development Center

1310 Beulah Road

Pittsburgh, PA 15235

S. C. Singhal 